Opposing Buffy:

\title{
Power, Responsibility and the Narrative Function of the Big Bad in Buffy the
}

\section{Vampire Slayer}

By

Joseph Lipsett

B.A Film Studies, Carleton University

\author{
A thesis submitted to the \\ Faculty of Graduate Studies and Research \\ In partial fulfillment of the requirements for the degree of \\ Masters of Arts \\ in Film Studies
}

Carleton University,

Ottawa, Ontario

April 25, 2006 


$\begin{array}{ll}\begin{array}{l}\text { Library and } \\ \text { Archives Canada }\end{array} & \begin{array}{l}\text { Bibliothèque et } \\ \text { Archives Canada }\end{array} \\ \begin{array}{l}\text { Published Heritage } \\ \text { Branch }\end{array} & \begin{array}{l}\text { Direction du } \\ \text { Patrimoine de l'édition }\end{array} \\ \begin{array}{l}\text { 395 Wellington Street } \\ \text { Ottawa ON K1A ON4 }\end{array} & \begin{array}{l}\text { 395, rue Wellington } \\ \text { Ottawa ON K1A ON4 } \\ \text { Canada }\end{array}\end{array}$

Your file Votre référence ISBN: 978-0-494-16430-3 Our file Notre référence ISBN: 978-0-494-16430-3

NOTICE:

The author has granted a nonexclusive license allowing Library and Archives Canada to reproduce, publish, archive, preserve, conserve, communicate to the public by telecommunication or on the Internet, loan, distribute and sell theses worldwide, for commercial or noncommercial purposes, in microform, paper, electronic and/or any other formats.

The author retains copyright ownership and moral rights in this thesis. Neither the thesis nor substantial extracts from it may be printed or otherwise reproduced without the author's permission.
AVIS:

L'auteur a accordé une licence non exclusive permettant à la Bibliothèque et Archives Canada de reproduire, publier, archiver, sauvegarder, conserver, transmettre au public par télécommunication ou par l'Internet, prêter, distribuer et vendre des thèses partout dans le monde, à des fins commerciales ou autres, sur support microforme, papier, électronique et/ou autres formats.

L'auteur conserve la propriété du droit d'auteur et des droits moraux qui protège cette thèse. $\mathrm{Ni}$ la thèse ni des extraits substantiels de celle-ci ne doivent être imprimés ou autrement reproduits sans son autorisation.
In compliance with the Canadian

Privacy Act some supporting forms may have been removed from this thesis.

While these forms may be included in the document page count, their removal does not represent any loss of content from the thesis.
Conformément à la loi canadienne sur la protection de la vie privée, quelques formulaires secondaires ont été enlevés de cette thèse.

Bien que ces formulaires aient inclus dans la pagination, il n'y aura aucun contenu manquant.

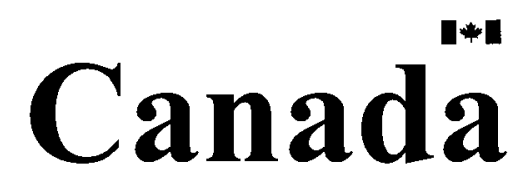




\begin{abstract}
Despite its seemingly frivolous exterior, Buffy the Vampire Slayer is a significant cultural text that has become one of the most studied television shows in history. One area sorely lacking in critical analysis is an examination of the season-long villains. This study approaches these Big Bads as narrative functions, each of whom forces Buffy to recognize the responsibilities of her dual roles as the Slayer and as the normal girl: as the Slayer she is responsible for the safety of the world and its inhabitants, in contrast to her responsibilities as Buffy when she must save her friends and their relationships. Each Big Bad affects this duality and their accompanying responsibilities. After consideration of the archaic evils who bookend the series, the Master and the First, the argument turns to the institutional villains from seasons three and four, the Mayor and the Initiative. The final two chapters consider the personalized villains - the friends and loves gone bad: Faith and Dark Willow in the former, Angelus and Spike in the latter. This thesis questions the narrative function of season-long villains and their effect on the show's heroine in the hopes of contributing to a new critical direction for Buffy academics.
\end{abstract}




\section{Acknowledgements}

First and foremost, I must thank two very dedicated men, Jonathan Hough and Kevin Johns, who have suffered through brainstorming sessions, first, second and third drafts and sudden doubts supported me unconditionally, while critically whipping this thesis into something readable. They truly encompass the possibilities of e-mail and embody the best characteristics of good friends.

It seems a little obvious to thank my thesis supervisor, Andre Loiselle, but poor Andre more than deserves his kudos. Not only has he been forced to read through constant drafts about characters and a series that he despises, he supported my last minute decision to scrap a year's worth of work in favour of examining all the possibilities that a Buffy offers. Perhaps one day he'll agree with me that Buffy is a fine, fine little show.

No Masters student can survive without their colleagues: Angie Chiang, Murray Leeder, Jeremy Marron, Sonya Poweska and Amy Ratelle, all of whom have provided a net of emotional support, snarky cynicism and fun conversations. Without these five, school would have been a great deal less interesting and first year papers would have been unbearable to grade.

Additionally, students are nothing without their professors. I can state unconditionally that the professors in Carleton University's Film Department have shaped and molded me from a raw beginning to the academic I am today, which is to say...they gave it their best shot. Thanks to José Sánchez Mosquera, Andre Loiselle, Chris Faulkner, Mark Langer, Charles O'Brien, Laura Marks, Tom McSorley, Mitsuyo Wada-Marciano and George McKnight.

Finally, I'd like to thank the person who has done more for me than anyone else, Tim Campbell. He's put up with my erratic behaviour, sudden mood swings, junk food cravings and constant whining for almost two years as I've struggled through a degree that's attributable to him in more than a few ways. Even though I'm sure he's wanted to kill me on more than a few occasions, he's always been there when I needed him and for that I'll always love him. 


\section{Table of Contents}

Introduction: Staking a Claim:

Exposing the Narrative Function of the Big Bad

1

Chapter 1: "It's About Power" or "You have Fruit Punch Mouth":

Archaic Evil as Big Bad Bookends

Chapter 2: "Down Here I'm the One in Control":

Institutional Villains as Elements of Transition

Chapter 3: “...In My Dream She Does It For A Guy"

Friends and Doubles as Personalized Big Bads

Chapter 4: "Every Slayer Has A Death Wish":

The Influence of Buffy's 'Bad Boys'

Conclusion: "NewsFlash, Hairdo. It's Not Always About You":

Works Cited

Appendixes: $\mathrm{A}-\mathrm{M}$

Characters

Plot 


\section{Introduction: \\ Staking a Claim: \\ Exposing the Narrative Function of the Big Bad}

To a great many academics, Buffy the Vampire Slayer requires no introduction.

These are the people who have become well-versed in all matters Buffy over the course of its seven seasons. To the uninitiated, the show invariably invokes a few questions:

What's so great about it? Why are so many people obsessed with it? And, finally, what kind of academic essay can possibly be written about it?

The first two questions can be answered in one response, which is that Buffy is far more complex, intelligent and witty than most people give it credit for. Admittedly it is not a show for everyone, but those who are willing to invest the time to get to know the principal characters and invest in the dramatic arcs will recognize that the show is about more than its unapologetically genre-based, Valley girl-speak title. Roz Kaveney explains her interest in the series in the introductory essay of Reading the Vampire Slayer:

Sitting with friends watching and rewatching the shows on video made it clear that they were complex texts, the conceptual and verbal wit of the surface, the sheer loopy romanticism of the emotional plots and visceral excitement of the actions plots, the range of cultural references high and pop, sustaining deep readings of the show's underlying implied discussion of feminism, religion, politics and so on. (3)

The suggestion that Buffy is worthy of academic investigation is not an isolated phenomenon. Since its 1997 debut, Buffy has become the most academically studied onehour television show in history (Battis, 12), with numerous books, journal articles, conferences around the globe and its own online journal, Slayage. In 2000, "the show won the Viewers for Quality Television 'Founders Award,' given annually to a series that 'has made a significant contribution to quality television without receiving due 
criticism"" (Wilcox \& Lavery, xx), perhaps referring to the show's lack of award recognition from the Emmys and Golden Globes. ${ }^{1}$

The show has a basic premise: Buffy Summers is a newly relocated girl who has, along with her divorced mother, Joyce, moved to Sunnydale, California. All Buffy wants to do is make friends and fit in, but she is no ordinary teen. As librarian Giles, her officially imposed 'Watcher,' informs her in the pilot episode, she is the Slayer, destined to fight vampires, demons and the forces of evil ("Welcome to the Hellmouth," 1.01). Therein lies the central dichotomy of the show: Buffy's desires to be a normal girl are put in conflict with her responsibility to use her powers to protect innocent people from the monsters that inhabit her town. These innocents include the individuals who share her secret: Giles and her best friends, Willow Rosenberg and Xander Harris, and all the students at Sunnydale High and UC Sunnydale (rich bitch cheerleader Cordelia, outspoken ex-demon Anya, quiet witch Tara, etc). ${ }^{2}$

The off-putting title reinforces this duality. Buffy is such a vapid, blonde name that she could be a sorority princess at any high school, but in the context of the show, she defies this stigmatization. Despite her petite, blonde and occasionally ditzy demeanor, she is the only person who can save the world (several times over, in fact). Wilcox and Lavery echo this statement in their introduction to Fighting the Forces:

The name "Buffy" suggests the lightest of lightweight girls of stereotypical limitation - thoughtless, materialistic, superficial. Yet this is the name of the heroine who will, over the years of the series, repeatedly risk (and finally give) her life - and perhaps even more frightening - her social status to do what is right. (xviii)

\footnotetext{
${ }^{1}$ Aside from its technical nominations in hair, sound editing and make-up, the show has only been nominated twice: once for an Emmy (Best Writing for Joss Whedon, "Hush") and once in 2001 for a Golden Globe - Best Actress (Sarah Michelle Gellar). The show lost both times.

${ }^{2}$ See Appendix Plot for a complete list of character descriptions.
} 
What this preliminary recap fails to establish is the sheer innovation of the show. Joss Whedon, series creator, is infamously quoted as saying that he came up with the show's concept after watching countless horror films that feature an attractive, helpless blonde who runs into an alley, encounters a monster and is brutally killed. His decision to invert the stereotype and have the blonde girl not only survive, but defeat the monster, is the origin of Buffy (Whedon DVD Commentary, "Welcome to the Hellmouth"). Originally conceived as a feature, Buffy the Vampire Slayer (Rubel Kuzui, 1992) has the same premise, but focuses more on parody and light comedy. When given the opportunity to turn Buffy into a series, Whedon and his writing team retained the humour, and added equal measures of horror, fantasy and pathos. Ultimately Buffy is far better suited for television, where the narrative can develop characters and lines of action across twenty-two episodes, not unlike a "novel in episodic installments that resemble miniature chapters" (Battis, 11).

Whedon's original idea highlights several of the show's great strengths: stereotype inversion and genre mixing. To those who have never watched the show, it is equated with the horror genre, with elements of science-fiction. Wilcox suggests that "Buffy suffers from prejudice related to its medium, television, and its genre, fantasy" (Why, 2). Indeed, the entire genre is steeped in stigma, and has only recently been accepted in the popular consciousness courtesy of recent mainstream television hits such as Lost (Abrams, Lindelof \& Lieber, 2004). To the casual observer, Buffy is another example of trashy sci-fi, and its debut on the WB network marked it as a show for teenagers, the network's principal audience demograph (academic Richard Campbell explains that it was his teenage daughter, Caitlin, that introduced him to WB shows). 
What the show ultimately demonstrates is a keen eye for deviating from the traditional sci-fi/fantasy conventions, while simultaneously incorporating a wide range of styles from other genres. While it should still be coded as fantasy/science-fiction, the show exhibits elements of horror (the gothic horror of silent fairytale episode "Hush," 4.10), musical (“Once More, with Feeling," 6.07), actuality drama ("The Body," 5.16), and romance ("Surprise," 2.13, or the darkly disturbing "Passion," 2.17).

Whedon and his crew's ability to import the essential qualities of a number of genres and adapt them to suit the show's needs has oft been recognized. Most academics casually refer to the show's genre hybridity, although several essays question Buffy's genre influences. One is Giada Da Ros' essay 'When, Where, and How Much is Buffy a Soap Opera?' (Slayage 13) in which she argues that Buffy shares a number of characteristics with daytime television shows such as narrative arcs that focus on character problems (wherein even Buffy's fighting style is attributable to "symbolic gestures" of her emotions). Da Ros primarily compares Buffy to the daytime series, Port Charles (Culliton \& Riche, 1997-2003), Passions (Reilly, 1999-Present) and Dark Shadows (a series created by Dan Curtis that aired on ABC from 1966-71 and featured, according to Da Ros, "vampires, witches, zombies...[as] part of the show's mythology"). Ultimately she acknowledges that Buffy has a number of differences from daytime television, but the similarities are startling.

Many Buffy scholars focus on one episode in particular, the sixth season musical "Once More, with Feeling" when examining genre influences in the show. In addition to Jeffrey Middents' essay (discussed below), there's William Donaruma's 'Once More With Feeling: The Hellmouth in Postmodern Heaven,' and Richard S. Albright's “"Once 
More, with Feeling" and Genre' (Slayage 17). Albright examines how Whedon's desire for the series to be "a cull-from-every-genre-all-the-time-thing" is evident in the show's unexpected shifts in mood (bleak and comedic moments co-exist continuously during narrative arcs). He links these ideas to Buffy's musical episode in which the show's "previously on Buffy" segment feeds into a 1950s musical credit sequence." The musical episode exposes its own genre artifice by having characters question the reasons behind the singing (even as they are singing) and revels in the different musical options such as Buffy's Disney-esque 'Going Through the Motions' and Spike's hard rock 'Rest In Peace.' Several song lines, as well as the entire song 'I'll Never Tell,' can be linked to Buffy's self-conscious awareness of its status as a show, a performance and a commodity that

... simultaneously calls attention to its own unreality even as it invites us to be a part of its figurative theater audience. [T] he episode constantly negotiates a tension between the real and the true (which is often hidden) and the fantastic, stylized, and artificial.

This delicate balance between the real and the fantastic is constantly negotiated on the show. Da Ros opens her article with a variety of quotes that demonstrate a dialogue between shows: two from Buffy in which Spike references watching Passions, one from Passions referencing Buffy, and the last from Port Charles in which a principal character has been directly modeled on Buffy herself (Slayage 13).

These are not the only extra-textual references on the show. As quoted above, Buffy is known for its "range of cultural references high and pop" (Kaveney, 3), which requires an education in both high art and contemporary camp. This idea is intricately tied to Buffy's humour, as discussed by Steve Wilson in his article 'Laugh, Spawn of 
Hell, Laugh.' The article discusses the wide range of jokes present in the 'Buffyverse, 3 many of which require audiences to understand their cultural relevance in order to be funny. The musical numbers in "Once More, With Feeling" have substantially less impact if their parody of others musicals is misunderstood or unknown, just as much as a line like Cordelia's, "Willow, nice to see you've seen the lighter side of Sears," loses its impact without knowledge of a certain Sears marketing campaign ("Welcome to the Hellmouth"). Similarly high art gets its due with "formal, literary" (Wilson, 94) forms of speech, demonstrated in any line of dialogue from season one's The Master, as well as references to classic literature (Principal Snyder argues that everything that comes out of Xander's mouth is an "airborne toxic event" - a reference to Don DeLillo's White Noise) and its authors (Xander insinuates that his summer travels between seasons three and four equate him with Jack Kerouac).

The intricate interactions of humour and self-referentiality lend the show a unique language of its own. Several of the jokes Wilson references have their own special brand of Buffy logic to them, constructed when

the writers routinely dismantle parts of speech and jury-rig them back together as they please. In a free-for-all grammar-implosion of a typical episode, adjectives make themselves verbs, (Buffy: "Gee, can you vague that up for me?"), verbs force themselves on nouns (Giles: "This leaves me flummoxed." Buffy: "What's the flum?"), nouns cling desperately to their turf (Buffy: "I'm sorry, I've been crankiness all day."), participles mutate with prepositions (Xander: "They were in the ugly way looking") while pop culture (Buffy: "I'm the one getting Single White Femaled here") and consumer culture (Willow: "He's a super-maxi jerk for doing it right before the prom") fill in the remaining cracks. (93)

Language is not, however, merely broken down and used for comic purposes. On Buffy, language is a powerful weapon. In their essay 'Staking in Tongues: Speech Act as Weapon in Buffy,' Overbey and Preston-Matto argue that "words and utterances have

\footnotetext{
${ }^{3}$ Buffyverse is the name given to the fictional world of the show.
} 
palpable power, and their rules must be respected if they are to be wielded as weapons in the fight against evil" (73). There are numerous references in episodes about Buffy's ability to joke in the face of danger, from her climatic confrontation with The Master in "Prophecy Girl," 1.12 (Master: You were meant to die! It was written. Buffy: What can I say? I flunked the written) to the final episode of the series, "Chosen," 7.22 (The First: Where's your witty retort? Buffy: You're right. The First: Huh, not your best)

The power of language is continuously on display throughout the series, ranging from little examples (as when Xander accidentally lights his book on fire after "speaking Latin in front of the books" in "Superstar," 4.17) to far reaching consequences (in "The Wish," 3.09 , Cordelia creates an alternate universe simply by making a wish to vengeance demon, Anyanka). ${ }^{4}$ Overbey and Preston-Matto argue that "the true theory of language in Buffy is the one that requires four specialized voices in combination to fight the forces of evil" (75), suggesting that each member of the 'Scooby gang' or 'Scoobies's have a role to play: Buffy is the wisecracking punner; Xander is the defensive jokester; Willow has skills with computers as well as magic (thereby 'speaking' information technology as well as the technology of magic); and Giles is the interpreter, albeit more so when it comes to texts than the spoken word. In this way, their mode of language reflects their character.

Several academics have taken Buffy to task for its artificial representation of a heterogeneous world, complete with racial differences. Kent Ono is one of the sources cited most often in relation to this topic, possibly because he is one of the angriest

\footnotetext{
${ }^{4}$ The power of language is also covered in Jane Hodson's “'You Made A Wish To Someone You've Never Seen Before?": The Dangerous Power of Speech Acts in Buffy the Vampire Slayer.'

${ }^{5}$ One of Buffy's many intertextual references compares Buffy and her friends to the mystery solving group from Scooby-Doo.
} 
theorists to write about Buffy. In his article 'To be a Vampire on Buffy, the Vampire Slayer: Race and (“Other") Socially Marginalizing Positions on Horror TV,' Ono examines the role of the vampire, whom he believes is racially marked with darkness, noting that these characters "function to reaffirm contemporary racial and gender hierarchies" (cited in Edwards 86). Similarly, Lynne Edwards examines the role of Kendra, Buffy's successor after she is momentarily killed by the Master in "Prophecy Girl," as an example of a 'tragic mulatta, ${ }^{6}$ whose otherness marks her for death after a mere three episodes.

Not everyone agrees with these portrayals, however. In the same compilation as Edwards, Mary Alice Money believes that as the series progresses, its (successful and unsuccessful) attempts at rehabilitating demons suggests the ways that "society may come to terms with differences in race, culture and lifestyle" (98). Her examination, however, focuses on themes of redemption in the characters of Spike and Anya, two white characters, which hardly addresses the criticism of other race-oriented essays. Alternately, Jeffrey Middents explores the role of Sweet in Slayage 17, the jazz infused demon in "Once More, with Feeling" as a positive portrayal considering it is he who controls the citizens of Sunnydale with his musical spell (Middents goes so far as to suggest that Sweet is the "most powerful character in the episode"). It is significant, then, that Sweet is not defeated by Buffy at the end of the episode, but disappears of his own volition, as Middent explains:

\footnotetext{
${ }^{6}$ The tragic mulatta myth centers around a light skinned black woman who goes on a quest to fit in with white culture. Either way the quest will not succeed, because if she a) succeeds, she fails the black community through her denial or b) fails, she must return home and accept her place in the community. Edwards believes Kendra fits this role because she comes to Sunnydale to be the Slayer, is assimilated into Buffy's world and killed by Drusilla in 'Becoming, Part 1,' 2.21. (Edwards 88-91).
} 
Although he says "Big smiles everyone, you beat the bad guy," this is stated ironically, punctuated by Sweet's final vamp, the reprise of "What You Feel" which gives the episode its title: "And there's not a one/Who can say this ended well./All those secrets you've been concealing,/Say you're happy now-once more, with feeling." (Slayage 17)

Middents' observation (that Sweet's escape is a demonstration of his power) is telling when the small number of adversaries who manage to evade Buffy and her Scooby gang is considered. This can be attributed to Buffy's powers as the Slayer, although in the academic Buffyverse there are almost as many essays on the powers of Buffy's friends as the heroine herself.

Principal among the work done on the series, especially works that focus on individual characters, are those dealing with sexuality and gender. In relation to Xander, a primary focus seems to be on his masculine status within the group - for he is not a dominant, aggressive male as much as a marginalized, feminized male due to his lack of superpower (as evidenced to comic effects in "The Zeppo," 3.13) Aside from his semiaggressive posturing (especially in the episodes concerning Buffy's relationship with vampire-with-a-soul Angel in seasons two and three), Xander's two best features are his heart and his ability to see. Although the latter is less developed, it becomes a principal element in the final season of the show when Xander comforts Dawn by addressing his marginalization from the group's powers ("Potential," 7.12) and his subsequent blinding by Caleb in the vineyard ("Dirty Girls," 7.18). The former is showcased primarily in the fourth season battle with the Frankenstein-cyborg, Adam ("Primeval," 4.21) when his combined elemental power to create $u$ ber-Buffy is heart. Jes Battis claims this speaks to 
Xander's role as "big brother," "which Battis believes foreshadows Xander's role as the only person who can truly combat Dark Willow in "Grave" (6.22).

While Battis doesn't go so far as to suggest that Xander's ability to speak the language of women on the show ${ }^{8}$ demonstrates his homosexuality, he does maintain that Xander is a feminized male and then there is a "visible tension between Xander's desire to be a heroic straight male (with heroism being coded as "straight"), and his various performances as a non-heroic, emotional, terrified and physically inept anti-hero" (50). This is especially apparent in his interactions with Riley in season four, when Battis believes he is at his most sexually ambiguous (53).

The sexuality of Willow is of principal concern to academics, although this is filtered through her relationships with magic and Tara. Writings on Willow address the use of spells on the show (which Overbey \& Preston-Matto tie to the power of language), and is one of the primary interests of Tanya Krzywinska's essay 'Hubble-Bubble, Herbs, and Grimoires.' In her essay, Krzywinska charts Willow's magical education from its initial inception and development in season two to full-fledged weapon in season four (the essay was written between seasons four and five). The root of Willow's power, however, is in its practicality: her spells require ingredients, which suggests an earthly connection (prominently exhibited in season seven's opener, "Lessons," 7.01) unlike the New Age connotations associated with Wicca and its practitioners (186-88).

Jes Battis examines Willow and magic in a different way, classifying Willow as "torn between a number of competing identities." He believes she has "lingered on the

\footnotetext{
${ }^{7}$ This is a line of dialogue delivered by Buffy in the all dream-sequence season four finale, "Restless," 4.22

${ }^{8}$ It is a language that other men on the show clearly have difficult with. Consider Angel's inability to speak about his feelings for Buffy in the first season, and Riley and Spike's identical problem in the fourth and fifth. Additionally, Giles is continually flustered by Buffy and often has difficulty speaking to her without stuttering
} 
outer edges, and proven herself to be a chaotic force more powerful than the Slayer, the Watchers or any other instrument of authority within the show's diagesis" (26). Willow, is therefore, the most unformed and fluid of the Scooby gang as she traverses any number of identities throughout the series' run, including witch and lesbian. It is her transformation from heterosexual to homosexual that several scholars focus on, especially her tragic lesbian relationship with Tara. The implications of Tara's death for the show and society, as well as the show's portrayal of homosexuality in comparison to other shows on television are explored in Todd Ramlow's article 'I Killed Tara: Death and Desire in Buffy.' He examines the show's initial hesitancy in showcasing physical affection between the girls (lesbianism is coded as witchcraft, "and, specifically, lesbian sex as spell-casting"), as well as the suggestion that lesbian sex leads to death (the lovers spend the entire episode preceding Tara's death in bed).

The dangers of sexuality are inevitably tied to Buffy, and in many situations, the vampire Spike. Their destructive relationship is a focal point for season six's narrative arc, although Buffy has always been showcased in relation to her sex, sexuality and gender. A random glance at Slayage's Gender and Feminism Studies section reveals a number of essays with titles such as 'Just a Girl: Buffy as Icon,' 'Deconstructing Buffy: Buffy the Vampire Slayer's Contribution to the Discourse on Gender Construction,' 'Men Dig Up the Corpses, Women Have the Babies': Negotiating Gender in Buffy the Vampire Slayer,' 'Buffy the Feminist Slayer? Constructions of Femininity in Buffy the Vampire Slayer,' "'Bite Me": Buffy and the Penetration of the Gendered Warrior-hero,' and 'First Word 'Jail,' Second Word 'Bait': Adolescent Sexuality, Feminist Theories, and Buffy the Vampire Slayer.' There are several competing points of view on how Buffy should be 
seen through a feminist view: is Buffy a third-wave feminist? Considering her obsession with duty and weapons, is she a masculinized hero? Why is Buffy's sexuality routinely punished (Angel's post-coital transformation into Angelus in "Surprise") or presented as unhealthy (season six's sadomasochistic relationship with Spike)?

And then there are the larger implications for sex and female characters, especially the close relationship of sex and death. Rogue Slayer Faith mentions that "slaying always makes me hungry and horny" in "Faith, Hope, and Trick" (3.03), while villains Drusilla and Darla are allowed free rein of their own sexuality, possibly because of the liberating effects of being a vampire (see also "The Wish" for its sadomasochistic associations, or Spike's throwaway line about torture in "Lovers Walk," 3.08). Romance novelist Jennifer Crusie notes in her essay 'Dating Death' that Buffy's relationships are inevitably tied to pain and loss and not all of it is emotional. To Crusie "...love in this world really is a matter of life and death" (91) and Buffy's relationship with Spike is the only one that makes sense to the romance novelist because she considers it the ultimate embrace of Buffy's dark side - something she must learn to use as a weapon in her battle with the First in the final season.

This initial overview of Buffy studies is illuminating for the diversity of topics that the series inspires in the academic community. However, it also answers the third question posed in the initial paragraph of this introduction: what kind of academic essay can possibly be written about it? Or rather, what topic is left to examine? My answer, and the one that forms the principal analysis of this thesis, is the one area that seems to have gone completely lacking in critical analysis: an examination of Buffy's opposition, the monsters. 
While these characters have been briefly addressed in essays on race, sexuality and economic status, they are rarely, if ever, given the in-depth analysis Buffy and the Scoobies receive. Certainly there is mention of Spike and Angelus, but it is always in the context of their vampiric representation ("New Men: "Playing the Sensitive Lad"' by Lorna Jewett; 'Sex and the Single Vampire: The Evolution of the Vampire Lothario and Its Representation in Buffy, the Vampire Slayer' by Diane DeKelb-Rittenhouse), which is associated with their redemptive narrative arcs and their sexuality ("“Love's Bitch but Man Enough to Admit It": Spike's Hybridized Gender' by Arwen Spicer). Other villains are referenced (Laura Diehl's 'Why Drusilla's More Interesting than Buffy'; Martin Tomlinson's 'A Question of Faith'), but are rarely examined beyond their moral, sexual or genre role on the show. In short, these characters are never examined for being monstrous villains and the effect that their presence has on the series. This is ironic given that Buffy the Vampire Slayer is all about monsters.

Monsters occupy a good portion of the show's time. Whether it is a one-off villain or a recurring threat, Buffy tracks them down, stakes them, beheads them or dismembers them. Whether a viewer chooses to acknowledge these monsters as literal or metaphorical depends on the depth to which they read the show. There can be little doubt, however, that monsters preoccupy the narrative as much as its titular heroine. Without these characters, there could be no show, for Buffy would simply be the normal girl she longs to be. Instead, Buffy is drawn into the dark underworld of Sunnydale, placed outside normality, which she addresses in "Halloween," (2.06) when she tells Angel

Buffy: Dates are things normal girls have. Girls who have time to think about nail polish and facials. You know what I think about? Ambush tactics. Beheading. Not exactly the stuff dreams are made of. 
And therein lies one of the show's greatest strengths: Buffy Summers isn't merely a teenage girl, nor is she simply a vampire slayer; she is both. Negotiating the equally important halves of her world (the Buffy and the Slayer) prove central to the show's seasonal dramatic arcs. In lieu of showcasing an adult with a fully formed personality dispatching killer lunch ladies and maggoty assassins, Buffy presents the audience with a deeply flawed teenage girl who yearns for normality, but has been chosen to represent good in an epic battle with evil.

There are dozens of episodes in which the desires of the Buffy role must be balanced, contradicted or compromised for the values of the Slayer. It is the monsters that force her to make fundamental moral decisions regarding her role as the Slayer. As mentioned above, not only are monsters in Sunnydale literal as well as metaphorical, but a vast majority of them reinforce the dichotomy represented in the title of the show: the teenage girl who must cope with the trauma of surviving High School, University and the world beyond (Buffy) and the warrior who must fight the vampires and the demons (the Slayer) ${ }^{9}$

These individual monsters, the praying mantis teacher ("Teacher's Pet," 1.04), the prom dogs ("The Prom," 3.20), and the fear demon ("Fear, Itself," 4.04), are all part of Buffy's monster make-up. And while all of Buffy's monsters are relevant in a critical examination of the show, as one-off villains they affect the long-term narrative less than Big Bads, such as the Master, Spike \& Drusilla, Angel's alter ego, Angelus, the Mayor, Faith, the Initiative, Adam, Glory, The Trio of Nerds, Dark Willow and the First, all of

\footnotetext{
${ }^{9}$ For the purposes of the thesis, the 'Buffy' side refers to her role as a teenager: sister, friend, (surrogate) daughter and student. Her 'Slayer' side refers to her superpowers (strength and healing) as well as her role as a demon/vampire hunter, defender of the community and averter of apocalypses. Additionally, the words 'role,' 'self' and 'side' will be used interchangeably in conjunction with her duality as Buffy and Slayer.
} 
whom play a crucial role in emphasizing the duality inherent in Buffy's roles as Slayer and normal girl.

So how are the Big Bads different from other villains and why is this important? From a structural standpoint, the Big Bads dictate the structure of the series from season to season. Episodes invariably revolve around their evil plots, and even when they are not represented in an episode, there is a mention of researching their weaknesses, attempting to determine their plan, etc. Within the episode, Big Bads comprise the rising action and determine the chapter breaks, often appearing in the pre-credit sequence or just before commercial breaks. Additionally they mark the significant turning points on the show, such as the mid-season twist (Angel becomes Angelus; Faith goes rogue; Adam kills Prof. Walsh, etc) and the climatic battle that marks the end of a season (all save one: season four's Adam is destroyed in the penultimate episode).

Unlike the one-off or minor recurring villains, the Big Bads have multiple episode arcs to test Buffy. Although certain minor villains pose a threat to Buffy and force her to evaluate which of her roles should be prioritized, these episodes hold less dramatic weight than a season long adversary whose plans develop increasingly problematic undertones for Buffy and her friends.

An examination of the word apocalypse is useful here as it is frequently uttered to describe the plans of the Big Bad, while it is used only once (humourously) in a non-Big Bad related episode ("The Zeppo," 3.13). The very word means unveiling or revelation, which is the performative function of all of Buffy's Big Bads: the unveiling of the responsibilities that accompany her powers. The implication is clear: the significance of the Big Bad lies in their level of destruction (they have been nicknamed so for a reason). 
The result of the Big Bad's plans then, is the greater the threat, the more painful the revelation about Buffy's duality. She rarely frets over regular vampires and demons because she slays them on a weekly basis, often without skipping a beat ("Once More, With Feeling'). The level of threat of the Big Bad is underscored by the fact that they cannot be destroyed until the season finale, when the stakes are at their highest.

Although it can be argued that each character is inevitably affected by the plans of the Big Bad, the focus here will be on the show's heroine, Buffy, for it is she who is selected to bear the burden of the show as its namesake and heroine. This thesis will examine how the Big Bads force Buffy to confront the duality of her two opposing roles as Buffy and the Slayer; roles that are governed by the need to balance power and responsibility. On the series, it is the Big Bad's responsibility to force Buffy to reconcile her two selves, and, in doing so, balance her powers and the responsibilities that accompany them. In her Buffy role, she has a responsibility towards individuals (her friends, her mother, etc), whereas as the Slayer she has a responsibility to the world. The Buffy role involves saving her friends and maintaining their relationships, whereas the Slayer role involves saving humanity.

In this way Buffy is the journey of a hero. As Wilcox explains, she follows Joseph Campbell's hero monomyth:

It is not difficult to see the monomyth pattern for the hero Buffy. Buffy refuses her call to slay, and then accepts it; she faces trial after trial, crosses over to death, and then returns (Why, 38).

The monomyth refers to a hero's "journey and return" (Wilcox, Why, 66) and is "a continuous 'recurrence of birth'...to nullify the unremitting circumstances of death" (Wilcox, Why, 38) or a cycle consisting of death and rebirth. Wilcox identifies Buffy's death and subsequent return at the end of season one, as well as her "travel(s) to a strange 
land (in this case, Los Angeles), fights monsters and return(s) home changed" (Who, 6-7) in the episodes that make up the end of season two and the beginning of the third. Additionally, her death, resurrection and painful societal reintegration in season six are indicative of Campbell's "difficult return," which Wilcox explains helps add "weight to the hero's death" (Why, 39).

At the same time, it is useful to consider Sartre's descriptions of existentialism laid out in Existentialism is a Humanism. He explains that existentialism is "a doctrine to render human life possible" by admitting that "every truth and every action imply both an environment and a human subjectivity" which, while potentially pessimistic, ultimately "confronts man with a possibility for choice." Sartre, as a supporter of atheistic existentialism, believes that there are beings whose existence precedes their essence, so that man begins as nothing and he is what he wills himself to be at a later stage, which Sartre identifies as a "subjective life." In this way, each man is responsible for himself and, by extension, he is responsible for all men. As a result the choices made by a man shape himself and presents the image that he would have others be.

If this concept is applied to Buffy, then she is the one responsible for determining who she is. While the idea that Slayers are 'chosen' supports the claim that man is created with an understanding of their purpose by their creator before their existence ("in each generation, a Slayer is chosen..."), Buffy resists this categorization because she determines what type of Slayer she is. Initially she does not accept her calling and instead tries to fashion herself in accordance to other 'normal' girls, which is to say that she has choice in her own development; she is responsible to herself despite her preordained destiny as the chosen one. 
In this way, Buffy also adheres to the problems of existentialism: when people are responsible for the whole of mankind, they "cannot escape from the sense of complete and profound responsibility." Despite Buffy's responsibilities to use her powers for the good of mankind (to be a hero), she cannot always accept her responsibilities because she is burdened by them. She does not initially want to be a hero, and must consciously make the choice to accept her abilities and the responsibilities that accompany them. In this regard, Buffy must learn to "trust her instincts" (which on the show inevitably turns out to be the correct choice) and to live by making choices, since "Life is nothing until it is lived; but it is yours to make sense of, and the value of it is nothing else but the sense that you choose."

The inclusion of these philosophical positions should not imply that this thesis will examine Buffy as a "Sartrean," or "Campbellian" text, but rather as a pop-culture version of philosophical issues dealing with fundamental questions of subjectivity and its relation to the social/physical world around it. Additionally, because several texts, such as Wilcox's 'There Will Never Be a Very “Special”' Episode of Buffy,' have already acknowledged the metaphorical and allegorical function of the Big Bads, this examination will focus entirely on a close-reading of the series.

The struggle between Buffy's two selves comprises the entire series' narrative arc. When she begins her journey in the first season, Buffy is reluctant to return to Slaying, preferring to focus on the Buffy side of her duality. This is because the series follows the events of the feature film of the same name, in which Buffy was expelled after she burned down her previous school's gym. By changing the medium to television, the series can dedicate more screen time to Buffy's efforts at balancing her individual 
goals with those of the community. This process is aided by the season one Big Bad, The Master, who forces her to accept the responsibilities that accompany her Slaying (and die for them in "Prophecy Girl"). Buffy attempts to find a balance even as she embarks on an emotionally mature relationship with Angel in season two. When he becomes Angelus, Buffy discovers that her romantic attachment to him clouds her judgment. Her love for Angel causes her to overlook her responsibilities to protect her friends and the world. Angel's transformation from caring boyfriend to murderous killer is contrasted by Spike, who starts off the season trying to kill Buffy and works with her as an ally by the end.

Season three brings an alternate point of view to Slaying in the form of Faith, as Buffy attempts to survive high school and prepare for a life with Angel. Faith and the Mayor both suggest that her relationship with Angel is impossible, and the Mayor allows her to mature into adulthood and move past high school when she blows him (and it) up. University life in season four offers a wide range of possibilities for Buffy, one of which is joining a drone-like office group called the Initiative. The group, a government sponsored military organization, ultimately proves to Buffy that she understands what works for her as a Slayer: her small-group, Scooby approach to researching, understanding and, most importantly, respecting the supernatural world she works in. In this way the Scoobies represent a collectivity that work together to defeat cyborg-demon, Adam. In contrast, the policies of the Initiative are organized in an ill-informed top-down approach that emphasizes blind obedience and results in chaos and death.

Following her second death in season five, Buffy must learn how to rejoin the living world in season six, a process aided by an unhealthy relationship with Spike, who demonstrates that even without romanticism, sex negatively affects Buffy's ability to 
perform either of her roles. It is during this season that she makes her worst decisions, and proves inept at dealing with adult life-decisions or supporting her friends in times of crisis. As she and Willow embark on parallel addictions, Buffy's inability to relate to Willow in either of her Slayer or Buffy roles culminates in Willow's descent into Big Bad status, and Buffy's inability to save the world.

Her fallibility reinforces her determination to live a balanced life when she emerges stronger than ever in the seventh season. When Buffy fully accepts the responsibilities of both her roles, she finds her most powerful asset in the scythe. It is the First who forces her to realize that success (as a Slayer and as Buffy) comes by sharing her powers, not remaining isolated. In doing so, she no longer bears the sole responsibility for saving the world and can retire as the Slayer. It is because of her seven years of struggle with various Big Bads, each of whom highlights her conflicting selves and the responsibilities that accompany her powers, that in the series finale Buffy is prepared to handle her most difficult responsibility: living a normal life as someone other than the Slayer.

The first chapter will examine the two villains that bookend the series. Both force Buffy to recognize the true value of her gift as the Slayer. Throughout her first year at Sunnydale High, Buffy is still equipped with Slayer strength, but the events of her past prompt the disavowal of her responsibilities as a Slayer. It is through the Master's attempts as ascension, especially in the season finale, "Prophecy Girl," that Buffy realizes she has a responsibility as the Slayer to battle the Master and any other Big Bad that threatens her world. 
By the seventh season, Buffy has completely accepted her responsibilities after an uneven year following her resurrection. In her battles with the First, Buffy recognizes the importance of becoming a leader, which ultimately means sharing her powers with all the potential Slayers. In giving away her status as the Slayer to defeat the First's army of ubervamps, Buffy finally reconciles her two selves and can live a life of her own choosing. In providing the tools for the community to protect itself, she no longer bears the sole responsibility for its safety. The series ends on a positive note with the suggestion that Buffy can go off and live the normal life she always wished for. Although she will always possess Slayer skills and there is still evil (in Cleveland no less), the decision of what her future holds can now be determined by her wants as opposed to her sense of responsibility.

The second chapter will examine the institutional Big Bads: season three's Mayor Richard Wilkins III, and season four's Adam and the Initiative. These seasons mark transitional years in Buffy's life between high school and University and a shift in her priorities. The Initiative allows Buffy the opportunity to expand her powers through a demon-hunting organization, thereby reducing her responsibility since she no longer has to protect her friends and can rely on others to support her. Her experiences with the Initiative demonstrate that working in the supernatural world requires an open mind-set determined by the collectivity of a group with an understanding of its rules and regulations, all qualities that the Scoobies possess. It is because of this that they ultimately triumph while the Initiative remains blind to the consequences of their actions.

Upon examining Adam, it becomes clear that he fails as a Big Bad because he does not engage both of Buffy's selves. Although the Mayor shares a number of 
characteristics with Adam, he is a successful Big Bad. One of his primary functions is to reinforce the consequences of Buffy's romantic relationship with Angel while allowing her transition from high school to University in the symbolic destruction of the high school. The Mayor's ascension also prompts Buffy's early attempt at mounting an offensive by attacking him before his plan goes into effect and also forces her to become a leader by mobilizing the Sunnydale High students into an army (both reactions foreshadow her conflict with The First in season seven).

The third and fourth chapters focus on the personalized villain: characters who are significant factors in Buffy's personal life who become Big Bads. The first includes examinations of Buffy's friendships-gone-wrong Big Bads with Faith (seasons three and four) and Dark Willow (season six). Faith is Buffy's shadow double. Her function as Big Bad is to reveal the secret desires that Buffy hides, again in relation to sex, death and the abuse of her powers. Faith irresponsible actions also extend to showcasing the level to which Buffy's relationships affect both her Buffy and her Slayer side, since Faith consistently acts as a foil to Buffy's romantic life.

The other personalized Big Bad, Dark Willow, is unique. She is the most personal villain Buffy faces over the course of the seven seasons and she also appears the least of any Big Bad (three episodes). It is the build-up to her conversion to evil that affects Buffy the most: Willow's addiction to magic runs parallel to Buffy's sexual addiction to Spike. The way Buffy treats her closest friend highlights not only Buffy's irresponsible use of Willow's skills (Willow's magical dependency is only a problem when it directly affects Buffy), but also highlights Buffy's clouded judgment in matters concerning sex. The fact that Buffy does not defeat Dark Willow suggests that Buffy is unable to reconcile the 
responsibilities of either of her roles when her true friends become villains - with Willow, she does not know how to be a Slayer (contain the evil threat) or a normal girl (help her friends). In this way Dark Willow is different from all the other Big Bads.

The fourth chapter continues the work initiated in chapter three with an examination of Spike (season two) and Angelus (season two) as romantic/sexualrelationships-gone-wrong. Both Spike and Angelus demonstrate Buffy's relationship with sex, death and slaying and show how romantic and sexual relationships distract Buffy from her responsibilities as Slayer by clouding her judgment.

Upon reflection, three significant villains are absent from this list and will be dealt with in the conclusion, albeit in far less detail. Drusilla and the Trio of Nerds will both be briefly examined, as well as Glory, the Big Bad of season five. Season five is unique in that it embodies key characteristics that define the Big Bads as well as the other seasons. As a result, this thesis will conclude with an examination of Glory and season five as the embodiment of the Buffy Big Bad: character who functions as narrative foils by bringing into conflict Buffy's dual roles as Slayer and normal girl by highlighting the responsibilities that accompany her power.

The goal of such an examination is to widen the parameters of Buffy's critical analysis by calling attention to overlooked characters. While the breadth of Buffy analysis is diverse, there is a tendency to rest on the laurels of others and continually examine like-minded topics such as those discussed earlier in this introductory chapter. While there remains a significant amount of mileage to be covered on those topics, it is my personal hope that this thesis will reveal the need to go beyond conventional topics and 
expose the depths to which Buffy can be mined. If the reasons behind the show's ravenous critical attention truly is the variety of subjects that can be analyzed, this thesis proposes it is time for Buffy academics to turn our attention to new and innovative topics. 


\section{Chapter One \\ "It's About Power" or "You have Fruit Punch Mouth": Archaic Evil as Big Bad Bookends}

The Buffy Summers that is first spied upon while nightmaring in "Welcome to the Hellmouth" (1.01) is not the same girl standing on the edge of the precipice that was once Sunnydale at the end of "Chosen" (7.22), the series finale. She is a Slayer in both situations, but her identity has shifted in a number of ways. Buffy is no longer a teenager, or a girl - she has developed into a woman, who has experienced love and heartbreak, lost a family member and gained another, stood together with friends and stood alone. And - perhaps most importantly - the Buffy who stands on the edge of her former town is wiser. Unlike the girl who tries to abandon her calling in the first episode, walking out on Giles when he recognizes her as a Slayer, the Buffy in "Chosen" has learned the value of not only using her gift, but sharing it with the world.

Although it would be simple to explain the change in character to a narrative arc seven seasons in the making, there is another reason to consider: Buffy has survived more than six apocalypses (what is the plural form of the word after all?) ${ }^{10}$ and more than twelve Big Bads ${ }^{11}$ throughout her series run. These characters, the evil representations that Buffy must battle in her quest to protect her friends, family and world, are not merely adversaries in the traditional sense of the word. Instead, as Joss Whedon, show creator, explains in an interview for The Watcher's Guide, Vol. 1, these monsters have a role in Buffy's life:

A lot of times, the story doesn't make sense until we figure who's suffering and why. Including the bad guy. If the bad guy's not hurting, not relating to her

\footnotetext{
${ }^{10}$ Riley asks Buffy this question in "Doomed" (4.11)

11 The list includes The Master, Spike, Drusilla, Angelus, The Mayor, Faith, The Initiative, Adam, Glory, Trio of Nerds, Dark Willow, and The First. However, for the purposes of brevity, only ten will be examined in detail.
} 
(Buffy), then it's just a cardboard guy to knock down. And the same thing goes for the audience. If they're not feeling it[...] it's not going to resonate. (Golden \& Holder, reprinted in Edwards 86-87)

Whedon's belief that these villains must "relate to her" is important when considering the Slayer's relationship with each season's Big Bad. Whether he is suggesting that the two mirror each other's struggle, or they must have a personal involvement in the affairs of the other, Buffy and the Big Bad must have a relationship. Without it, they become just like the other villains on the show who appear for an episode or two, "cardboard guy(s) to knock down," stake, behead and incinerate.

Instead of a casual violent encounter, these Big Bads are legitimate characters in the series, occupying a position of privilege afforded to recurring cast members and special guest stars. A quick summary of their appearances in the credits demonstrate that they are the actors and actresses who often claim the coveted first credit or the special guest star status (the 'and' or 'with' at the end of the cast credits). These are the same positions occupied by Kristine Sutherland (Joyce Summers), Anthony Stewart Head (Giles), Seth Green $(\mathrm{Oz})$ and David Boreanaz (Angel) when their characters are no longer part of the principal cast.

This first chapter focuses on the impact of two of the most powerful Big Bads Buffy faces: season one's the Master and season seven's the First. Together the two villains form complimentary bookends that begin and end the series, creating the structure to which the other Big Bads adhere, and wrapping it up in the final season.

The fact that these Big Bads open and close the series is their defining characteristic with regard to their relationship with the Slayer. The object of this initial chapter is to chronicle the ways in which Buffy changes from the first abbreviated season when she was just beginning her life in Sunnydale, to the final year, when she destroys it. 
And while Jes Battis suggests that "Buffy experiences, more or less, the same essential conflicts (Slayer versus teenager, prophecy versus normality) until Season 5" (26), I would argue that her reactions to the Master is entirely different from any other Big Bad, especially The First.

This is because her relationship with her dual selves - the Buffy and the Slayer has changed, and with it her sense of responsibility in regard to her powers. These changes are brought about by the ten Big Bads in between, so that when she finally faces The First in "Chosen," Buffy no longer fears her calling. Over the course of seven seasons, Buffy has learned to accept the responsibilities that accompany her roles so that she has a balance between her Buffy self and her Slayer self.

The Master is important because he forces Buffy to recognize her responsibilities as a Slayer. Initially she refuses her calling as Slayer because of what happened at her old high school in Los Angeles. Over the course of the season, Buffy struggles to prioritize her 'normal' life, but the Master's prophecies continually reinforce Buffy's responsibility to protect the community with her powers. This conflict - her desire to be a normal sixteen year old girl versus her responsibilities as a Slayer - comes to a climax in "Prophecy Girl" (1.12), when she learns she will die at the Master's hands. ${ }^{12}$ Her Buffy self cannot accept that she will die at such a young age, but after listening to Willow describe the attack at the school, Buffy knows that she must accept her responsibility to take back the world from vampires who have "made it theirs." Even though she realizes

\footnotetext{
${ }^{12}$ Technically he kills her twice, making him doubly important. The first time is in the season one finale "Prophecy Girl," and the second time is in Cordelia's wish-inspired alternate universe "The Wish." Although no one remembers the events that took place in the alternate universe once Giles smashes Anyanka's amulet, The Master remains Buffy's most deadly foe in that he is the only Big Bad to actually kill her.
} 
that she will die doing it, Buffy recognizes that she must do whatever she can since she is the only one with the powers to stop the Master's ascension.

The relationship between the Master and Buffy is established in her first scene in the pilot episode, "Welcome to the Hellmouth" (1.01). Following the teaser (any scenes before the credits), Buffy is shown having a nightmare. Her dream consists of images that foreshadow her conflicts throughout the first season, focusing primarily on the Master and his underground lair. The dream's concluding image is its least blurry, a shoulder shot of the Master's face in close-up profile. A barking noise can be heard on the soundtrack as he suddenly turns his head to look directly into the camera, a motion repeated by Buffy as she startles awake from her dream.

This dream is of particular importance for a number of reasons: it introduces the Master and Buffy in a single 41 second sequence, and suggests that Buffy has a connection to him through her (prophetic) dreams as well as their shared head gesture. This makes for an effective counter to the normality that follows, when Joyce calls Buffy for her first day of school - an early suggestion that the monstrous occupies the same space as normality in the show's universe. Buffy's quiet demeanour in the car ride to school suggests she recognizes the importance of the dream, but her disavowal of anything wrong indicates her refusal to let anything disrupt her first day.

The dream specifically functions within the narrative as a prophecy, in that it foreshadows the Master's plans. This indicates early on the important role of prophecy and ritual in the first season. More than any other Big Bad, the Master is associated with these ideas. Of his six appearances in the first season, ${ }^{13}$ half involve his use of prophecy

\footnotetext{
${ }^{13}$ Welcome to the Hellmouth (1.01), The Harvest (1.02), Never Kill a Boy on the First Date (1.05), Angel (1.07), Nightmares (1.10), and Prophecy Girl (1.12).
} 
as a narrative device. It is significant that all of the Master's prophecies fall on the important dates in Buffy's life. The Harvest occurs during her first two days of school; the appearance of the Anointed occurs during her first (and only) date of the first season and the Codex prophecy falls on prom night. In this way, the Master's nefarious schemes counterbalance Buffy's attempts to live a normal life. The duality of her roles becomes apparent in the opening sequence of the pilot as her roles are placed in conjunction one after the other: the dream (a symbol of her role as Slayer) immediately precedes her first day of school (student being the societal role of a sixteen year old). For this reason, the examination of the Master will focus on the four episodes which feature prophecy and apocalypse: "Welcome to the Hellmouth/The Harvest," (1.01-1.02) "Never Kill a Boy on the First Date," (1.05) and "Prophecy Girl." ${ }^{\prime 14}$ It is important for the Master's prophecies to occur on important days in Buffy's life because it establishes a formula for successive Big Bads (witness the various traumas Buffy endures on her birthdays), but, more importantly, it highlights the level to which Buffy tries to suppress her Slayer self and the responsibilities that accompany her powers.

The Buffy presented in the two part-pilot has abandoned her calling in favour of normalcy. The introductory scenes between Buffy and Giles demonstrate that Buffy has become a wary Slayer, unwilling to let her responsibilities as the Slayer compromise her Buffy side. If the Master serves one important function, it is to force Buffy to recognize that she cannot simply disavow her calling. She still retains the powers of a Slayer, and since only one Slayer exists at a time, she has a responsibility as the Slayer to use her powers to fight evil. Instead, season one features Buffy continuously putting her normal

\footnotetext{
${ }^{14}$ The other episodes featuring the Master are less useful for this discussion. "Angel" showcases the Master's humanity when his favourite servant is killed, while it is unclear whether the events involving the Master in "Nightmares" truly happen.
} 
life ahead of her Slayer responsibilities - at least, until aspects of her Buffy life are threatened. Only when her 'normal' life is put in peril does she break into Slayer mode to protect her friends, family, school and sex life.

These ideas are clearly present in the conversations Buffy has with Giles in "Welcome to the Hellmouth." These initial scenes establish Buffy as an unwilling hero, in that she understands her role, but refuses to accept it. Even when Giles warns her of the recent influx of vampires and "signs of mystical upheaval," she sarcastically remarks, “Oh, come on. This is Sunnydale. How bad an evil can there be here?" A quick dissolve to the exterior of the school, followed by a slow track through the earth to the Master's underground lair follows as the omniscient camera answers her question.

These questions serve to undermine Buffy's role as the Slayer. Her deductive reasoning has decreased since she has decided she will no longer uphold her responsibilities. Instead, her Slayer instincts are replaced by the power she wields as a teenage girl. This is demonstrated when Giles asks her if there are any vampires in the Bronze, a local youth nightclub, and she spots one ${ }^{15}$ based on his "carbon dated" clothes, noting that "only someone living underground for ten years would think that is still a look." In this case, her fashion sense has replaced the "honing" abilities Giles insists a Slayer should possess.

As details emerge about the Master's Harvest, the impact of first prophecy is explored. Not only does Buffy risk expulsion from Principal Flutie, but she has her first argument with Joyce. In this way, the Master puts Buffy at odds with the two authority figures in her Buffy life (school and family), foreshadowing the difficulties that will

\footnotetext{
${ }^{15}$ Here Buffy is once again undermined when she exclaims to Giles that she can handle one vampire, following which the camera focuses on Darla and cuts to the Master's rise from the bubbling pool of blood underground.
} 
accompany her role as Slayer (notably her expulsion from both sanctuaries the following season in "Becoming, Part 2," 2.22). ${ }^{16}$ Additionally the connection between Buffy and the Master is strengthened when she defeats Luke: shots cross-cut between the Master falling to his knees in a high angle, extreme long shot and a 'power' shot of Buffy filmed at a low angle, with a blue filter, as she defiantly stares down a pair of his minions. In this way (and despite the fact that they have not met in person), Buffy's privileging low angle shot beats the Master's judgmental high angle long shot, suggesting she has won the first battle. By accepting the responsibilities that accompany her powers, Buffy saves the day and strengthens her friendship with Giles, Willow and Xander, which is suggested at the end of the episode when the gang walks in the sunshine, laughing. In this way, her success as a Slayer is conducive to her success as Buffy, suggesting that a balance between the two is ideal.

The Master reappears in "Never Kill a Boy on the First Date," the first (and only) date episode of season one. Buffy's desire for normalcy prompts her to overlook the severity of the coming of the Anointed in favour of meeting potential boyfriend Owen at the Bronze. In this episode, both Buffy's Slayer status and her falling out with Cordelia in "Welcome..." derail her date. Not only is Buffy forced to protect Owen from Cordelia, she must contend with Andrew Borba - a religious fanatic turned vampire whom she and Giles believe is the Anointed after five people are killed when vampires attack a bus. This episode lays the groundwork for all of Buffy's future relationships in that Buffy must accept that she cannot date people who don't know her Slayer status. Giles warns "If your

\footnotetext{
${ }^{16}$ The role of authority and its ultimate subversion by Buffy is explored in Daniel A. Clark \& P. Andrew Miller's "Buffy, the Scooby Gang, and Monstrous Authority: BtVS and the Subversion of Authority." Clark \& Andrew demonstrate that all authority figures are undermined, shown to be evil, compromised and often killed by Buffy, who often proves to be the most adept at determining the correct course of action.
} 
identity as a Slayer is revealed, it could put you and all those around you in grave danger" a self-fulfilling statement when he is trapped in the funeral home by vampires as well as when Borba seemingly kills Owen in the crematorium.

The Anointed ultimately proves to Buffy that her duty - to her friends and the world - is more important than her love life. As the series continues, all of Buffy's serious relationships will be with men who understand and match her abilities (two vampires and a government soldier). The other men she dates - Scott Hope in season two, and Owen in season one - ultimately cannot handle the two people that define Buffy. ${ }^{17}$ The end of the episode continues the subversion of the Scooby gang when Giles and Buffy discuss that they at least managed to prevent the rise of the Anointed when a cut reveals that it was the child from the bus crash, not Borba, who is the Master's warrior. The episode ends with the Master and the Anointed together, suggesting that the Master has now evened the score.

The best example of the Master's ability to highlight Buffy's dichotomy occurs in the climatic season finale "Prophecy Girl" when Buffy learns that the latest prophecy forecasts her death at the Masters hands. Echoing her initial scene with Giles in "Welcome..." Buffy rejects her calling, throws away the (symbolic) cross Angel gave her and tries to convince her mother to leave town with her. Only after Willow explains that a vampire attack at the school made her feel as if "it wasn't our world anymore - they made it theirs," does Buffy realize that she must attend her prophetic date with the Master. She knocks Giles out when he tries to take her place, reclaims Angel's cross and

\footnotetext{
${ }^{17}$ Owen is enamored only with the dangerousness of the Slayer, not the Buffy aspects while Scott feels that Buffy is too distant - a symptom that others remark upon that is actually the result of Angel's return from hell in season three
} 
follows the Anointed into the sewers, where she submits to the Master and drowns in a shallow pond. Krimmer and Raval believe this moment is

fraught with romantic imagery and thereby evokes the topos of Death and the Maiden: the white prom dress that she wears as she goes to meet the Master is eerily reminiscent of a bridal gown, the Master's underground cave is lit by hundreds of white candles, and with his mesmerizing gaze, the Master reduces Buffy to a passive object with no will of her own and then penetrates her neck with his teeth. The camera angles for the shots in the bite scene, with the close-up of Buffy's terrified face, her gasp, followed by the focus on the traces of blood on her white skin, making it clear that viewers are to read the Master's act as a form of sexual initiation. (158)

Krimmer and Raval's comment about sexual initiation is telling. The scene when the Master kills her - their first encounter in person ${ }^{18}-$ is the first demonstration of the show's link between sex and death. The penetrative aspects of the vampire's bite, followed by Buffy's death at his hands, links the two themes and prefaces Buffy's second season relationship with Angel. ${ }^{19}$ It also looks forward to season five when Buffy learns that her power is tied to death ("Fool for Love," 5.07), love ("Intervention," 5.18) and sacrifice ("The Gift," 5.22). Following her revival, she tells Xander and Angel that she "feels strong" - she emerges from death stronger than ever.

During their second confrontation, this time above ground (Buffy's domain), the Master attempts to restate the power of prophecy when he exclaims: "You were meant to die. It was written." This prompts Buffy to flippantly tell him that she "failed the written." Instead of the submission and inaction ${ }^{20}$ that defines their first confrontation, Buffy's death enables her to fight the Master physically and verbally. This is signified in

\footnotetext{
${ }^{18}$ See footnote 14 regarding "Nightmares," which can be argued is the first meeting between the two.

${ }^{19}$ Diane DeKelb-Rittenhouse explains: "Only after the young people walk on does Angelus drop the drained body of his partner, revealing the embrace for what it was: the counterfeit of love - a sensual, ecstatic rendering of death" (147). See Chapter 4 for further explanations of Buffy's sexual attraction to death.

${ }^{20}$ These are qualities that define the unsuitability of a Slayer. See Faith's section in chapter 3
} 
her ability to block his blows, as well as the restoration of her verbal wit (in addition to the aforementioned quote, she remarks that the Master has "fruit punch mouth").

In this way, prophecy, the Master's dependency on it and the power of the written word are all dispatched as Buffy instructs the Master verbally to go to hell and promptly stakes him on the broken library table below. The subversion of Buffy and the Scooby gang's verbal language, which have been bested by the Master and his written prophecies throughout the season, comes to an end. The episode, however, does not end with the typical sunny conversation in the courtyard that marks the other prophecy episodes. Although the words are reflective of Buffy's attitude, it remains night outside and the final lingering shot of the season is of the Master's bones, suggestive of his return in the second season opener "When She was Bad" (2.01) for one final prophecy: his restoration to life.

This episode is the first to establish a recurring theme on the show when Buffy cannot adequately cope with a deposed Big Bad. It is unique, however, because the Master is the only Big Bad who fits this pattern, but is not personalized. ${ }^{21}$ Upon Buffy's return from Los Angeles, her friends note her continued detached and out of character behaviour. The first indication is her new haircut, ${ }^{22}$ which is indicative of a major personal crisis (an idea repeated in season six's "Gone," 6.11 , when she cuts off her hair in frustration over her relationship with Spike). Buffy's attitude change is commented on not only in dialogue (Willow suggests she's become a bitch and Xander believes she's possessed), but also in action and mise en scene. When Buffy goes to the Bronze, she rebukes Angel, ignores Willow and dances seductively with Xander. Here the lighting is

21 Personalized Big Bads are addressed in chapters three and four.

22 The change in hairstyle is actually attributable to her role in the film I Know What You Did Last Summer [Gillespie, 1997]. 
low key and casts shadows across her face as she moves, suggesting her conflicted feelings.

These feelings are the result of an imbalance between Buffy's Slayer self and her Buffy self. This prompts Buffy to be overly responsible to her Slayer skills as a way of appeasing her Buffy side, which cannot cope with her premature death. Her decision to resume her training immediately and her overzealous attacks are desperate attempts by her Slayer side to compensate for her emotionally wounded Buffy side. This produces an improper balance and, despite her best attempts, makes her a weaker Slayer. This is clear when she breaks Giles' training equipment and allows her friends to fall into a trap.

In this way, the Master continues to affect her duality. Even though he is dead, his connection to Buffy remains: she tells the group, "We killed each other. It really promotes togetherness" and envisions his face when she is training, and again in a dream when she rips off his Giles mask. ${ }^{23}$ Her inability to vocalize her feelings, as well as her refusal to address the issue with her friends is a denial of her Buffy needs. Her attempts to remain distant and focus on Slaying disavow her responsibilities as a friend and result in the kidnapping of Giles, Jenny Calendar, Willow and Cordelia. It is when Buffy works with Xander and Angel (reuniting the same players from "Prophecy Girl"), that she is able to defeat the Anointed One's followers. Only in the cathartic destruction of the Master's bones at the end of the episode and with a release of tears can Buffy move on to face her next Big Bads, Spike and Drusilla.

The Master reappears two more times following his destruction in "When She Was Bad": "The Wish" (3.09) and "Lessons" (7.01). The former is an unusual episode in

\footnotetext{
${ }^{23}$ Stacey Abbott's "A Little Less Ritual, A Little More Fun" in Slayage 3 examines how adults are coded similarly to Big Bads. She believes that by associating Giles and Joyce with the Master, the show reveals adulthood and growing old is one of the fears of Buffy, Xander and Willow.
} 
that it takes place in a parallel world where Buffy never came to Sunnydale. While the dual universe is forgotten by episode's end, ${ }^{24}$ its events are indicative of her duality as both Slayer and Buffy. She is presented as a cold and efficient Slayer, without concern for individuals or social niceties. In this way, she is lacking defining Buffy qualities: she lacks a sense of humour, lacks compassion for others / her friends and even lacks a (feminine) fashion sense. The lack of these defining Buffy qualities demonstrates the importance of balancing both the Slayer side and the Buffy side and foreshadows Spike's comments in "Fool for Love," when he equates her longevity to her "ties to the world."

Here it is possible to see Sartre's beliefs regarding the choices of man: the Buffy of the 'real' world has built her character based on the admirable qualities that she sees in her friends, so she is compassionate and caring. By removing herself from humanity, the Buffy from the alternate reality in "The Wish" remains a hero (she chooses action over inaction, and she uses her powers for the collective good), but her personality is missing the essential qualities that come from associating with friends. When Buffy goes into battle with the Master and he breaks her neck in the alternative world, it proves that without both sides - the Slayer and the Buffy - Buffy is not as effective a Slayer.

Joss Whedon characterizes the final appearance of the Master on the show as an indication it is entering its final season. The Master seen at the end of "Lessons," is not the same Big Bad glimpsed in season one, two or three - it is the new Big Bad of Buffy's final year: The First. Just as the Master started the traditions encompassed by previous Big Bads (traps, using Buffy's friendships against her, a season finale climax), the First

\footnotetext{
${ }^{24}$ Vamp Willow appears in the real world later in the season in "Dopelgangland," (3.16). At episode's end, she is returned to her proper place in "The Wish" universe so she can be staked just as she was before.
} 
wraps them up, as indicated by its speech at the end of the first episode. ${ }^{25}$ Contained within this speech (and, more generally, within this episode) is the blueprint for the entire season: ${ }^{26}$ the use of Spike as a weapon, activated by a trigger; a return to the beginning, the power that unites Buffy and the First, Buffy instructing girls on how to use their power and finally, the appearance (and deaths) of potentials, the group of girls from whom the next Slayer will be chosen should Buffy or Faith be killed.

The episode makes it clear that the First is no ordinary Big Bad. Kevin Johns explains that the Big Bads become progressively more difficult as the seasons progress, “escalat(ing) from vampire (the Master and Spike/Drusilla/Angelus) to demon (Mayor Wilkins and Adam), to God (Glory)" (3). While Johns explains that the Trio of Nerds deviate from this formula, the First is easily the most difficult villain for Buffy because of its incorporeal status. She encountered the same dilemma when it appeared in "Amends" (3.10) and while it frustrated her then, it has a significantly different effect here.

The threat posed by the First forces Buffy to not only balance her dualities once and for all, but to embrace her responsibilities as a Slayer in a way she never imagined possible. The army of ubervamps that Buffy sees in a vision in "Get It Done" (7.15) prompt Buffy's realization that without a powerful army of her own, she will be defeated by the First. Her responsibilities as the Slayer demand that she fight, but she recognizes the implausibility of a group of "scared little girls" surviving the First's attack. Since it is her responsibility to protect the girls as well as the world, she decides to use the scythe she steals from the First's minion, Caleb, to disseminate her powers to all the potential

\footnotetext{
${ }^{25}$ See Appendix A for full transcript.

${ }^{26}$ For a more complete examination of how "Lessons" looks both forward at the upcoming season and back to previous seasons, see Elizabeth Rambo's essay "Lessons" for Season Seven of Buffy the Vampire Slayer' in Slayage $11 \& 12$.
} 
Slayers. It is the ultimate act of sacrifice because in giving up her status as the Slayer, Buffy loses the one thing that makes her unique. At the same time, however, it alleviates Buffy of the responsibility of looking after the community, allowing her to choose, for the first time, whether to continue using her powers or live the normal life she's desired since the first season. It is because of the First that Buffy finally ends the conflict between her dualities by embracing her responsibility to share her power. Additionally, the scale of the First's attack (a global crisis that destroys the Watchers Council and brings all potentials to Buffy's house), forces Buffy to embrace her skills as a leader and teacher.

It is appropriate then that the first episode is called "Lessons." In addition to foreshadowing the season's conflicts and reinforcing Buffy's essential qualities (touched upon in the introduction), the episode introduces the First. Its presentation is interesting: by morphing from Big Bad to Big Bad in a reverse chronological order (starting with season six and working down to season one and finally Buffy herself), it is insinuated that the First is made of each up of aspects of the other Big Bads. This makes sense in light of the revelation in "Bring On The Night" (7.10) that it can only take the shape of the dead and Giles's explanation that "There's evil, and then there's...the thing that created evil the source." As the origin of evil, the First undoubtedly contributed to the motivations of previous Big Bads, and its ability to accurately copy the physical and vocal mannerisms of dead characters clearly establishes the idea that evil, in some small part, lives in "every man, woman and child on the planet." ${ }^{27}$ Joyce supports these ideas when she appears to

\footnotetext{
${ }^{27}$ The First explains to Caleb that its endgame is to "enter every man, woman and child on this earth just as I enter you." The key part of the phrase is "just as I enter you" since Caleb is the only person strong enough to survive. This does not suggest, however, that the First does not already exist to a certain degree in every man, woman and child, especially since it is the root of all evil.
} 
Buffy in a dream, explaining “Evil isn't coming. It's already here. Evil is always here." In this way, the morphing of past Big Bads at the end of "Lessons," as well as the Master/the First's line "going all the way back to the beginning" indicates that of all the villains, this will be the most difficult to vanquish as it contains all the others, including their speech patterns (Glory's use of “fabulous," Warren's misogyny, Adam's use of the word "parameters," etc).

Unlike other seasons, however, there is no new actor to portray this evil.

Following on the heels of season six, when the villains are arguably all human (see chapter three), the visage that the First takes most often is that of Spike (for the first half of the season) and Buffy (for the final two-thirds). This suggests that in season seven the Scooby gang will have to conquer their dark sides again, which is exactly what Buffy does in "Chosen," when she faces off against the First posing as herself. This is made increasingly clear when the First's visage is revealed in both "Bring On The Night" and "End of Days" (7.21): it emerges from within Willow and Buffy as a giant horned devil.

Although Whedon suggests in his audio commentary that it is financial and time restrictions that prohibit bringing back the actors who portrayed the Big Bads, ${ }^{28}$ it makes sense thematically to have Buffy contend with a physical impostor of herself. It immediately brings to mind the idea that Buffy and the Big Bad are connected, which is developed in "Lessons": Buffy's first line is, "It's about Power," which is the same line Buffy-The First speaks at the end of the episode.

The connection between the two also works because of the First's incorporeal state. Since it is not physical, it can be said it is everything and nothing (an idea that further supports that it is in everyone and yet simultaneously not). Since its endgame is a

\footnotetext{
${ }^{28}$ Only Harry Groener (The Mayor) and Juliet Landau (Drusilla) return later in the season as the First.
} 
variation of possession, it makes sense for the First to possess Buffy's form. As the Slayer, she is a figure of power and a representation of everything Caleb must destroy in order for the First to succeed. There is even an insinuation that in taking on Buffy's form, the First becomes more like Buffy when it teases Caleb's inability to woo it before they merge in "End of Days" (7.21). He warns it (as Buffy) to "Watch what you say now. You're startin' to sound like her."

The gender implications of such a statement are interesting, especially in light of the roles the First and Buffy play in "Chosen." The First's power relates to entering every man, woman and child on earth, suggestive of a penetrative, masculine action (the implications are more severe if the fact that this would be an unsolicited, intrusive action is considered). In contrast, Buffy's power involves sharing her power with a group of girls. The nurturing, feminine aspect of Buffy's plan is further elaborated on in her speech in "Chosen," when she offers the girls the choice to become strong. In this way, the First is associated with possessive masculine power, while Buffy is shared feminine power.

The connection between the First and Buffy falls in line with the tradition that originated with the Master in season one. It is no coincidence that its initial appearance takes place directly after the final (true) appearance of the Master in season three. The back to back episodes suggest the end of one type of Big Bad and the introduction of another. Indeed, just as the Master was proven to rely on written prophecy, so too do the following two seasons worth of Big Bad (Angelus/Spike/Drusilla \& the Mayor). They can be aligned with the Master because written texts can be used to discuss their history and future plans. After the appearance of the First in "Amends," the Big Bads in 
following seasons are all original (the Frankenstein-cyborg Adam who is created specially by Maggie Walsh) or have no written history (Dark Willow, who can only be judged against her own 'normal' self, ${ }^{29}$ and Glory and the First, both of whom predates the written word). Following the Mayor, the villains become increasingly difficult for Buffy and her friends to battle because of the lack of information about them, leading to different explorations of her dichotomous selves.

Finally, unlike the Master, who appears in half of the first season episodes and is mentioned only in passing in other episodes, the First dominates the seventh season. Just as the Glory section of its speech in "Lessons" suggests, its name truly is on everyone's lips. It organizes the season in a similar structural manner, overtaking the teaser section of both the first and second episodes (although it is not revealed exactly how the girls' deaths are related until Giles' appearance in "Bring On The Night"). Ultimately narrative events involving, attributed to or surrounding the First can be found in eighteen of the twenty-two episodes, including "Lessons," "Beneath You" (7.02), and every episode onwards following "Him" (7.06).

Because there are so many episodes involving the First, only selected episodes will be examined. "Lessons" has already been spoken of at length, leaving "Sleeper," "Never Leave Me," and "Bring On The Night," (7.08-7.10) which take place back to back; "Get It Done," (7.15) when Buffy first starts speechifying ${ }^{30}$ out of frustration, and "Dirty Girls," "Empty Places," "Touched," "End of Days” and finally “Chosen" (7.187.22) which again take place back to back.

\footnotetext{
${ }^{29}$ Examinations for Adam, Dark Willow and Glory take place in chapters 2, 3, and the conclusion, respectively.

${ }^{30}$ This word is a reference to Andrew's analysis of Buffy's tendency to launch into speeches during his focal episode, "Storyteller" (7.16).
} 
The large number of back-to-back episodes is as important as it is rare before season seven. While there are many episodes that affect the seasonal narrative or reference future/past events throughout the series, ${ }^{31}$ there are rarely episodes which begin immediately after the events of the previous episode. The fact that season seven features nine episodes which do so suggests several things.

First, the season is running on a condensed timeline. Unlike previous seasons, the climatic confrontation between Buffy and the First does not take place at the end of the school year. ${ }^{32}$ As discussed below, one reason for this is because Buffy goes on the offensive instead of working around the Big Bad's schedule.

Second, because of the increased number of episodes featuring the First, there are fewer stand-alone episodes than in the past. As a result conclusions are more apt to be open-ended or cliffhangers. The First episodes involve narrative elements that take multiple weeks to explore and therefore require more episodes than previous seasons of Buffy, which some (Saxey, 195) have argued is already more drawn out than other arc shows on television. In this way the First creates story lines that are more complicated, and demand immediate conversation and action from Buffy and her friends.

Third, in season seven, problems involving life and death situations that in the past might have been treated more casually now appear more dire because of the back-toback presentation of the episodes. There is a suggestion that events are culminating faster than before, that the situation is rapidly deteriorating, and that Buffy and her friends are becoming overwhelmed. This is most clearly represented by Buffy and her lack of sleep:

\footnotetext{
${ }^{31}$ For an expansive look at the variety of endings employed in Buffy narratives, see David Lavery's 'Apocalyptic Apocalypses: The Narrative Eschatology of Buffy, the Vampire Slayer.' In it, he breaks down the endings of episodes into 12 categories such as cliffhanger, tear-jerker, not-over and pay-off.

${ }^{32}$ Possible exceptions include seasons five and six, when it is unclear when the climax takes place.
} 
she stays awake for several days straight over the course of the first four back to back episodes ${ }^{33}$ because she is out patrolling or researching. In these initial episodes, the First has attacked in two ways: with the ubervamp and with Spike's trigger, causing him to kill despite his Initiative implanted chip. ${ }^{34}$ Both attacks affect Buffy's ability to Slay: the ubervamp overpowers her, while Buffy's romantic attachment to Spike puts her friends in danger. $^{35}$

The increasing threat of the First, especially the destruction of the Watchers Council in "Never Leave Me," prompts the transformation of the Summers house into a base camp for Buffy's army. As more potentials arrive, the threat of the First forces Buffy to accept more responsibility: she must now protect Dawn and her friends, rescue Spike and train the potentials for the upcoming battle. In this way, the First serves to bring about the leadership skills briefly hinted at in other crisis situations, such as "Becoming, Part 2" (2.22), when Giles is kidnapped and "Graduation, Part 2" (3.22), when she leads Sunnydale High's graduating class into battle against the Mayor. It is the overwhelming threat of the First, and then the ubervamp, and then Caleb that forces Buffy to accept responsibility for protecting not only the potentials' lives, but the entire Slayer lineage.

Initially Buffy's role is not presented as such. In the first set of back-to-back episodes, she is exhausted and frustrated. The appearance of Joyce in "Never Leave Me" is evocative of Buffy's need for parental guidance - she needs someone to tell her to get

\footnotetext{
${ }^{33}$ She is seen returning to the house the morning after "Conversations...", Joyce begs her to sleep during "Never Leave Me" and Giles suggests she sleep after the initial ubervamp attack in "Bring On The Night."

${ }^{34}$ The chip is part of the Initiative's attempt to protect society from vampires and demons - it causes excessive pain if the vampire / demon tries to harm a living creature.

${ }^{35}$ See chapter three and four for detailed examinations of how Buffy's romantic relationships affect her responsibilities as both Slayer and Buffy.
} 
sleep and comfort her about the upcoming battle. Giles fulfills this role when he appears in "Bring On The Night," telling her to get some rest and accompanying her on patrol to the Christmas tree lot. Just as Giles suggests in "Once More, With Feeling" (6.07), his presence is "standing in the way" of Buffy's development as an adult, which can be expanded on to include her responsibility as the Slayer to be a leader to future generations of girls.

When the ubervamp appears, her defeat at the construction site forces her to assume leadership of the group. After listening to her friends (off-screen) in a dark room, her knees curled up in a fetal position, she appears in the crowded dinning room and delivers a passionate speech about building an army. This speech marks Buffy's emergence as the leader and teacher of the potentials - a role she brings to fruition in the episodes that follow when she defeats the ubervamp in a gladiator showdown ("Showtime") and begins to train the girls in battle tactics ("Potential," 7.12).

Despite Buffy's new leadership abilities, her frustration and inability to inflict damage on the First grows. "Get It Done" includes the death of a potential, Chloe, who commits suicide rather than face the First. The speech that Buffy gives following Chloe's burial is self-indulgent, ${ }^{36}$ but it demonstrates the feelings of responsibility that only Buffy carries. As the Slayer, she alone has superpowers, and is therefore responsible for the safety of the group. However, while part of the speech expresses frustration that she failed to protect a potential, it is also suggestive of the burden she bears, despite Willow's magical abilities and Spike's vampirism. In her speech, she specifically targets these two allies and then leads by example when she disappears in the portal created from Robin's “emergency Slayer kit."

${ }^{36}$ See Appendix B for full transcript. 
In this way her decisions as leader of the group force Willow and Spike into action: Willow must conjure a powerful spell to recall the portal and Spike must find a way to kill the demon that emerges from the portal in Buffy's place. This episode is also a dramatic step forward for Buffy because she refuses more power from the Shadow Men when it becomes apparent that it involves a symbolic rape. Her decision to reject the Shadow Men's power is appropriate in that it marks another instance in a long line when Buffy refuses to do the bidding of men (the Watcher's Council in season three and seven, the Initiative in season four). Instead, by opting to embrace her own power, she prepares for "Chosen," when it is her own powers, and not those granted by men, which provide the strength to win the battle. By season seven, Buffy is comfortable with her abilities as a Slayer and her decision to remain true to herself demonstrates this.

Unfortunately, her attempt to take control of the situation by doing something irrational (jumping into the portal without knowing how to return) in "Get It Done" reveals that the situation is worse than she knew. This is represented once again by an image of Buffy sitting alone in her dark bedroom, covered in blankets and staring into nothing. Her silence is explained by the episode's final image, which arguably constitutes season seven's mid-season twist and drives the rest of the season: a vision given to Buffy by the Shadow Men of an army of hundreds of ubervamps, camped out below the seal.

The events of "Get It Done" prompt several important developments. Buffy knows what the group is facing, and realizes that she has a responsibility as a leader and as a Slayer charged with protecting the world to prepare the girls for battle. She also recognizes that if she is going to win, she needs more firepower. Although she recognizes 
Willow and Spike as her "big guns,"37 she uses Faith's recent escape from a Los Angeles prison to her advantage and brings her back to Sunnydale.

It is Caleb and Faith, who enter Sunnydale within minutes of each other, who heavily influence the final five episodes of the series. Caleb clearly echoes season one in his "overt religiosity" (and penchant for eye dismemberment ${ }^{38}$ ) as well as his role as the First's vessel (a role occupied by Luke in "Welcome..." and "Harvest"). His entrance also initiates the second round of back-to-back episodes as Buffy now has something to fight. Her dismay with regard to the potentials' progress and the efforts of her friends, which began in "Get It Done" and reaches the point of parody in "Storyteller," is actually a reaction to her own feelings of frustration and impotence. Buffy can see the signs of approaching apocalypse (the influence of the Hellmouth; the mass evacuation of Sunnydale in "Empty Places"), but these are events she cannot do anything about it.

Her second irrational action is the battle at the vineyard. The fight itself is interesting in that it foreshadows the bloodshed the Scoobies will suffer: Spike, Faith and Kennedy are all knocked into barrels that spill rivers of blood-like wine across the floor, which anticipates the destruction of Xander's eye and the deaths of two potentials. Buffy's encounters with Caleb echo her battles with the ubervamp in the first series of back-to-back episodes: she fights an incredibly powerful ally of the First (uberveramp / Caleb), is defeated several times (Christmas tree /construction site vs vineyard/school) before finally emerging victorious in front of spectators (the potentials vs Spike/Angel). In this way the First's initial attacks with the ubervamp anticipates the arrival of Caleb in

\footnotetext{
${ }^{37}$ Wilcox explains that, in "Chosen," each plays an important part in saving and changing the world (Why, 98). Spike's sacrifice "saves" the world from the ubervamps, while Willow's "change" is the dissemination of Buffy's Slayer powers using the scythe.

${ }^{38}$ The Master kills one of his minions by jamming his finger (offscreen) into its ocular cavity in "The Harvest."
} 
both narrative and emotional terms: Buffy's spirit is broken and then restored. These highs and lows are matched thematically with Buffy's struggle to lead the girls into battle. Just as the Master's prophecies target important dates in Buffy's life (the first day of school, first date, the prom), so too does the First.

As remarked earlier, Buffy's priorities have changed between the first season and last because she has accepted both her roles. She no longer struggles to balance dueling aspects of her life, simply taking one when she can afford it. This is demonstrated in "First Date" (7.14), when she goes on a date with Robin. She manages both her Buffy and Slayer duties: it is an opportunity to investigate his true intentions, and simultaneously sample brandied-pears. When Spike informs her that Xander's date has not gone so well, however, she immediately goes to his rescue.

The final episodes focus on Buffy's attempts to manage her frustrations with her sense of responsibility for the potentials. Buffy's speeches go into overdrive following the First Slayer's ${ }^{39}$ warning that her actions are "not enough" in "Get It Done." After the failed attempt to storm the vineyard in "Dirty Girls," Buffy attempts to restore calm, but instead encounters a mutiny. The situation is made worse because of the presence of Faith, who already has a tumultuous past with Buffy from seasons three and four.

The leadership debate in "Empty Places" is important because it demonstrates the demands of being the Slayer as well as the isolation that accompanies them. The First has Buffy questioning all of her relationships when Giles betrays her ("Lies My Parents Told Me") as well as her best friends and her own sister ("Empty Places"), and Spike

\footnotetext{
${ }^{39}$ The First Slayer is an spirit that initially appears in "Restless" (4.22) after the enjoining spell taps into its power. The suggestion is that Buffy, and all Slayers before her, carry the essence - the power - of the First Slayer, and she appears to guide Buffy in other episodes such as "Intervention" (5.18) and "Get It Done" (6.15).
} 
convinces her of her worth ("Touched"). But it is the debate that ends "Empty Places" that forces Buffy to reconsider the decisions she has been making as a leader.

Buffy's increasingly erratic decisions (the vineyard) are based primarily on her frustrated sense of responsibility to protect the potentials despite her knowledge that they will eventually have to go into battle and many will die. After "Dirty Girls," in the potentials' eyes, Faith is a viable choice for leadership because she is a Slayer, but is less severe in her leadership style than Buffy. However, as Wilcox explains, it is Buffy who knows which decisions must be made in order to lead:

In "Get It Done," she refuses to accept "more power" because she didn't "like the loophole" of becoming "less human." But she has, in spite of the original choice, come to accept the demonic as part of a balance within herself - psychologically, she accepts the power of the id; politically she incorporates the Other. It is such a person who can become a leader, can be a Slayer. (Why, 105)

Wilcox suggests that Buffy's acceptance of her power, even though it is shown to be of demonic origin, as well as her "incorporation of the Other," be it former adversaries (Spike, Anya), different species (kind hearted demon Clem) or races (potentials from across the globe, Kendra, Robin Wood), are the qualities that determine Buffy is fit to be leader of the group.

Anya's bitter speech during the "Empty Places" argument is interesting for its implications about Buffy's ability to lead: ${ }^{40}$

Buffy: You need someone to lead you.

Anya: And it's automatically you. You really do think you're better than we are.

Buffy: No, I-

Anya (con't): But we don't know. We don't know if you're actually better. I mean, you came into the world with certain advantages, sure. I mean, it's the legacy. Buffy: I-

Anya: But you didn't earn it. You didn't work for it. You've never had anybody come up to you and say that you deserve these things more than anyone else. They were just handed to you. So, that doesn't make you better than us. That makes you luckier than us.

\footnotetext{
${ }^{40}$ See Appendix C for full transcript.
} 
While Anya is correct is claiming that being the chosen one does make Buffy (and Faith) luckier than them, ${ }^{41}$ she is incorrect in claiming Buffy hasn't earned it. Buffy has struggled for seven years to improve herself as both a Slayer and a normal girl. Faith, on the other hand, has been using jail to rehabilitate herself in an attempt to earn back the responsibilities that accompany her Slayer powers, ones that she abused in seasons three and four. The simple fact is that the group exists only because of Buffy - she is the one who keeps them united, even when they are not facing apocalypse (Wall \& Zyrd, 60). Only Xander and Willow have a relationship prior to Buffy's appearance in season one ${ }^{42}$ which means that everyone else is there because of her.

Buffy is more adept at being a leader than Faith because she has more practice. She has been a Slayer at least two years longer than Faith (who is called in the third season following Kendra's death). Buffy also knows more about the Slayer history/lineage and is more socially involved in group dynamics. Faith's immediate adoption of Buffy's leadership style signals that she is still learning from the Slayer (it is important that Buffy calls herself the Slayer in the "Empty Places" argument, whereas potential Rona calls Faith $a$ Slayer, suggesting Faith remains secondary to Buffy).

It is easier for Buffy to blame Faith's ability to "dance and get everybody drunk" than admit she has become a totalitarian. The framing of the scene is effective in demonstrating Buffy's social isolation and the unification of the others: Buffy is seen individually, with several potentials behind her out of focus (suggestively tying in with Faith's comments that Buffy doesn't even know their names). The shots of the others, however, are all deep focus, so every disapproving face is visible. In addition to deep

\footnotetext{
${ }^{41}$ Buffy and Faith are likelier to survive the final battle than the others due to their Slayer powers such as increased strength, speed and healing powers.

${ }^{42}$ The importance of this fact will be explored in Willow's section in chapter three.
} 
focus, the Scoobies and potentials are rarely seen individually: Faith and Robin stand side by side; Anya, Willow and Kennedy sit on one end of the couch; Rona and a few other potentials occupy the other side; and Xander sits with Dawn and the rest of the potentials. Only Giles is seen by himself, although his standing position directly opposite Buffy suggests their continued struggle of authority after the events of "Lies My Parents Told Me" (7.17). The framing therefore suggests that Buffy's position of power - her status as the Slayer - has isolated her from the group. Her desperation to defeat the First and end the conflict she fears will kill the girls is the quality that results in eviction from her own house.

Similar film techniques are used in "Touched" when Faith takes over the group. In their initial conversations, camera movement replaces framing as a means to visualize the feelings of the group, indicated by the quick pans, often in hand-held, jerky motions. These movements suggest events are hectic, chaotic and out of control as everyone attempts to have their say. Conversations overlap as the group bickers, even after the lights go out and they begin again in the basement. This continues even after Faith takes charge, explaining that while she's "not Buffy," she is their leader "which means, I go first, and I make the rules, and the rest of you follow after me - is that clear?"

In this way, even though Buffy has been banished and spends the rest of the episode doubting her abilities until Spike returns, her ideas remain at large in the Summers' household through Faith's leadership skills. Faith unconsciously adopts a similar mentality to Buffy: there can only be one leader, who "makes the rules" and the rest "follow after" or else the group will get nowhere. Only after Faith establishes her dominance and they decide to kidnap a Bringer do the jerky camera movements end. 
Buffy's time away from the group is important for a number of reasons: it allows her to reconnect to Spike, both physically (he holds her while she sleeps) and mentally (he gives her the strength to go after the scythe by herself). Another reason Buffy's away time is important is that Faith needs to try her hand at leadership and fail so that the group can accept Buffy again. The final reason for the isolation is that Buffy needs to spend time without the pressures of leading the group. With the scythe, the group has a powerful weapon, but one that can only be appropriated by Buffy herself (or else it would have been uncovered by Faith's group in "Touched" or during their initial venture to the vineyard in "Dirty Girls"). With the scythe, group cohesion is restored and Buffy is ready to resume her place as leader. Spike and the scythe deliver Buffy's confidence, and conversations with Faith and the First (in disguise as Buffy) about the Slayer's propensity for being "alone" convince her to share her Slayer status and turn the girls into a true army.

This is the best, and final, example of how Buffy has embraced her responsibilities as the Slayer and become an active participant in shaping her life (echoing Sartre beliefs about humans determining who they are through choice and action). Unlike season one, when her powers are passed along without consent after her death, in season seven, Buffy willingly shares her gift, a logical extension of the education she's been giving the potentials all season. Passing along the Slayer's powers ultimately proves to be the winning blow in her battle with the First and brings to an end Buffy's ongoing battle with patriarchal order. What began with the Master (a vampiric father figure) and extended to "Get It Done" with the Shadow Men, has now been thwarted: Buffy has eliminated the Slayer lineage herself, on her own terms, by 
displacing the men who decided thousands of years ago that there could only be one Slayer at a time.

In doing so, Buffy frees future generations of Slayers from the solitary existence that has plagued her, and, as a result, frees herself. Because of the overwhelming threat of the First and its unstoppable army of ubervamps, Buffy has to do something she's never done before, prompting even Giles to comment that "it flies in the face of everything we've ever - every generation has ever done in the fight against evil." Her ambitious plan also marks the first time that she has not operated on a Big Bad's timeline. ${ }^{43}$ Throughout the seventh season, and especially in "Chosen," Buffy seeks out confrontation instead of waiting for the endgame. That this strategy isn't always successful (both "Dirty Girls" and "Touched" involve deadly traps) doesn't belittle the fact that at this stage in her career, Buffy no longer waits to determine when to attack: she has evolved into a true leader (this is suggestive in multiple comments on war, armies and Giles' speech on responsibility in "Lies My Parents Told Me"). When she leads the potentials into battle in "Chosen," it is no longer because it is her duty to do so as it was in other seasons (such as season three when it was her responsibility to protect the graduating class, or season five to save her sister and the world). Instead, Buffy clearly states that she's "ending this once and for all."

With the defeat of the ubervamps and the First, Buffy is finally able to bridge her status as two selves: she can now live her life as a normal girl, as a Slayer or as both. ${ }^{44}$ In

\footnotetext{
${ }^{43}$ This is not the first time she has attempted this, but season seven marks several occasions when she goes on an all out offensive over several episodes, unlike the events of season three, which are discussed in chapter two.

${ }^{44}$ Although she is no longer the Slayer because other girls now possess the same powers, she does not lose her abilities in the transfer. It is her unique distinction that is lost, so Buffy simply remains a Slayer among many others.
} 
the past her duty as a Slayer prevents her from doing everything she wants, and suggests she is bound for an early grave. By passing her power to all the potentials, the responsibility no longer lies with her to protect the world, because they are all capable of doing the job. Additionally, the town (and its Hellmouth) that designate her reign as Slayer is destroyed, suggesting Buffy has a chance at a fresh start and a new life somewhere with Dawn. This is evident in the final shots of the episode when the 'Welcome to Sunnydale' sign falls into the crater and Buffy is asked what she wants to do. Despite the fact that she, Willow and Xander addressed the question earlier (they want to go to the mall), the question refers to her long term plans. That the episode, and the series, ends with a question (and no answer), just a close-up of Buffy's hesitant smile, suggests that Buffy Summers' life is now free to truly begin. ${ }^{45}$

In this way, both the Master and the First contribute to her development as a human being and as a Slayer. In the first season, Buffy is unwilling to take on the responsibilities of her calling: she consistently puts her 'normal' life before her duties. The Master is a narrative agent who serves to demonstrate Buffy's need to balance her dual selves and the responsibilities that accompany them. It is for this reason that his prophecies are always tied to important dates in Buffy's life. This begins a trend that continues throughout the series, and on several levels, the Master operates as a blueprint for future Big Bads in terms of episode structure, prophecy (especially in seasons two and three) and climatic showdowns.

Comparatively, it is the First who closes the circle. The journey Buffy takes over seven seasons in discovering the truth behind her powers and herself, including visits with the First Slayer in seasons four and five, are completed when she learns how the

\footnotetext{
${ }^{45}$ Or, to paraphrase Joss Whedon's script, she can begin baking towards cookie status.
} 
Slayer lineage was created in "Get It Done." The lengths to which Buffy goes to protect her friends and family (including the potentials) due to the overwhelming presence of the First is one of the most important aspects of the final season, for Buffy must learn to share her powers willingly. Her sacrifice ends the Slayer lineage on her terms and allows Buffy to become the leader her responsibilities suggest she was meant to be. The optimistic, open-ended conclusion suggests that Buffy can focus on 'becoming' the Buffy Summers she always wished she could be, although it is unclear what this entails after seven years of balancing her responsibilities as the Slayer with her Buffy desires.

In order to get to this point, however, she has to face other Big Bads - ones that require completely different tactics and showcase her dual roles and their various responsibilities in different lights. In seasons three and four, Buffy faces new villains and experiences when she goes toe to toe with institutional Big Bads such as the Mayor, the Initiative and Adam. 


\section{Chapter Two \\ "Down Here I'm the One in Control": Institutional Villains as Elements of Transition}

The third and fourth seasons of Buffy the Vampire Slayer mark a number of important transitions for the show: season three is the final year of High School and season four marks the beginning of adulthood. It is here that the group begins to mature. Buffy and Angel break up; Willow enters an academic institution that embraces knowledge as well as liberalism (the character comes out in the fourth season); Xander begins a steady relationship with Anya; and Giles must accept his unemployment not once, but twice (first when he is fired from the Watchers Council in season three, and again in season four when he no longer works as a librarian after Buffy blows up the school in “Graduation Day, Part 2," 3.22).

These transitions are reflected in the Big Bads: season four's Adam \& The Initiative and season three's Mayor Richard Wilkins III. What these Big Bads share in common is corruption at the institutional level. The Mayor operates at the municipal level, making sure his campaign promises are kept - to humans and demons alike - while the Initiative operates on a national and possibly global basis. Interestingly, these shadowy organizations echo Buffy's own experience with the Watcher's Council, who are also secretive, experimental and covert. Season three and four's deployment of the Council's thugs to abduct Faith suggests they run their operations in a military fashion like the Initiative, and that the operations fall outside of the constraints of the law like the Mayor. $^{46}$

\footnotetext{
${ }^{46}$ Mayor Wilkins controls the police ("Consequences," 3.15, finds the police investigating the two Slayers because he orders it) and the people ("Gingerbread," 3.11, when he allows MOO - Mothers Opposed to the Occult - to use City Hall to burn witches)
} 
As mentioned above, seasons three and four revolve significantly around transitioning between high school and the adult world. ${ }^{47}$ These Big Bads play a vital role in exposing the difficulties of bridging the gap between high school and adult life.

The Initiative allows Buffy to briefly join a corporate world in which workers are forced to think, dress and follow orders without question. This is the main function of the Initiative as Big Bad: the identity-effacing nature of the organization causes Buffy to lose elements which define her as the Slayer by turning her into just another soldier. Her enthusiasm for the group derives from their strength in numbers and ability to protect themselves. The result of her interest in their abilities highlights the Initiative's other narrative function, which is to distance her Buffy side from her Scooby friends. When it becomes clear that the Initiative does not understand the supernatural world in which they work, Buffy realizes her powers distinguish her as an individual and that her place is with the Scoobies. It is only when Buffy returns to her band of outsiders who endorse an openminded point of view when dealing with the supernatural that Buffy is able to defeat Adam and put the Initiative out of commission.

Unlike seasons one and two, in early episodes of season four, it is unclear who or what the Initiative is. They are repeatedly seen in the background or the periphery of the frame in their camouflage uniforms in "The Freshman" (4.01), "Living Conditions" (4.02) and "Fear, Itself" (4.04). It is not until "The Initiative" (4.07) that any answers are provided. The episode is a deviation from the typical Buffy narrative layout in that members of the Initiative control the narrative equally with Buffy. Typically when

\footnotetext{
${ }^{47}$ I use the term 'adult world' in lieu of University because season four is not exclusively about school. Although 'high school' is too broad a term for describing seasons one through three, all four principal characters did attend Sunnydale High. In season four, neither Giles nor Xander "matriculate" at UC Sunnydale, and by the end of the season there are very few occasions when Willow or Buffy do either.
} 
villains are given their own scenes, their activities often comment on events surrounding Buffy or develop their character so that they are elevated above the two-dimensional “cardboard cutouts" Whedon spoke of.

Instead "The Initiative" establishes that the group is not the threat that Buffy and Giles believe them to be. The group takes on a human face by revealing the commandos (who have never been seen without their uniforms) are people like Riley, his friends, Forrest and Graham, and Maggie Walsh. The fact that both Riley and Walsh, familiar characters from Buffy's psychology course, are heavily involved in the Initiative is used to diffuse the group's threatening nature: they have been seen interacting with Buffy and do not seem evil.

By using characters that are members of Buffy's 'normal' University life as potential villains as well as situating their base underneath the school, the show introduces an adult version of "the high school is hell" metaphor used throughout the first three seasons. The introduction of Riley as Buffy's new romantic love interest, as well as a member of the season's Big Bad in the same episode, "The Initiative," suggests that Buffy's school life and her Slayer life will continue to conflict.

That Buffy and the Scoobies are unaware of Riley's involvement in the Initiative, or what their agenda is, follows the pattern laid out in season three. In both seasons, it is unclear to the Scoobies - but not to the audience - who is the Big Bad until several episodes have passed. In the early episodes of season four, Buffy is busy fighting standalone villains, each of whom represents transitional elements that she must contend with. ${ }^{48}$ Her Buffy self's inability to adjust to the new situations overwhelms her ability to

\footnotetext{
${ }^{48}$ Sunshine, the vampire villain in "The Freshman," appears when Buffy feels overwhelmed in her new surroundings and prompts Buffy to discover University is simply a larger version of High School. Her
} 
function properly as the Slayer. As a result, she becomes irritable and irrational, treating the other Scoobies poorly. Her imbalance is demonstrated when she is more interested in the Thanksgiving dinner than the safety of her friends in "Pangs" and when she is unwilling to vocalize her problems in "The Freshman." It is her inability to detect the presence of the Initiative - a key Slayer skill alluded to by Giles in the pilot episode that most clearly indicates that Buffy is off-balance.

The suggestion is that the displacement from one 'world' to another returns Buffy to a state akin to the first season. The difference is that Buffy fully accepts and even celebrates her Slayer side, which is one of the reasons her inability to defeat an unspectacular vampire such as Sunshine is so shocking.

Buffy doesn't truly get her bearings back until "The Initiative." The shift is apparent when the Initiative begins to assume more influence on the narrative. ${ }^{49}$ At this point, Buffy is starting to succeed in her new settings (her new living situation with Willow is good; she is receiving good grades in her psych class; she has recovered emotionally from her one-night stand with Parker Abrams and is ready for her next romantic relationship). It is important that a new love interest and a new threat are simultaneously introduced, not only because it unites Buffy's previously unbalanced selves, but because her relationship with the Initiative is influenced by her romantic relationship with Riley. These ideas are explored in "Hush" (4.10) when Buffy and Riley share their first kiss (make believe and real) and they discover each other's secret identities in the same episode.

roommate, Kathy, in "Living Conditions" demonstrates the difficulties of learning to share the same space with someone, while the phantom Shumash Indians of "Pangs" (4.08) disrupt Buffy's first Thanksgiving away from home.

${ }^{49}$ Narrative influence and character developing scenes without the Slayer are two of the defining qualities of a Big Bad, established by the Master in season one. 
The implication is that, although the Scoobies have been actively researching the Initiative as a Big Bad, Buffy's feelings for Riley determine her reaction, which is to remain silent. She cannot categorize the Initiative as evil because of her attraction to Riley, whom she believes is a good person. This is another example of Buffy's romantic relationships clouding her judgment, ${ }^{50}$ but unlike her relationship with Angel in seasons two and three, Buffy approaches the situation as an adult.

Unlike her romance with Angel, which was idealistically naïve, Buffy decides not to pursue a relationship with Riley because he is involved in her supernatural world. Her feelings are informed by the heartache she suffered by dating a vampire, which are displaced onto Riley despite his human status. By rejecting Riley, Buffy is attempting to separate her two selves - to break her sexual attraction to death embodied in the supernatural world in which she works. She is, in effect, trying to move beyond a "work" relationship like the one she had with Angel.

It is only when she returns to high school in "Doomed" (4.11) that Buffy finally accepts that she is no longer the same person she was then. Only after viewing the wreckage of her past does Buffy realize that University offers her a reinvention of sorts. This has already been alluded to in "The Freshman" when Buffy tells Willow that her secret identity has been reinstated and Sunshine destroys her class protector umbrella. Her realization in "Doomed" is that she has an opportunity to try again - to correctly balance her responsibilities as both Slayer and Buffy by dating a human with supernatural connections who can appreciate her role as the Slayer. With yet another apocalypse averted, Buffy decides to move beyond high school and accepts Riley. By extension, she also accepts the Initiative.

${ }^{50}$ For further analysis of this phenomenon, see chapters three and four. 
Buffy's entry into the Initiative showcases her point of view and methods for working in a supernatural workforce. For the first time, she is working with a large group of organized individuals, working with state of the art weapons. The distinction between her methods and theirs is made clear in several scenes.

The first scene occurs in "A New Man" (4.12) when Buffy and Riley visit Walsh in her office. She explains to Buffy that "It's only our methods that differ. We use the latest in scientific technology and state-of-the-art weaponry and you, if I understand correctly...poke them with a sharp stick." In this way, Walsh and the Initiative are associated with modernity and new technology, while Buffy and the Slayer lineage is coded as inferior and outdated. This is made clear in Walsh's choice of the word "stick" instead of stake. The latter has connotations of death and violence, whereas the former, in comparison, seems inadequate and childish. This implication denies the importance of Buffy's role and belittles her responsibility to use her powers to protect the innocent.

There is very little indication that the Initiative captures demons and vampires to protect the public. Although Riley and other commandos comment about keeping the campus safe by tagging "hostiles," time spent inside the halls of the Initiative with Spike suggests the institution is interested in other activities. When Spike awakens in "The Initiative," he is warned by a vampire that the blood they are given is drugged. The explanation given is that the "army guys" conduct experiments, which is eventually revealed to be Spike's behaviour-modification implant. Later, though, when 314 and Adam are revealed, it is clear that implants are not the only experiments being conducted by the Initiative. In this way, modernity and technology are corrupt, associated with genetic experiments and god complexes. In comparison, Buffy's 'outdated' methods 
(using a stake, adhering to her responsibilities to protect the innocent, etc) are responsible for the destruction of Adam and the rescue of the remaining Initiative members in "Primeval" (4.21).

The second scene that demonstrates the distinction between Buffy and the Initiative's methods occurs when Buffy is given the grand tour in "The ' $\mathrm{I}$ ' in Team" (4.13). ${ }^{51}$ Buffy is almost speechless when she takes in the magnitude of the installation, which is framed in high angle panning shots to illustrate its size. The grandeur of the operation is unlike anything Buffy has encountered while fighting demons and, even though Riley's kill count (seventeen) suggests their operation is less effective than hers, the Initiative remains an attractive offer. The main draw is the Initiative's selfsufficiency, so unlike Buffy's friends who constantly require rescuing and protecting, the Initiative soldiers can protect themselves and back her up without fear of injury. As she excitedly explains to Willow in "The ' $I$ ' in Team," she gets to patrol with powerful backup. Even when she was working for the Council, Buffy never had resources such as these on her side.

By joining the Initiative, Buffy entrusts her responsibilities to the group. This is problematic because, as discussed above, the goals of the Initiative are not always Buffy's goals. Her time with the Initiative demonstrates how individuality (a key component of both the Slayer and the Buffy) is effaced by institutions. The Initiative's treatment of its soldiers adheres in part to the way Buffy is treated by the Watchers

\footnotetext{
${ }^{51}$ The episode title is particularly useful in distinguishing Buffy "traditional" role from the "modern" commandos in that she is the only Slayer - a single, solitary agent. In this way, the "I" in the title refers not only to her individuality within the Initiative (to be discussed), but to the qualities that define her Slayer status.
} 
Council, in that both use their 'employees' in a conformist manner for whatever purpose they believe in.

The principal difference between the two is that Giles - an operative of the Watchers Council - is in charge of watching Buffy. Her relationship with Giles (as his surrogate daughter) allows Buffy a certain amount of control, despite what the Council's position advocates or what the Slayer Handbook suggests. The result of this freedom is that Buffy's status as Slayer is marked by an open, two-way dialogue, and she is allowed to participate in the planning, execution and details of her missions. This freedom and open communication is contrasted by the rules and regulations of the Initiative when Buffy participates in a mission in "The 'I' in Team."

Early in the episode Buffy brings Riley and some of the Initiative to a Scooby function at the Bronze. As Riley introduces his friends, individuality is effaced by the group. Initiative members Kevin and Jay are mentioned, but barely seen and group conformity is pushed to the forefront again when all the Initiative beepers erupt at the same time, suggestively associating Buffy with them and not the Scoobies. Later, when the Initiative members have assembled for a briefing in the lab, Buffy sits in the middle of an all male group of identically dressed commandos. The introductory shot is a slow pan across three rows of stationary men until the camera reaches Buffy, shifting and moving in her seat in a bright orange halter top. Her clothes and blonde hair make a startling contrast to the dark haired men surrounding her, visually isolating her as different or separate from the group. While her outfit is used for comic effect in the scene (she comments that she has patrolled in "this halter" many times before), it serves to distinguish her as not only female, but different from the others. Walsh even suggests she 
slip into conformity by wearing camouflage like the other Initiative members, an idea Buffy immediately rejects.

Although Buffy's comments and her questions throughout Dr. Angleman's explanation of the Polgara beast are comical, they serve a more important function. Her attempt to establish a dialogue as opposed to being commanded (Dr. Angleman suggests "that's all they need to know") reinforces the fact that Buffy has never shied away from asking questions about a mission or her role in it. Unlike the uniform sea of green that surrounds her, Buffy refuses to simply be told what to do unless she knows the reasons behind it. This is one of the ways Buffy ensures she is using her powers responsibly, by dictating how and when they are used instead of simply going where she is directed.

This is contrasted by the men of the Initiative, who do as they are told without question. In this way the Initiative is representative of workplace conformity. The men are rarely identified by name, merely "soldier." Only Riley, Forrest and Graham are important enough to have first names or well-rounded characters. The lack of questions posed effectively shields the soldiers from taking responsibility for their actions. The events that occur at the end of the season in "Primeval" suggest that it is partially this lack of responsibility that allows people such as Walsh and Angleman to create Adam. ${ }^{52}$ Until Buffy there was no one to question their motives and ensure their military powers were being used appropriately. The Initiative's inaction and lack of responsibility bear a striking similarity to the qualities that led to Faith's downfall in season three. ${ }^{53}$ In season

\footnotetext{
${ }^{52}$ For the close parallels between the Iniative, Adam and the story of Frankenstein, see Anita Rose's essay 'Of Creatures and Creators: Buffy Does Frankenstein.' Rose believes that Buffy offers "antipatriarchal and postfeminist solutions to the problems Shelly saw in Romantic ideology" (135) which are exemplified by the Adam storyline in season four.

${ }^{53}$ See chapter 3 - Faith - for further analysis.
} 
four, it is these qualities that result in the deaths of innocent humans and demons when Adam escapes.

Buffy's introduction into this world of cookie-cutter drones is as an outcast, marked by her hair colour, her clothes and her demeanor. Throughout four seasons, these are the elements that make Buffy who she is: her hair is a testament to the double meaning suggested in the title (Buffy the blonde vs Buffy the vampire slayer), while her clothes, body language and verbal wit are all important aspects of both her selves.

The clothes mark Buffy as an attractive girl ${ }^{54}$ and her ability to pun and mock are essential for slaying demons. This is especially apparent when, in the alternate universe of "Superstar" (4.17), Buffy is unsure of her Slayer abilities and loses her ability to insult and joke:

Buffy (to Spike, after he calls her Betty) "It's Buffy, you big, bleached...stupid guy." 55

In attempting to silence and dress her up, the Initiative takes away essential characteristics of both of Buffy's roles. They are trying to force her into workplace conformity, a lesson that Buffy can only experience under these circumstances because, as Slayer, she will never have a normal "job.” Interestingly the Initiative's military attitude (reducing individuals into mindless drones) paves the way for the ultimate in workplace conformity when, in season six, Buffy takes a job at the fast food chain, The Doublemeat Palace, which reduces her to complete idiocy. This is clearly insinuated in "As You Were" (6.15) when Buffy explains to Riley that she has "a cow on my hat."56

\footnotetext{
${ }^{54}$ It is her looks that attract Forrest's attention in "The Initiative," which he later mocks in "The ' $\mathrm{I}$ ' in Team" when Riley picks her over Forrest to be his second in command.

${ }^{55}$ See also examples from chapter one: Witness how much she upsets the Master in "Prophecy Girl" when she mocks his "fruit-punch mouth" and admits she "failed the written" and similarly how the First, in turn, mocks her lack of snappy comeback during their conversation in "Chosen."

${ }^{56}$ It also suggests that under alternate circumstances (following her resurrection), Buffy might have made a good Initiative drone.
} 
Buffy's essential qualities of independence and free-speech mark her as a target within the Initiative. The fact that Walsh believes a trap comprised of a faulty taser gun, a blocked exit and two demons with axes is sufficient to kill a Slayer is part of a larger recurring theme involving the Initiative's misunderstanding of the supernatural world in which they work. This is because the modernity implicit in the Initiative's techniques, morals and rationale rejects the ancient world where the Slayer lineage and evil creatures such as Glory, the First and the Master are created.

Throughout previous episodes, starting with "Doomed," it is clear that the Initiative does not understand what a Slayer is. Riley has no clue when she tells him, Forrest suggests that it is a myth ${ }^{57}$ akin to the bogeyman for demons and Walsh demonstrates her contempt with her "poke it with a stick" comment. Considering that Buffy has by this point defeated a six hundred year old vampire, averted multiple apocalypses and destroyed a giant snake (a pure demon no less), Walsh's trap demonstrates the fact that the Initiative has no idea who they are dealing with.

To reinforce this idea, when Buffy survives the trap, her face appears on three monitors over Walsh's shoulder. Framed tightly in close up, she threateningly tells Walsh: "If you think that's enough to kill me, you really don't know what a Slayer is. Trust me when I say you're going to find out." With these words, expectations are laid for a battle between Buffy and the Initiative, represented by Walsh.

In a single episode, Buffy reinforces what it took her the first three seasons to do: declare her independence from an identity-effacing organization. Just as she realizes that no longer being in High School is an opportunity to pursue a new relationship and apply

\footnotetext{
${ }^{57}$ Which, in a Campbellian sense, is correct: the Slayer is a mythical hero.
} 
herself academically, Buffy knows that she is more powerful when she relies on herself and her Scooby friends (to whom she immediately returns at episode's end).

The narrative supports this fact by exposing the structural corruption within the Initiative for the rest of the season. These incidents range from large scale, such as Walsh's creation of Adam and the revelation that she drafted plans for a full scale attack on demons and humans alike, ${ }^{58}$ as well as smaller details such as the fact that she and Dr. Angleman were administering performance enhancing drugs to Riley and the other army men without their knowledge.

The Initiative is continually proven to have a limited grasp on the way of the world in relation to magic and demons because of its modernity. Forrest is the mouthpiece for the Initiative's misconstrued version of the world as he continually refers to demons as "animals" ("Doomed”; "The 'I' in Team”), although Riley also demonstrates his lack of understanding when he confronts Buffy in Willie's bar in "Goodbye, Iowa" (4.14). His accusation that she socializes with demons instead of hunting them indicates that he fails to understand how bartering or buying information works in the demon world. Later, he does not understand Jonathan's magical ability to change the world in "Superstar," or the fact that demons and vampires don't like each other in "Where the Wild Things Are" (4.18). As a result, the uninformed nature of the government-ordered program casts Buffy and the other Scoobies in a positive light. Despite revealing her own bigotry in "Pangs" when she decries the Shumash Indians for attempting to destroy her Thanksgiving dinner, Buffy comes off as a well-rounded individual for her defense of Spike and especially Oz.

\footnotetext{
${ }^{58}$ It is unclear why Maggie Walsh wanted Adam to build a race of demonoid monsters from the body parts of demons and men, but it is clear that these were her plans when Adam produces a disc and tells Riley: "It's here. The plan she had for us. What happens. How it ends" in "Goodbye, Iowa" (4.14).
} 
The two different perspectives - Buffy's and the Initiative's - come into conflict in "New Moon Rising" (4.19) when it becomes clear that the members of the Initiative do not accept the idea of a person sharing the same body with a demon. Initially Riley agrees with this stance when he learns $\mathrm{Oz}$ is a werewolf. To Buffy, his bigotry is upsetting because of the unique nature of her relationship with Angel. She correctly ties his attitudes to his job when she tells him: "You sounded like Mr. Initiative. Demons bad, people good." This is because Riley, and the Initiative, have never been involved in a personal way with a demon or vampire. Buffy's ability to show Riley the elements of humanity in demons and vampires is only possible because she loved Angel.

The episode demonstrates the Initiative's moral compass, which is presented in opposition to the show's typical stance (favoured by Buffy and the Scoobies). The Initiative clearly distinguishes between good and bad, but without the possibility of exceptions (such as Oz or even Spike). One of the episode's most important moments occurs when Buffy and Riley's storm the Initiative's underground lair to rescue Oz. This distances them both from the Initiative's moral standpoint, and finally severs their connections to the institution. Armed with the knowledge that her boyfriend is no longer "Mr. Initiative" in terms of morals, free speech and group conformity, Buffy is free to fully invest herself in their relationship.

Wall \& Zyrd reinforce the idea that the Initiative's techniques are presented in a negative light:

The Initiative, embodying instrumental reason, tries to understand the supernatural by literally dissecting demons and harnessing their power for military reasons. This approach is presented as a fundamentally flawed form of knowledge, one that both creates Adam as the logical extension of its logic and cannot distinguish between the increasingly subtle moral and ethical distinctions among the demons that inhabit the world. (65) 
Wall \& Zyrd suggest that it is misguided morals and beliefs about the supernatural world that results in the creation of Adam, the Initiative's fatal mistake. These qualities also prepare for the destruction of the Initiative when they fail to understand why demons have been so numerous and easy to catch in "New Moon Rising" through "Primeval." In this way, the Initiative demonstrates a lack of understanding about the possibilities of an endgame - they wonder aloud at the reasons behind the strange events, but do not attempt to investigate the why. Buffy and the Scoobies, however, go into research mode and figure out Adam's plan. The government council that close "Primeval" makes it clear that it is only because of Buffy and the Scoobies that the casualty rate of soldiers isn't higher. Instead the Initiative is made to look a fool. In "Primeval," Buffy and the others are confronted by the Initiative's acting Colonel. This is the man who previously called Buffy and her friends "freaks" ("New Moon Rising") and suggested to his Pentagon superior that Buffy was "just a girl" ("The Yoko Factor"). The narrative serves to highlight his stupidity when he is repeatedly proven wrong or upstaged in his two minute conversation with the Scoobies in the control room. ${ }^{59}$ By the end of the episode he is dead. Additionally, when the battle between the Initiative and the demons is shown, it is the humans who are being killed, maimed or attacked.

As a result of her interaction with the Initiative, or because of her refusal to conform to their standards, Buffy doesn't help the Initiative in battle. Instead she leads the Scoobies to a safe place where the enjoining spell ${ }^{60}$ can take place so that she can attack Adam. This is interesting given that stopping Adam won't end the attack on the Initiative, but it will save the larger population from his hybrid army.

\footnotetext{
${ }^{59}$ See Appendix D for full transcript.

${ }^{60}$ This spell was mentioned briefly in the introduction when speaking about Xander (his contribution was heart), and will be examined in more detail in the section on Adam below.
} 
This decision exemplifies Buffy's responsibility to protect the larger community and suggests that it is only when she embraces her individual qualities (and those of the Scoobies) that she is capable of fully utilizing her Slayer powers. Instead of remaining with the identity-effacing Initiative whose members endorse a lack of responsibility that allows the creation of Adam and the destruction of their complex, it is clear that Buffy's unification with her friends provides the balance of her two selves that is missing during her time at the Initiative. It is only with the reunion of the group that understands the rules that regulate the supernatural world in which they work that Buffy is capable of defeating season four's other Big Bad: Adam.

In a sense, Adam is a continuation of the Big Bad evolution. As suggested in the previous chapter, the seasons following the introduction of the First in "Amends" (3.10) feature Big Bads who are associated less with prophecy, if at all. This makes them considerably more difficult to research, and therefore defeat. Adam's role as Maggie Walsh's "ultimate warrior" is a reflection of this new situation. As Buffy learns in "Doomed," this is no longer High School, so the monsters are more difficult to conquer. While these facts undeniably distinguish Adam as a Buffy Big Bad, he is by far the most ineffective. One of the identifying qualities of a Big Bad is its ability to challenge both sides of Buffy - her Slayer side and her Buffy side. While Adam is formidable in combat, he rarely engages the Buffy side of her duality. Additionally, Adam's presence in the show is dilated after his appearance in "Goodbye, Iowa." Although he appears in most episodes, these scenes are brief and he is rarely shown advancing the narrative. Typically his actions consist of using a computer ("Superstar"; "The Yoko Factor") or delivering sermons to vampires ("This Year's Girl"; "Who Are 
You?"). None of these activities address or impact his endgame in "Primeval" in a significant manner.

Unlike the First, who attacks Buffy's lineage and threatens her personal relationships with Giles (when it is suspected he has been killed and is actually a manifestation of the First), Spike (when he is used as a trigger) and Willow (when her magical powers are used against her), Adam does not interact with Buffy's friends. The closest he comes to damaging her personal relationships is in his use of Spike as a "Yoko factor" to separate the Scoobies. However, Adam's use of Spike suggests that it is Spike who actually affects the Buffy side. In a comical manner, Adam is the ultimate in Big Bad institution because he subcontracts evil.

In comparison to other Big Bads, Adam is also one of the least interactive. The First appears consistently to torment and mock in season seven, just as Glory does in season five, Spike and Angelus in season two and to a certain extent, the Mayor in season three. Adam is most comparable to the Master in season one in that he interacts with Buffy only once or twice. However, unlike the Master, whose presence consistently drives the narrative because of his prophecies, Adam only has his endgame.

He and Buffy meet face to face three times in eight episodes: "Goodbye, Iowa," "The Yoko Factor" and "Primeval." Of these, the only time he actually speaks at length is "Goodbye, Iowa" and the majority of the conversation centers around Adam's relationship with Riley and Walsh. Throughout the conversation he barely addresses Buffy, reducing her to a passive 'object' whose only purpose is to react to Adam's statements. This carries over to their following meeting in "The Yoko Factor" when Forrest is skewered (associating him with both Dr. Angleman and Walsh as Initiative 
failures). Buffy's relationship with Forrest is one of animosity, so the impact of his death falls on Riley. This frees Buffy to uncover Adam's plan and since the episode immediately precedes the final battle, she goes into battle with very little time spent addressing Riley's grief. As a result, Adam barely affects her romantic relationship.

There is one area in which Adam is instrumental: he fuses her fractured relationship with the other Scoobies. Throughout season four, the friendship of the four main characters is tested and found lacking, as Willow and Xander insinuate separately during their fight in "The Yoko Factor":

Willow: Buffy, things have been wrong for awhile. Don't you see that? Xander: Since you two went off to college and forgot about me

This is one of the principal conflicts of season four as each member of the group struggles to redefine their identity in their new surroundings and situations. Buffy admits in "Primeval" that she's been into Riley, while Willow counters that she was into Tara. It is the all-powerful Adam that forces the group to bond, reuniting them with the issue that solidified their friendship in the pilot episode: apocalyptic doom. When Xander suggests they need "combo Buffy," he strikes upon the solution to all their problems. It is only by reuniting the group and utilizing their shared talents that they can defeat Adam. This reformation of the group has been commented on by several scholars, including Overbey $\&$ Matto in their article on the power of language, noting that:

The spell itself requires and highlights the strengths of each of the four main characters. [...] As each card is revealed, the trio speak the names of the figures displayed in front of them: Willow is Spiritus, "Spirit"; Xander is Animus, "Heart"; and Giles is Sophus, "Mind." Willow places the final card, Manus, "The Hand," in the center of the triangle and begins an incantation: "We enjoin that we may inhabit the vessel-the hand...," thus joining them with Buffy. A room away, Buffy faces Adam, and as the collective energies collide, she becomes Uber-Buffy: charged, flowing, all-powerful. She speaks, and we hear four voices: "We are forever." She begins to chant in Sumerian, which only Giles is capable of understanding. She remains steadfast in facing Adam and successfully deflects his attacks, a shield that Xander's heart provides. Adam's ammunition transforms, as she raises a hand, into 
clouds and doves, an effect of Willow's magical, technological matrix. Finally, with her own hand, she divests Adam of his uranium core, saying (in English this time and reverting to her punning), "You could never hope to grasp the source of our power. But yours is right here." (89)

In this way, Adam restores the group's fractured friendship by fusing each of their unique characteristics in a single entity, literally endowing Buffy with her friends' usefulness. The act also highlights their ability to get the job done, in contrast to the Initiative men who are barely capable of defending themselves against the demons Adam lets loose.

Aside from the spell in "Primeval" and Forrest's death in "The Yoko Factor," though, it is primarily the Initiative who occupies Buffy's time and thoughts. In contrast, Adam's lack of physical presence in the episodes and somewhat meaningless contributions to other episodes showcase that his narrative function is that of a formidable physical Big Bad. His inability to engage Buffy's duality, however, eliminates him as a true Big Bad.

Season three's Mayor Richard Wilkins, on the other hand, shares a number of similarities with Adam, but rises above his shortcomings. Not unlike Adam, the Mayor contracts out, initially using Mr. Trick, a vampire introduced in "Faith, Hope \& Trick" (3.03) and, later, Faith herself to do his evil deeds. By staying out of the limelight, the Mayor is capable of hiding his plans from Buffy until "Consequences" (3.15), the 'twist' episode in which Faith turns bad. Although he is glimpsed throughout other episodes, the Mayor is rarely seen outside his office in City Hall and while it is hinted at that he has an endgame, it is not until "Bad Girls" (3.14) that his ascension begins to figure prominently in the seasonal arc. 
As a result, the Mayor comes off as a cross between Adam and the Master. Just like Adam, the Mayor prefers to let others do his dirty work, remaining relatively low key until his final phase is ready. At the same time, however, there are several steps that must be undertaken. Just as the Master requires the Anointed One and the correct date to invoke the Codex prophecy, the Mayor also adheres to specific rituals and dates, such as eating spiders from the box of Gavrok to invoke the hundred days preceding his ascension, whose date coincides with the founding of Sunnydale. ${ }^{61}$

What distinguishes the Mayor from Adam is that his appearances on the show serve to create conflict for Buffy. Whereas Adam's presence causes a lot of worry, it ultimately fails to initiate tension between Buffy's two selves. Instead, her conflict is with the Initiative and her friends. These conflicts are highlighted by Adam's endgame, but are not necessarily affected by his presence.

In contrast, the Mayor's presence is consistently used to generate tension and conflict. Even before Buffy is aware that he is a Big Bad, his plans affect her. In "Band Candy" (3.06) the Mayor adheres to his election promise to pay a tribute of babies to a demon snake, which necessitates turning all of the adults into teenagers with magic chocolate bars. Although the plan belongs to Ethan Rayne, who is subcontracted by Mr. Trick, Buffy's ties to Giles and her mother complicate her efforts to thwart the death of the babies. In this way the Mayor complicates her abilities to perform her Slayer responsibilities by pitting her Buffy self (protecting the adults she loves) against her Slayer side (protecting the innocent).

\footnotetext{
${ }^{61}$ In this way the Mayor is, unlike the Initiative and Adam, anti-modern and therefore more in line with the traditional, ancient aspects of Buffy's Slayer status.
} 
In contrast, when Adam subcontracts Spike to separate the Scoobies in "The Yoko Factor," he provides no details, leaving the plan entirely to Spike. It is therefore Spike who causes the conflict. Although it was not the Mayor's plan to use magical candy bars, the plan was created around his need to separate the adults from the babies, which establishes his role in the plan.

In the third season, Mayor Richard Wilkins III has three principal narrative functions: he prompts Buffy's first offensive attacks before a Big Bad's endgame; he exposes how Buffy's relationship with Angel clouds her judgment; and by invading her private spaces, the threatening level of his ascension forces Buffy to share her powers by transforming the graduating class into an army.

The first of these three functions deals with Buffy's reaction to a Big Bad's endgame. In previous seasons she typically waits for the Big Bad to make a move and then reacts; she never goes on the offensive. Throughout season one, Buffy consistently reacts to the Master's prophecies, often preventing them in the nick of time. This pattern is repeated in the second season, when she waits for Spike, then Drusilla, then finally Angelus to act. In fact, the sole time she attacks Angelus without being prompted is in "Passion" (2.17). Even then, Buffy goes to rescue Giles, who is the one that initiates the attack following Jenny's murder.

Buffy's decision to wait for an attack may be an attempt to remain responsible to her duties as Slayer. One of the Slayer's most important responsibilities is to stay alive, thereby enabling her to continue protecting the innocent. It is more dangerous to initiate a battle because there may be risky elements involve, as opposed to fighting only when attacked, which is a safer and more responsible option. 
It is also possible that Buffy judges her situations according to the amount of knowledge acquired about the Big Bad. The only time the plans of a villain are truly laid out in advance is season one when the Master constantly adheres to prophecy. These opportunities go unnoticed partially because the Scoobies' research skills are less refined (Xander and Willow have only just been introduced to the supernatural world while Willow explains that Giles was recently a head librarian in Britain), but also because of Buffy. Season one marks the period when Buffy denies her responsibilities as a Slayer in favour of leading a normal, teenage life, which may explain her decision not to pursue the Master until "Prophecy Girl"; if she refuses to acknowledge her duties as the Slayer, why should she actively seek out the Big Bad?

The second season does not afford these opportunities. Spike, Drusilla and Angelus are all researchable villains in terms of their histories and personalities, but it is unknown what their plans are until they initiate them (their apocalyptic antics compliment their youthful vigour in comparison to the Master). In fact the only time Buffy truly mounts an offense against a Big Bad is in the seventh season when she attacks Caleb at the vineyard in "Dirty Girls" (7.18) and "Touched" / "End of Days" (7.20-7.21). As discussed in chapter one, these attacks are brought about by Buffy's feelings of frustration at her inability to damage the incorporeal First, especially when she knows that it is her responsibility to use the potentials in battle even though she knows many will die.

The situation in season seven is nearly identical to season three, where the origins of Buffy's offensive strategy are rooted. Just like her battle with the First, season three finds Buffy frustrated by the lack of knowledge about the Mayor's plan. In both seasons, 
her decision to act is born out of frustration - her responsibilities as a Slayer demand that she use her powers to protect, but without any knowledge about the Big Bad's endgame, Buffy cannot perform her duties.

Her first plan of action occurs in "Enemies" (3.17), when Angel pretends to lose his soul and become evil in order to extricate information from Faith about the Mayor. The episode is a red-herring in that it does not reveal until the end that Buffy, Angel and Giles hatched the plan together and that Angelus has not returned. While the plan is successful at uncovering the date of the Mayor's ascension and the fact that he is invincible, it does nothing to prevent his endgame. As a result, Buffy decides to go on the offensive a second time, although this time she is far more ambitious.

Her plan in "Choices" (3.19) revolves around the acquisition of the Box of Gavrok, an elements that is instrumental to the Mayor's ascension. Although Buffy's attempt to steal the box is an attempt to thwart the Mayor's graduation plans, it is actually informed by the needs of her Buffy self. Buffy learns that she has been accepted into several prestigious Colleges, but realizes that her duties as Slayer prevent her from leaving Sunnydale. Her decision to go on the offensive is actually an attempt to justify going to College like the rest of her friends. In this way, it is her Buffy self that drives her Slayer self into action in the hopes of ending the need for the Slayer altogether.

The fact that the offensive attacks in "Choices" and "Dirty Girls" both end in failure suggests that when the Buffy self prompts her Slayer self into action, it is her Buffy self that suffers. The deaths of several potentials and Xander's eye gouging are prefaced in a less dramatic form by Willow's kidnapping in "Choices," but unlike the seventh season, Buffy abandons her frustration because her friend is in danger. Although 
Buffy is giving the Mayor exactly what he needs to ascend by trading the box of Gavrok for Willow, the rewards acquired during the exchange redeem her decision: Buffy now knows what is inside the box, and she acquires Faith's knife, which proves instrumental in the third season finale. Additionally, Buffy restores the balance between her two selves by rescuing Willow. The act is doubly appeasing because she fulfills her Slayer responsibility to protect the innocent and reinforces the fact that her friends are more important to her than the will to leave Sunnydale. By balancing both of her selves, Buffy comes out stronger and better off.

The cafeteria exchange in "Choices" serves another function: it features the first face to face meeting between Big Bad and Slayer. ${ }^{62}$ The conversation that follows focuses on Buffy's relationship with Angel, which serves to highlight one of the principal recurring themes in season three: the slow and inevitable end of their romance.

Although the effect Buffy's relationships have on her responsibilities as both Slayer and Buffy will be discussed at length in the following two chapters, it is worth recognizing that Mayor Wilkins deliberately focuses on the idealistic romantic relationship between Buffy and Angel when they perform the exchange. ${ }^{63}$ As Anya explains in "Sleeper" (7.07), evil often speaks the truth. The Mayor adheres to her statement. In "Choices," he identifies all the problems of the Buffy-Angel relationship that they have been overlooking. It is significant that the end of the episode features a conversation between Buffy and Angel when they both express their disbelief in his words, only to lapse into silence, staring away from each other. That this conversation

\footnotetext{
${ }^{62}$ In truth they have met before, in "Band Candy" when Buffy storms the sewers. The Mayor immediately leaves in order to avoid being recognized, and Buffy does not associate him with the incident, believing Mr. Trick is to blame.

${ }^{63}$ See Appendix E for full transcript.
} 
takes place in the cemetery, with the lovers using a gravestone as a headboard, is suggestive of the demise of their relationship and recalls the Mayor's words when he describes Angel's inability to give Buffy what she needs:

The Mayor: I mean, come on, what kind of life can you offer her? I don't see a lot of Sunday picnics in the offing. I see skulking in the shadows, hiding from the sun. She's a blossoming young girl and you want to keep her from the life she should have til it's passed her by.

While both Buffy and Angel dismiss the Mayor's words because he is evil, it is clear that he is not alone in his observations. In the following episode, Joyce visits Angel and asks him to end his relationship with Buffy, which he obliges. Buffy associates the act with the Mayor, "Is this about what the Mayor said? Because he was just trying to shake us up," a fact that Angel doesn't deny, "He was right." In this way, unlike similar attempts by Big Bad, such the events of "The Yoko Factor" where lies based on the truth are used to separate the Scoobies, the Mayor simply speaks the truth to dissolve the Buffy-Angel union.

"Choices" also fulfills the third function of the Mayor in the season three narrative. The exchange in the cafeteria with the Big Bad continues the pattern of Big Bads infiltrating Buffy's private spaces, established by Angelus the previous season. Space is an important element on Buffy, which Karen Sayer argues must be approached as a "fluid text that exists in time and space" because "each episode belongs in a relationship with each other episode" (99). In this way, the locations seen in Buffy are not static and influence other locations. Sayer argues that episodes such as "Restless" (4.22) string together locations in dream imagery, while "The Body" features spaces that "seem to have grown" (99). Likewise audiences understand the geography of Sunnydale in relation to its various locations, such as the bus terminal, zoo, dock, and mall. 
This relationship is interesting when applied to Big Bads. As mentioned earlier, one of the defining characteristics of the season's villain is their stand alone scenes in which they develop their character and plot their evil plans. These scenes take place in one central defining area for the Big Bad: the Master's ruined church, the First's vineyard and adjoining caves, and Spike and Dru's factory. Oftentimes these are the locations that define the Big Bad, who is rarely seen outside their quarters. This is a device to help clarify what the villain is up to - scenes in these primary locations inevitably suggest how the Big Bad is controlling Buffy's actions (and the narrative) with their plans.

It is therefore significant when the Big Bad and Buffy merge spatially. It often amounts to developing their mutual conflict (fights at the zoo with Glory; fights in the caves with Adam or Caleb). And then there are the times when the meeting occurs within Buffy's private spaces: her home or the school, which suggests a threat to her sense of security. Normally these attacks occur with personalized villains - the Big Bads who have close personal relationships with Buffy such as Angelus or Faith - although this is not always the case. No matter what type of Big Bad, though, the effect is always the same: infiltrating Buffy's personal space is a humbling event for the Slayer.

Due to the personal nature of Angelus' relationship to Buffy, he is primarily interested in domestic spaces such as Willow's, Giles' and Buffy's respective houses, although his most severe attack occurs at the school when he kills Jenny Calendar. Faith operates on the same principles as Angel. As an institutional villain, the Mayor infiltrates Buffy's other space when he invades the school and although Angelus, Spike and Drusilla all stage attacks at the school, none do so as brazenly as the Mayor. The biggest 
difference is that, unlike the three Big Bads from season two, the Mayor does not infiltrate the school to attack, but to threaten.

It is the second time the Mayor infiltrates the school that is significant. Buffy has few personal ties to the cafeteria (save "Earshot," 3.18, when she hears someone thinking about killing students), so the exchange in "Choices" is less invasive. The second infiltration, in contrast, is much more invasive and occurs when the Mayor enters the school during "Graduation Day, Part 1" (3.21). The reason it is so invasive is not just because he infiltrates their space, but because he enters the library when the Scoobies are in the middle of a cramming session about his forthcoming ascension.

As $\mathrm{Oz}$ and Willow join the others, the Mayor walks in after them, exclaiming: "So this is the inner sanctum. Faith tells me this is where you people like to hang out and concoct your little schemes." The Mayor's dialogue is often delivered with what Wilson describes as "David-Letterman inspired use of colloquialisms" (92), but is very often threatening (the two are used casually back-to-back). Here the threat is implicit: the Mayor controls Faith, whom he has arguably stolen away from the Scoobies, and, as a result, he understands their methods and routines.

Throughout the first three seasons, the library is indeed an "inner sanctum" for the group to meet socially, research and prevent the opening of the Hellmouth. Very rarely are visitors welcomed into the library, and more often than not, they are greeted with hostility. This is the case when Owen comes looking for Emily Dickinson in "Never Kill a Boy on the First Date" (1.05):

Giles: What do you want?

Owen: A book?

Giles: Oh!

And the scene is even more offensive in "Passion" when Jonathan and a friend enter: 
Xander: Excuse me, but have you ever heard of knocking?

Jonathan: We're supposed to get some books. On Stalin.

Xander: Does this look like a Barnes \& Noble?

Giles: This is a school library, Xander.

Xander: Since when?

The Mayor's comments are a deliberate threat to the Scooby space. Typically when the library is compromised ("The Zeppo," 3.13; "Prophecy Girl"), the gang is ready for battle. Even those times when they aren't prepared, the result is an attack ("When She was Bad," 2.01; “Becoming, Part 1," 2.21), not a verbal threat. In this way the Mayor intimidates the group because he is brazen enough to walk into their war room and confront them. The fact that he does so to entertain himself - he knows they cannot harm him because he is still invincible - suggests that although his physical transformation is threatening, his verbosity is just as dangerous.

Both of these ideas are conveyed through dialogue and action in the scene. When Buffy asks the Mayor, "You never get even a little tired of hearing yourself speak, do you?" he laughs and addresses Giles, "That's one spunky girl you've raised." The shot cuts to a close up of his face as he continues, "I'm going to eat her." Giles responds by stabbing him in the chest with a fencing sword, but the Mayor simply pulls it out and wipes the blade:

The Mayor: I smell fear. That's smart. But some of your deaths will be quick, if that's worth anything. Well, see you all at graduation. You don't want to miss my commencement address. (He turns and begins to walk out as the camera slowly cranes up) It's going to be a heck of a speech.

The passage is brief, but instrumental in that it reinforces the powerlessness of the Scoobies. Their private space is violated, not for an attack, but merely as an opportunity for the Mayor to taunt them by reinforcing his indestructibility. He is so confident that he 
doesn't even address them when he speaks his final words. Their insignificance to him is reinforced by the slow crane up which renders them tiny looking and pathetic.

The violation of the library is akin to the violation of Buffy's home - it is a safe space for her. Following the Mayor's intrusion, it is clear that Buffy is scared, although when she is seen packing in the next scene, it becomes clear that she is scared for her mother, not herself. Buffy's explanation that she doesn't want to worry about her mother suggests an attempt to put aside her Buffy self in order to focus on the Slayer.

Traditionally she fears for her friends as well, but her decision to arm them and lead them as an army suggests another disavowal of her Buffy self. If the Mayor's intrusion into the library proved anything, it is that in order to defeat him, Buffy needs to use her Slayer powers and put aside her Buffy worries.

This idea is reinforced in the climatic battle sequence of "Graduation Day, Part 2." Her decision to outfit the graduating class as an army looks forward to her dissemination of her powers to the potentials in "Chosen" (7.22). Instead of trying to protect her friends and fellows classmates, Buffy recognizes that success is only possible if she shares her power. After the events of "The Prom" (3.20), she knows that she is recognized by the other students as the girl who helps people. And while she cannot yet share her Slayer powers, ${ }^{64}$ prompting her fellow students to engage in the battle is the next best thing. In endorsing their collective strike, Buffy encourages them to battle not only against the Mayor, but the forces of darkness that have killed so many at Sunnydale High. The result is the transition of all the surviving students from high school to

\footnotetext{
${ }^{64}$ This is because she is not yet prepared to let go of the element that makes her unique. Over the following four seasons (4-7) she will learn that her romantic and sexual relationships interfere with her responsibilities as both Slayer and Buffy and that she has a responsibility not only to teach, but to literally share her powers. It is with this realization that the scythe - the tool that grants her the ability to share her powers - is introduced and enables the events of "Chosen."
} 
adulthood. It is only by standing up for themselves in battle that the students of Sunnydale High can truly graduate.

Although Buffy embraces her Slayer side by transforming the other students, including her friends, into an army, this does not mean that she can completely suppress her Buffy side. When it becomes clear that the snake is going to eat the students and casualties rise, she orders Xander and the others to "fall back." In doing so she is left alone - the Buffy side who worries about the safety of her friends has "fallen back" with them, leaving only the Slayer side to face the former Mayor. She recognizes that as the only student with superpowers, it is her responsibility to face the Big Bad, not theirs. By allowing the students to escape, Buffy ensures that her primary goal as the Slayer - to protect the innocent - is achieved.

Interestingly, when Buffy faces the Mayor their dualities oppose each other. Free of her Buffy self, she uses her Slayer wit to taunt the Mayor, then her speed to outrun him inside the school. This contrasts the Mayor, who despite his transformation into a pure demon, acknowledges his human side when he recognizes the knife he gave to Faith. It is because of "his human side" that Buffy is able to bait the former Mayor through the school and into the explosive trap.

With the destruction of the High School, the high-school-as-hell metaphor ends. Oz's comment that they "survived" has a double meaning: not only did they survive the Mayor's attack and defeat the latest round of Big Bad, they survived the institution itself. With its destruction, Buffy is free to advance to the next level, which is itself a progression to the next level of Big Bad (the municipal Mayor Big Bad makes way for 
the national Big Bad in the Initiative). In this way, one Big Bad effectively transitions into the next, mirroring Buffy's journey towards adulthood.

Although the most obvious Big Bad in the third season is the Mayor, to admit that he is the only individual working to expose Buffy's dual selves and the responsibilities that accompany them is to do an injustice to one of the great villains on the show. This person is a friend of Buffy's, a shadow double and fellow Slayer named Faith.

Unlike the Initiative, Adam or the Mayor, Faith performs an altogether different function in the narrative, especially concerning Buffy. Unlike the institutional villains who compromise the safety of a large group of people such as the graduating class of the High School, or the population of Sunnydale and its University, Faith is a Big Bad on a more personal level. Together with Spike, Angelus and Dark Willow, Faith exists as the most personal of all Big Bads: a villain that Buffy knows intimately, interacts with regularly and must ultimately battle despite their relations as sisters, lovers, friends and allies. Chapters three and four will examine how these villains are different from the archaic and institutional Big Bads, as well as analyze how they contribute to Buffy's conflicting dualities and their separate responsibilities. 


\section{Chapter Three \\ “...In My Dream She Does It For A Guy": \\ Friends and Doubles as Personalized Big Bads}

The voice over monologue that introduces season one and season two episodes of Buffy the Vampire Slayer explains, "Into each generation a Slayer is born..." although it could just as easily say, "In every season there is a new villain." Unlike other science fiction/fantasy shows, Buffy uses its serial structure to maximize emotional plotlines. Whereas shows such as Smallville (Gough \& Millar, 2001) and The X-Files (Carter, 1993) feature a variety of one-off villains, Buffy employs Big Bads whose plans culminate in an epic battle at the end of the season. Unlike Star Trek: The Next Generation (Roddenberry, 1987) which features recurring villains (the Borg), but little character development or intratextual references, the events that occur on Buffy are reflected and commented upon and used to develop characters over the course of multiple seasons, prompting growth even for those characters on the periphery.

Saxey believes that:

Extended plotlines affect audiences in terms of the sheer weight of suspense. We have in Buffy a longer span than is usual in most series and a more delayed conclusion than is achieved in cinema. And if fighting evil is thus problematized, emotional plotlines are similarly extended and blurred (195)

He believes that just as the victories and defeats between the Slayer and the forces of evil are temporary (given the fact that evil always returns), so too is the structure of love and romance on the show (the emotional plotlines). He posits that as "the happy times become transitory, the threat becomes less threatening by the same process" (194). I would argue that this is the reason we see increasingly complex Big Bads as the series progresses; because as Buffy matures, so must her opponents. In this way the villains become more formidable and challenge her in increasingly serious and dangerous ways. 
The emotional plotlines function in much the same way. In season one, Buffy must contend with starting a new life in Sunnydale, and by the end of the season she is killed. In season five, four years later, Buffy loses her mother, and gains a sister for whom she acts as a guardian. She takes the job of protecting her sister so seriously that she is willing to give her own life to spare Dawn's. Running parallel with Buffy's increasingly complex emotional problems are increasingly complex opponents (a vampire in season one compared to a hell-god in season five) whose plots to take over the world are intricately intertwined with Buffy's regular problems. Saxey argues that this is because "emotional needs and risks often power the basic Buffy plotline, with the supernatural elements adding intensification" (197).

If this point of view is to be believed, then the role of the supernatural - the Big $\mathrm{Bad}$ - is to compliment or reinforce Buffy's emotional needs and risks. And while a large portion of the show is devoted to Buffy's Slaying duties and what her calling represents, an equal (possibly greater) portion is devoted to her Buffy qualities: her friends, her school and her romantic relationships. Just as Spike tells her in "Fool for Love" (5.07), the reason that she has lasted longer than the other Slayers is because she has "ties to the world" in her friends and family. These earthly connections compliment her Slayer self in the same way the emotional plotlines compliment the supernatural.

It is because of this that Buffy's personalized villains are so powerful. Unlike other Big Bads who have no relationship to Buffy prior to their conflict, personalized villains are the characters who are closest to Buffy - they know her as Buffy, the girl, not just as Buffy, the Slayer. Because of this they know how to hurt her the most; the places where she is the most insecure and defenseless. Additionally, they are aware of her 
tactics, and her relationship to the other Scoobies and they can exploit these areas, more so than other Big Bads.

As a result, Buffy is often wounded by these attacks, and not just physically. Although she is knocked unconscious, tortured, verbally threatened and very nearly killed, these are physical dangers that accompany her job as Slayer. These symptoms also accompany attacks by personalized villains, but included among them is another effect: emotional damage. These are the scars under the surface that Buffy must carry with her as she matures and develops through the seasons, for although her Slayer body heals faster than normal humans, she carries with her the scars of previous battles as well as those from everyday life. And while she may be affected by her ordeals with Big Bads such as the Master (whose face haunts her into the following season), her response to him is nothing compared to the scarring that accompanies Angel's transformation into Angelus or Faith's sisterly betrayal. The problems generated by these characters are compounded by the fact that, unlike other Big Bads, they often recur: personalized villains are never killed, thereby allowing them to return and reopen wounds Buffy thought were healed. These final two chapters explore the personalized Big Bads who are so difficult for Buffy to overcome. This chapter examines friendship gone bad and will focus on the two female personalized villains: Faith and Willow.

The first section concerns Faith, who functions as Buffy's shadow double in demonstrating the effects of a Slayer without a sense of responsibility as well as a romantic foil to demonstrate that Buffy's emphasis on romantic relationships detracts from her abilities to perform either of her two roles. 
The second section in this chapter concerns Dark Willow. The parallel addictions again show how Buffy, once again overwhelmed with a sexual relationship, does not functionally play the role of Willow's best friend. When Willow embraces evil at the end of the sixth season, her inability to be either Slayer or Buffy results in Buffy's failure to defeat a Big Bad - the only time it occurs in the series seven seasons.

Faith's function as a Big Bad is twofold. As a Slayer without a sense of responsibility, she is a literal shadow double of Buffy: someone with the same powers who uses them in a different - and ultimately evil - way. Her other function is an extension of both Drusilla's and the Mayor's roles in that Faith demonstrates to Buffy that her romantic relationships are a weakness that emphasize her Buffy desires as opposed to her Slayer responsibilities. Like Drusilla, Faith causes Buffy jealousy and suspicion, while like the Mayor, her actions and dialogue demonstrate that, by putting her romantic relationships first, Buffy puts her friends and the larger community at risk.

Her initial appearance in "Faith, Hope \& Trick" (3.03) sets the tone for her character: she is seen from the Scoobies' point of view dancing at the Bronze and is described by Cordelia as "Slut-O-Rama" due to her revealing clothes and provocative dancing. This scene carries with it the same judgmental connotations as "The Initiative" (4.07) when Riley and Forrest talk about Buffy as if she is a passive object. Here Faith is subject to the camera's gaze as well as those of the group (the Scoobies). In each case, the passive 'object' is invariably more than she is initially shown to be (Buffy is more than "peculiar" and clumsy; Faith is more than a "slut").

Several ideas are presented here: from her initial entrance, Faith is branded an outcast, separate from the group and judged by her appearance and behaviour. 
Additionally, she causes problems in Buffy's romantic relationship by coming between her and a potential boyfriend, Scott Hope. Both these elements, present in her very first scene, will come to define Faith and her relationship with Buffy.

Her first comment to Buffy is: "You're Buffy, right?" which marks one of the few times she addresses her fellow Slayer by her full name. Once the vampire has been taken care of, however, she calls Buffy "B," a nickname she continues to use throughout her stay on the show. In this way Faith is suggestively insinuating Buffy is less than whole. Faith is prone to addressing Buffy's 'lack': she believes Buffy fails to embrace all the qualities that accompany their role as Slayers, including the sexuality, violence and potential for heightened status. By addressing Buffy as "B" she renders Buffy incomplete and unnamed - an abbreviation of the Slayer that Faith believes Buffy is capable of becoming should she fully embrace her calling. ${ }^{1}$

This is because Buffy's actions are determined by her feelings of responsibility to her job. Buffy is not always content to be a Slayer (hence her Buffy side) and she often comments on it as if it were a job. In this capacity, Buffy equates a certain set of responsibilities to Slaying that guide her actions (such as no killing of humans and conducting research on enemies). Faith acts counter to these ideas because she embraces the physicality of Slaying: she is constantly talking about the feelings that go alongside killing, such as hunger and horniness ("Faith, Hope \& Trick”). For Faith, being a Slayer isn't a job - it's a super power that has a wide range of possibilities. This is an idea she embraces in her unofficial motto from "Bad Girls" (3.14): "See. Want. Take"

\footnotetext{
${ }^{1}$ Interestingly, this could also be Faith's attempt to rank Buffy's status below her own. If Buffy is the Slayer and Faith is $a$ Slayer, then her repeated referencing of Buffy as 'B.' would alphabetically allow her to rise above Buffy. This way Faith is allowed to become the Slayer she wants to be: the 'A' Slayer - the one on top. (Loiselle, April 15)
} 
In this way, Faith is a shadow double. Writer Doug Petrie explains that Faith is "a reflection of Buffy, what Buffy could be," while Wilcox sees her as a "dark double" (Who, 13) and DeKelb-Rittenhouse believes she "represents the darker side of Buffy" (147). Each of these explanations suggests that Faith and Buffy are opposites or mirrored versions of each other on the Slayer continuum.

As a double, Faith represents the elements of Slaying that Buffy does not explore. Faith and Buffy are dichotomies (one blonde, one brunette; one cautious, the other reckless, etc) and it is little wonder that they become enemies: they each represent aspects the other does not want to face. To suggest that Faith is simply an immoral version of Buffy overlooks the fact that Buffy also has these elements inside her. As Wilcox explains "... simple dualism is not allowed - virgin / whore, devil / angel, hero / villain, Buffy and Faith are both aspects of each other and complex characters in their own right" (Who, 16).

Faith's complexity lies in the aspects of being a Slayer she does not have: the ties to the world that Buffy has in her friends and family. ${ }^{2}$ In this way, Faith's lack of ties fuels her desire to be accepted, forcing her to play many roles for many people. Xander is intrigued by her sexuality, Willow by her recklessness, and Joyce by the possibility she can replace Buffy as the Slayer. It is significant that the only one not intrigued by Faith's presence is Buffy - the individual who most closely resembles her.

\footnotetext{
${ }^{2}$ These people are the very reason that Buffy has a sense of responsibility. Consider the number of times Buffy uses her Slayer powers to protect her Buffy life throughout the first three seasons.
} 
To Buffy, Faith is a reminder that she is replaceable. ${ }^{3}$ When Faith shows up, Buffy already feels as though her position has been compromised. In abandoning her responsibilities as Slayer and as a daughter, Buffy put her "ties" through a good deal of pain over the summer. Buffy's solution for her displacement is a return to defining elements of her previous life: high school, dating and Slaying. When a new Slayer turns up and siphons all the attention from Buffy, she feels threatened. As she tells Joyce "I'm just getting my life back. I'm not looking to go half-sies on it."

In this way Faith's second narrative function becomes apparent in her first episode. She makes Buffy appreciate her responsibilities as Slayer and Buffy by threatening them both. And while her early actions are harmless (eating dinner with Joyce, talking to Scott Hope), they foreshadow her evil deeds later when she literally tries to destroy the most important elements of Buffy's dual selves. This applies predominantly to Buffy's romantic relationships.

It begins with Scott Hope. When Buffy sees Faith talking to him in the hall, she becomes jealous and territorial. Her reaction is more extreme when it comes to Angel. Initially Faith is one of the few to address the topic head on when she asks if Buffy's uptight nature is an "Angel-thing." Later, when Buffy sees Faith confront her fears by killing Kakistos (the vampire who killed her old Watcher and brought Faith to Sunnydale), she mounts the courage to tell Giles that Angel was re-ensouled before she killed him. This is significant because it implies each Slayer can benefit from the

\footnotetext{
${ }^{3}$ Otto Rank, utilizing Freudian theories, believed that during the developmental stage, the double is created as a defense against the threat of the destruction of the self. The presence of the double denies death because "the self is incorporated in the shadow or in the reflected image" (Rank as quoted by Schneider, 108). Once this stage has passed, however, the presence of the double is a reminder of what it once protected again: "an uncanny harbinger of death" (Rank as quoted by Schneider, 109). Faith, as another Slayer, embodies this doubling aspect because she is a reminder of Buffy's previous death as well as a replacement should she die in the future. Buffy treats Kendra with similar apprehension and coldness in season two.
} 
presence of the other: each learns a lesson from the other (Faith in the literal sense when Buffy tells her the first "rule" of Slaying is "don't die").

The situation is reversed in "Revelations" (3.07). Here Faith's two narrative functions combine: (1) in attacking Angel, Faith demonstrates how a lack of "ties to the world" leaves a Slayer vulnerable to manipulation and evil and (2) how Buffy's romantic relationship clouds her judgment and impairs her ability to perform her responsibilities as the Slayer and as Buffy.

The first function demonstrates the necessity of Buffy's friends and family. It also starts Faith down the road to evil. By "Revelations," she has become isolated from the group, living at the motel away from the others and not attending school. Although she appears for Watcher meetings in the library, it is clear that Faith is a social outcast when she goes unseen for three consecutive episodes. Tjardes acknowledges this idea, suggesting that Faith, as a result, can be seen as a "border figure":

This class and sexual border crossing allows Faith a freedom not available to Buffy[...] She has no last name, she has no past except as a slayer. She is spatially unrestrained, moving freely through the town, library, and school. She appears briefly in several episodes, training or patrolling with Buffy, but is otherwise uninvolved in these narratives [...] She is outside the group, whether through her volition or their exclusion. (69)

"Revelations" reinforces this outsider status. When Faith's new Watcher, Gwendolyn Post, arrives, the dark haired Slayer resists her because she has trust issues and guilt for her role in her first Watcher's death. They ultimately bond over a shared exclusion from Buffy's secret meetings, which marks the second time Faith is held at arms length by the group. This is apparent when she and Buffy are on patrol and Faith discusses her old boyfriends, including her fears that she is a loser magnet. Instead of reciprocating, Buffy refuses to talk about Angel and contributes nothing to the conversation. 
This refusal to let Faith in, to let her know the truth about Angel and establish his character, are determining factors that allow Faith to be manipulated by Xander into thinking that Angel must be killed. The very reason that Faith attacks Angel is because Xander uses her outsider status - her lack of knowledge about Angel's soul - to his advantage and because she sees Post, the only person who confides in her, knocked unconscious by a vamp-faced Angel. Unlike other members who are admitted to the Scoobies (Oz, Tara, Anya, even Spike), Faith remains an outsider without ties, vulnerable to manipulation.

Faith's attack on Angel also serves a second function in the episode's narrative: it demonstrates Buffy's feelings for Angel overwhelm her other relationships. And while in this case, she is justified in her defense of him, "Revelations" foreshadows events later in the season when Buffy's affection for Angel comes at the cost of her responsibilities to the other Scoobies and the world.

The problem is that Buffy's mixed feelings about Angel (she wants to be with him, but cannot forget his time as Angelus) ${ }^{4}$ manifest themselves as an inability to talk openly about him. When she confronts Faith, Buffy cannot properly vocalize the reasons why Angel should not be killed. The ensuing dialogue suggests both of Faith's narrative functions:

Buffy: I can't let you do it, Faith.

Faith: You're confused, Twinkie. Let me clear you up. (Points to Angel) Vampire.

(Points to herself) Slayer. (Points back to Angel) Dead Vampire.

Buffy: There's a lot that you don't understand...

Post: Faith... she doesn't know. She's blinded by love.

Buffy: Faith, no.

Post: Trust me.

Buffy: Faith, we can figure this out-

(Faith roundhouse kicks her in the face)

${ }^{4}$ See chapter 4 - Angelus. 
Buffy's comment that "There's a lot that you don't understand" is actually a reinforcement that Faith has been excluded from the group, thereby representing Buffy's shadow double in her lack of ties to the world. Post's comment that "She's blinded by love" echoes Kendra's comments from season two ("What's My Line, Part 2," 2.11) and suggests that Buffy does not react like a Slayer so much as a girl in love when it comes to Angel.

The moment that Faith asks Post what she's doing, and she replies "Faith...You're an idiot" is the first step in Faith's descent into evil. It is here that Faith's ability to truly trust another individual disappears, as demonstrated in the final scene when Buffy visits her in her motel room. ${ }^{5}$ Faith sits on her bed, a large bruise on the left side of her mouth from her battle with Buffy. When Buffy compliments her on the room, Faith replies: "Yeah, it's real Spartan." This throwaway line ${ }^{6}$ reveals that despite the revelation that Gwendolyn Post lied, misled and tried to kill her, Faith still accepts her words and, by extension, the feelings of exclusion they discussed earlier. In this way, her choice of expression highlights Faith's separation from the Scoobies and suggests an opposition to Buffy. She rejects Buffy's peace offering, claiming "I am on my side. And that's enough." In this way Faith reaffirms her status as border figure and shadow double - a Slayer without friends or family to define her responsibilities to herself and humanity.

While Buffy constantly struggles to balance the responsibility that accompanies being a Slayer and a human being, Faith makes no such attempt and immediately gives in to the temptations of power. She demonstrates that Tjardes" "border crosser" cannot be

\footnotetext{
${ }^{5}$ See Appendix F for full transcript.

${ }^{6}$ When Post visits Faith earlier in the episode, she mentions that the Spartans lived like her "because a true fighter needs nothing else."
} 
the Slayer - Faith has no ties to the world as Buffy does and so she drifts into corruption and evil. There is no one to tell her right from wrong, no one to confide in or even spend time with.

Without these ties, Faith does not feel any responsibility to the humanity or the world. For her, there is no reason to fight for anyone but herself because that is the only person she trusts; the only person that she can depend on. This once again reveals Faith as Buffy's shadow: Sartre believes that part of the definition of a hero is making a commitment to humanity. Faith makes the wrong existential choices, and therefore fails as a hero. Wilcox explains that:

...in general in Buffy, characters' acknowledgment of their own and others' human weakness helps them keep from making Faith's mistakes, helps keep them from killing too easily. The tragic error is hubris, especially a Slayer's hubris-disregard for human weakness. The person you kill is as human as you. (Who, 15)

The finale scene of "Revelations" foreshadows the role each Slayers plays in the accidentally murder of Deputy Mayor Allan Finch in "Bad Girls" (3.14): Faith trusts only herself and wants to remain silent, while Buffy recognizes the need to involve her friends because remaining silent is not a solution. Throughout three seasons, Buffy has learned that part of her responsibility as a friend is to confide in the Scoobies, while her training with Giles as a Slayer is built on open communication to aid in solving problems. ${ }^{7}$

This is the episode that most clearly distinguishes the two Slayers as doubles. Just as Faith sees a lack in Buffy's non-acceptance of the possibilities that accompany Slaying, so too does Buffy see problems in Faith's moral decisions regarding the murder. The episode is revealing, though, because it is here that Buffy embraces her 'lack' and

\footnotetext{
${ }^{7}$ When Buffy does not adhere to these rules, as in "Revelations" when she remains silent about Angel's return, the group reacts angrily and the outcome is violent and nearly disastrous.
} 
shirks her responsibilities: treating life frivolously, skipping school, stealing weapons and escaping from police custody.

One of the most distressing aspects of the episode is the disregard for human life.

As Slayers both Faith and Buffy use their powers to protect the lives of the innocent from evil. Buffy routines ensures her own safety by planning her battles (ie: researching the villains, telling the others where she's going, having a plan of attack, etc) and in doing so respects her responsibilities as a Slayer. If she dies, there is a delay before another Slayer is called ${ }^{8}-$ a time in which the innocent go unprotected. This is the reason that the first lesson of Slaying is "don't get killed."

The recklessness for human life demonstrated throughout "Bad Girls" is therefore a denial of Buffy's slaying responsibilities. The fact that Faith embodies this characteristic is an aspect of her function as shadow double ${ }^{9}$ and suggests (like her time with the Initiative) that the decisions Buffy adheres to normally are the ones that make her a successful Slayer and have kept her alive longer than previous Slayers. As Spike suggests in "Fool For Love" (5.07), Slayers have a death wish, a fact demonstrated by both Buffy and Faith in "Bad Girls"...each with disastrous consequences. ${ }^{10}$

Each reckless encounter marks a period of increasing rising action en route to Finch's murder near the end of the episode, originating with the teaser as the two Slayers battle vampires in the cemetery. Faith is briefly knocked out against a headstone when she attacks without thinking, leaving Buffy to be overwhelmed. Faith stakes the vampire

\footnotetext{
${ }^{8}$ Explained by both the Mayor ("Enemies," 3.19) and Spike (What's My Line, Part 2").

${ }^{9}$ This idea once again refers Faith's role as an uncanny double whose presence suggests Buffy's own death. Additionally, Faith's lack of appreciation for life (discussed below) marks her as a harbinger of death because she enters into life and death situations without a plan or concern for the consequences. ${ }^{10}$ In contrast, Buffy's decision to end her own life in both "Prophecy Girl" - by choosing to face the Master knowing he will kill her - and "The Gift" (5.22) - when she jumps into the vortex - are examples of her dedication to Slaying. Each time marks a sacrifice Buffy makes for the larger community, wherein her death is necessary to protect the rest of society from the Big Bad's apocalypse.
} 
as he leans in to bite, exclaiming: "Nicely diverted, B." When Buffy tells her that she was fighting for her life, Faith dismisses her own recklessness, explaining: "This isn't a Tupperware party. It's a little hard to plan." In belittling Buffy's life and death situation, Faith opposes herself to Buffy's established practices as a Slayer (a plan of attack) and demonstrates that she does not recognize that her responsibilities as a Slayer include respecting human life, be it Buffy's or hers.

This sets up the conflict for their next battle. When members of the El Illuminati vampire sect disappear down a manhole, Faith immediately starts after them. Buffy stops to question her actions, ${ }^{11}$ pointing out that it is a "tight space" with "no escape" and they're outnumbered. Faith's reply (“Who said I had a plan? I don't know how many's down there, but I want to find out. And I'll know when I land, and if you don't come in after me, I might die.") once again shows a troubling lack of appreciation for life. The effect of both their decisions is revealed moments later when Buffy is nearly drowned while Faith watches helplessly (echoing both season one's "Prophecy Girl," as well as Faith's inability to save her first Watcher).

"Prophecy Girl" suggests that Buffy returns from near death experiences more powerful. The aftermath of "Bad Girls" is a willingness on Buffy's behalf to try Slaying from Faith's perspective. Unsurprisingly, this involves abandoning the responsibilities she fought so hard to reclaim following her return from Los Angeles: she leaves behind her friends and an exam to stake out a nest of vampires with Faith (again without a plan) and embrace her inner "Slut-O-Rama" by dancing provocatively at the Bronze.

In this way, it is clear that Faith's influence has overwhelmed Buffy's rationality. The sequence mirrors their battle in the sewer (tight space, no escape, outnumbered),

\footnotetext{
${ }^{11}$ See Appendix G for full transcript.
} 
although here it is off-set by Faith's equation of sex with Slaying. These elements are present once Faith and Buffy storm the nest, with one notable distinction. Typically in Buffy, fight scenes are played out in their entirety, unless they are influenced by sex. Consider "The ' $I$ ' in Team" (4.13) where the fight is intercut with scenes of Buffy and Riley making love. In "Bad Girls" the sex eclipses the fight.

This can be attributed to Faith's presence, as it is a reflection of her beliefs involving sex and Slaying. The narrative (and all its formal techniques, including editing) typically revolve around Buffy, so when she begins to act like Faith, the show's editing reflects this. Instead of showcasing the fight, the scene cuts from the two Slayers bursting into the nest to Buffy and Faith dancing at the Bronze. The dancing is filmed in a series of rapid-cuts (medium-long profile shots and overhead shots) which showcase the physical proximity of the Slayers to each other (suggesting their similar mindset), as well as the group of guys encircling them. ${ }^{12}$

Even after Angel approaches, Buffy's sexualized behaviour continues as she jumps up and wraps her legs around him (suggestive of a sexual position). Considering the season's early episodes focused heavily on Buffy's make-up exams as well as her inability to be near Angel, much less physically roughhouse him, her behaviour in these scenes is unorthodox for her. Now that it has been established that Buffy has disassociated herself from the responsibilities of her two roles, the stage is set.

\footnotetext{
12 This recalls Sartre's visqueux in its associations to material comfort and sex, both of which a hero must extract themselves from to perform their duty. Sartre describes the slimy having "a soft, yielding action, a moist and feminine sucking" but insists "it is a trap...the slime is like a liquid seen in a nightmare, where all its properties are animated by a sort of life and turn back against me...Slime is the revenge...a sicklysweet, feminine revenge" (Being, 609). By cutting from the fight - the duty the Slayers perform - to the Bronze - the visqueux - the show suggests Buffy has submitted to sex and comfort at the expense of her responsibilities.
} 
Events culminate near the end of the episode when the girls make their way down an alley to attack the demon Balthazar. The alley has all the same characteristics as the manhole (tight space, no exit, and they are outnumbered) but because Buffy is acting like Faith, she does comment on it. At the end of the alley, after a succession of attacking vampires, Faith stakes Allan Finch and he dies in front of them.

In the episode's last scene, Buffy goes to Faith's motel room to discuss what they should do about the murder, but Faith refuses to discuss it. ${ }^{13}$ Instead she tells Buffy that "There is no body. I took it, weighted it, and dumped it. The body doesn't exist." When Buffy tries to tell her it doesn't erase what they did, Faith tells her “you don't get it. I don't care." Faith's reiteration of her beliefs - her lack of responsibility for Finch echoes her comments regarding a lack of appreciation for life made to Buffy throughout the episode. If Faith is Buffy's shadow double, a 'Buffy without friends or morals' the distinction between the two is solidified here. Buffy feels horrible and responsible, while Faith claims she feels nothing. ${ }^{14}$ The conflict that drives the rest of the season (dark shadow versus blonde shadow) is born of this moment as Buffy returns to her dual selves and the responsibilities that accompany them while Faith slides further into mistrust and then darkness.

Both "Bad Girls" and "Consequences" reaffirm Faith's two functions in the narrative in addition to developing her as a Big Bad. Although Buffy is open to Faith's suggestions initially, she knows that she must be accountable and responsible when using

\footnotetext{
${ }^{13}$ See Appendix G for full transcript.

${ }^{14}$ Her statement isn't entirely true. Faith returns, alone, to the body (clearly the moment immediately before she "dumped the body") but the scene shows her hesitation, discomfort and scared face as she bends down to tentatively touch the wound. The blood spot that she washes in her motel in the final scene is clearly visible on the arm with which she touches Finch, suggestively tying her to him not only as killer/victim, but also as a victim herself - victim of an accident she believes will destroy her life.
} 
her skills. In this way, it is important that it is Faith that murders Allan Finch because it shows how Faith - as Buffy's shadow double - does not consider herself responsible for her actions. This is clearly demonstrated, not in the murder, which is an accident (Buffy tells Faith as much), but in Faith's disavowal of responsibility for it and her attempt to shift the blame onto Buffy. The way the group rallies around Buffy despite Faith's attempts to paint her as a murderer reaffirms the importance of ties to the world something Faith lacks.

“Enemies" (3.17) showcases Faith's struggle to accept or deny her responsibilities as a Slayer. After murdering a demon bookseller to steal the books of Ascension for the Mayor, Faith stares at the blood on her hands, which are shown in close-up. This moment not only recalls the shot used when Angel discovered Buffy in the alley with blood on her hands following Finch's murder in "Bad Girls," but also the end of that episode when Faith desperately scrubbed the blood from her shirt. The moment has ties to Lady MacBeth and her desperation to remove the blood from her hands following the King's murder: Faith has committed acts of violence to further her male companion (the Mayor)'s agenda, but cannot eliminate the stains of her deeds. Although she does not admit her guilt (be it to the police, the Watcher's Council or even the Scoobies), her decision to approach Angel - the only individual who identifies with her plight (especially after their shared conversations in "Consequences") - suggests she wants redemption.

At the same time, though, her status as border figure prohibits her from opening up. Just as Buffy battles between her two selves, so too does her shadow double: Faith goes back and forth between wanting to do the right thing and being unwilling to face the 
consequences. This struggle, or rather her descent towards evil, is reinforced in lighting and dialogue. At Angel's mansion Faith and the area surrounding her are shrouded in darkness and shadow, suggesting her deceptive intentions. This is reinforced later when Buffy and Faith investigate the murder scene and Buffy comments that it wasn't a hit, “this was somebody's idea of a party" suggesting the murderer (Faith) overzealously enjoyed killing the demon. Although it is a Slayer's job to kill demons, it was previously established that this demon was harmless and he put up no fight when Faith approached him. By killing the helpless demon bookseller, Faith is no longer adhering to her responsibility as a Slayer to protect innocents, but rather using her powers for profit.

When Faith and 'Angelus' (for it is actually Angel acting) chain Buffy up, the conversation between the two Slayers allows each to verbalize the feelings they have been repressing since Faith first appeared in town. Faith's comments reveal that she understands her status as Buffy's shadow when she explains that she cannot compete with Buffy's image. Tjardes believes that her jealousy and her narcissism ("This was supposed to be my town"; "I'm the world's best actor"):

...again allows viewers to produce a variety of readings. Faith's "I-hate-Buffy" speech...is evidence that her actions result from jealousy of Buffy's role as the "good slayer" and her awareness of her own failure as just warrior. (73)

It is therefore significant that Buffy calls Faith a "loser." The jab not only references one of Faith's fears (earlier in the episode, she told Angel, "I don't want to end up like everyone said I would: dead or alone or a loser"), but it also suggests Buffy's own recognition of her status as the Slayer. Faith's status as the second Slayer is equivalent to being less important, even unwanted (since there are not supposed to be two Slayers, Buffy occupies the position of privilege as the first). 
It is also a turning point for Buffy since her comment (subconsciously) associates Faith with the Master. At the end of "Prophecy Girl," Buffy calls down "loser" after staking him on the broken library table. Considering this is a term that Buffy rarely uses, it automatically associates Faith with the Master, effectively tying the second Slayer to Big Bad status and the ancient vampire.

The fallout from the events of "Enemies" is the damage Faith causes to the BuffyAngel relationship. Earlier in the episode Buffy witnesses Faith's attempt at seducing Angel. The moment is presented from Buffy's point of view, as Faith kisses Angel on the cheek and then walks away, suggesting that it is with Buffy that the audience is supposed to side. The veil behind which Faith passes carries symbolic connotations as the sheet before Buffy's eyes is lifted away and her fears about the relationship between Angel and Faith appear to be justified. Her reaction is akin to the somber attitude she adopted in season two when she saw Angel and Drusilla together in "Lie to Me" (2.06). When she is abducted, Buffy is forced to watch him kiss Faith passionately, and although she knows it is part of the plan, she cannot overcome her jealousy. This is made explicit in the following episode "Earshot" (3.18) when she tries to use her newfound ability to hear thoughts to discover what happened between Angel and Faith.

It is significant that these are the thoughts that occupy Buffy's mind after discovering the Mayor intends on massacring the Sunnydale High graduating class. Instead of thinking of her Slayer duties, the ruse with Faith drives Buffy into jealousy about her relationship with Angel. Faith therefore functionally demonstrates that Buffy's romantic relationships distract her from her greater responsibilities as a Slayer. ${ }^{15}$

\footnotetext{
${ }^{15}$ Sartre describes the slimy in subtly sexual, feminine word choices: "It draws itself out, it displays itself, it flattens itself out, it is sof $t$ " (Being, 608) and "Slime is the revenge... a sickly-sweet, feminine revenge"
} 
These emotions continue to resonate in the next confrontation between Faith and Buffy. They don't see each other until "Choices," when it is suggested that Faith's deception affects Buffy's duality more than initially implied. Each time a new Slayer appears, Buffy considers how their presence affects her future, starting with Kendra in season two's "What's My Line, Part 2" (2.10). The appearance of a second Slayer prompts Buffy to question whether she could abandon her responsibilities as a Slayer and let Kendra take over.

These questions are compounded in season three with Faith because Buffy faces the end of High School and the option of leaving Sunnydale to attend College. Buffy knows that the current events prohibit her from leaving, although when she is accepted at prestigious Northwestern in "Choices"16 she makes it clear that she had initially considered the idea.

She tells Willow that "Faith's turn to the dark side pretty much puts a kobosch on any away plans for me. U.C. Sunnydale. At least I got in." Her decision to derail the Mayor's ascension plans are fueled by her desire to change her future - if she can eliminate the Mayor and stop Faith, there remains a chance she can leave Sunnydale. When, at episode's end, she decides to attend Sunnydale University, it is another example of Buffy recognizing the importance of her role as Slayer. She knows that even if she stops the Mayor and Faith, she will continue to have responsibilities to protect the people who live above the Hellmouth.

(Being, 609). If the visqueux is the feminine sex that distracts a hero from their duties, in Buffy it is represented by Faith and manifests in the form of sexual jealousy. However, since Buffy herself possesses this visqueux as a female, Faith - as her double - reflects her own desires to abandon her heroic duties. ${ }^{16}$ The title refers to her choices affecting each of her selves: strategically deciding to go on the offensive against the Mayor ( Slayer side); trading Willow and deliberating on what her future holds (Buffy side) 
At the same time, Buffy's attack suggests that she's no longer content simply to accept her destiny; she now wants the power to shape it. By telling Wesley that she wants to leave after graduation, she takes an important step towards independence, one that will become more explicit when she quits the Watchers Council. Wesley refutes her statement by claiming: "But you're a Slayer." His choice of words is revealing: he does not call her Buffy, or even the Slayer. As a result, she becomes merely a Slayer - one in a long line of many. Just as Faith's name effacing 'B' references reduce Buffy's Slayer status to an abbreviation (and belittles her Buffy side entirely since it is her given name), Wesley's comment suggests that she is little more than a weapon to be wielded against evil. He has no sympathy for her plight as a teenage girl whose friends are going to leave her and go off to University. Her response is just as insightful: "Yeah. I'm also a person. You can't just define me by my Slayerness."

Faith's situation shows a clear contrast. Unlike Buffy, who rebels against her generic classification, Faith enjoys being the Mayor's henchman. She takes obvious delight in killing the deliveryman at the airport. Her progression from sorrowful killer in "Bad Girls" to dangerous, but tortured Lady MacBeth in "Enemies" is rounded out in "Choices:" Faith has, as Angel suggested, developed a taste for murder. Her refusal to accept responsibility for her role in Finch's death has compounded her lack of appreciation for life, but she is not simply "evil." As Wilcox explains, there remains elements of Buffy in her - grey areas - as suggested by her actions in the cafeteria in "Choices." Instead of allowing an escaped Gavrok spider to kill Wesley and Giles, she saves their lives by impaling it with her knife. 
This once again classifies Faith in an uncertain moral light: there is no reason for her to kill the spider, unless it is to ensure that none escape to harm the innocent. Faith shouldn't care about this considering her earlier actions, but she complies to Giles' order that none can be allowed to escape by killing a spider immediately after Buffy does (once again pairing them). When the Mayor orders her to leave with him, she hesitates, looking at the knife. To the Mayor it may simply be a knife, but to her it is "a thing of beauty" and, more importantly, a symbol of his love for her. Although she has accepted her new role as the Mayor's henchman, she still desires acceptance and affection. Faith doesn't want to give the knife up, but accepts the Mayor's orders. Despite her comments in "Bad Girls" that Slayers don't have to take orders, in a two minute time span she has followed two. In this way, Faith is identified as a submissive Slayer (the loser), while Buffy is associated with action and independence (as the Slayer).

This continues as the season progresses, to the point that Faith rarely speaks for herself or explains her own motivations. "Enemies" is the only true example when she speaks her mind, compared to "Choices" when she does nothing but gesture and threaten while the Mayor speaks for her. Tjardes explains that

In later episodes of the third season, Faith is shown increasingly in brief reaction shots. Buffy, Willow, and the mayor attribute thoughts, feelings, and motivations to her; she doesn't voice them herself. (73)

In this way, Faith's submission can be associated to her "failure" as a Slayer.

Characterized by inaction and inability to accept responsibility, Faith is shown to be "lacking" as a Slayer, which explains why she is the one compared to Buffy and not vice versa. Their contrasting personalities in turn suggest that Buffy, as the heroine, embodies elements that are required for being a success as the Slayer. Their status as shadow 
doubles highlights the importance of a balanced duality: when responsibility is accepted, success as a Slayer is imminent, whereas denial results in submission and failure.

Buffy flirts with these ideas once more in the two part finale, "Graduation Day" (3.21-3.22). Faith, as a personalized villain, knows just how to attack Buffy: through Angel. She knows that a blow to Angel is akin to striking Buffy's Achilles heel and although they have been broken-up for two episodes, Buffy remains unwilling to let Angel die. His sickness from a poisoned arrow instigates a rash of emotional responses, ranging from her decision to quit the Council to finally facing Faith in a death-match. Her actions make it clear that her romantic relationship with Angel is the most important part of her world: she is unable to kill Faith in "Enemies" and "Choices," but a cure for Angel is more than enough to overcome her hesitation to kill in "Graduation Day, Part 1."

Tjardes believes that it is this drama, and the three players in it, that comprise the season's "vital battle," and not the Mayor. She explains it is made clear in the "montage [that] pans from Buffy, gazing deeply at her reflection, to Angel, sweating and delirious, to Faith, hitting a punching bag with abandon" (75). This idea is supported by the amount of screen time afforded to the battle: when Buffy faces the Mayor in the following episode, Buffy blows him up in a matter of seconds. Her fight with Faith, in contrast, lasts for well over four and a half minutes (split in two parts: 36.20 - 38.57, 40:42 $42: 52)$.

Faith identifies their duality when she says Buffy is "all dressed up in big sister's clothes" in red leather pants and black shirt. This moment marks the climax of their escalating conflict by recalling their previous physical encounters. In "Enemies," Wilcox believes "the two slayers visually mirror each other: Faith dressed in blood-red and Buffy 
in black with touches of red, dark-haired Faith to blond Buffy, they hold knives at each other's throats" (Who, 14). The final kneeling position is similar to their positions at the end of "Revelations." Faith wears red leather in one fight ("Enemies"), Buffy wears it in the next. The similarities in fighting styles, physical posturing and clothes creates a layer of intratextual references and mirrors, suggestively blurring the boundaries between their identities and what is right/wrong. It is therefore appropriate that Buffy uses Faith's own knife to stab her - it gives weight to Buffy's retort that Faith is "about to get it back," and echoes the violence Faith used to kill the demon bookseller. Additionally it closes the conflict between them that began when Faith stabbed Allan Finch (Faith starts it, Buffy finishes it).

By acting on her murderous feelings, Buffy comes desperately close to using her Slayer powers in the same way that doomed Faith. Her desire to use Faith as a cure for Angel's disease is coded as an irresponsible way to use her powers (by Wesley) with potentially dangerous consequences (Xander's concerns, Faith's motto, "kill me, you become me" and Angel's belief that one murder creates a taste for it). Faith's actions, therefore, serve several purposes. By poisoning Angel, she exposes the lengths to which Buffy is prepared to go in order to preserve their fractured romance (the willingness to kill). At the same time, Faith's sacrifice - martyring herself by jumping onto the flatbed truck - once again questions how "evil" she is because her actions prevent Buffy from becoming a killer. In doing so, she also allows Buffy and Angel's pseudo-sexual reunion when Buffy offers herself to save him.

The fact that this scene occurs almost immediately after Buffy's near-miss homicidal attack on Faith links the two acts: through Faith, Buffy and Angel are able to 
consummate their relationship one final time. And, just like the first time, it produces disastrous results as the following scene shows Angel rushing into the emergency room with an unconscious Buffy in his arms. While Faith's actions allow a final intimate moment between the two lovers, it also highlights the reasons they can no longer function as lovers. The message is simple: the love between Buffy and Angel, if acted upon, will kill one or both of them (him through his loss of soul, or her as a bloodless corpse).

Faith's two functions as Big Bad continue when she reappears in season four. Although she is comatose for more than half the season, when she returns, she overhauls the entire narrative. Recalling the privileging narrative granted the Initiative earlier in the season, Faith's dreams occupy a significant portion of "This Year's Girl” (4.15) and reduces the threat of Adam to a subplot.

Her two dream sequences suggest that, in Faith's eyes, it is Buffy who is the killer and she the victim. The two dream sequences, as well as Faith's initial conversation with Buffy at UC Sunnydale, ${ }^{17}$ suggest the show is attempting to demonstrate that Faith is not simply an evil being, but a misunderstood girl who feels she has been mistreated. It is only after the events of the two part episode that Faith finally realizes it is her responsibility to admit that the blame is hers.

This is possible because of the body swap at the end of "This Year's Girl." Faithas-Buffy discovers what it feels like to have ties to the world and be loved unconditionally, but she finds herself unable to accept it because it is as Buffy and not herself. Her own self-hatred is demonstrated in the oft-cited passages ${ }^{18}$ in "Who Are You?": first, when she remarks, "You can't do that because it's wrong" and for the first

\footnotetext{
${ }^{17}$ See Appendix $\mathrm{H}$ for full transcript.

${ }^{18}$ Battis (86); Wilcox (Who, 15-16).
} 
time means it, ${ }^{19}$ and when Faith-as-Buffy punches her true body, crying, "You're nothing!" In this way, Faith recognizes that as a Slayer she has a responsibility to use her powers to save the innocents at the church and that she is unhappy with herself and her actions (she calls herself a "lying, cheating, murderous bitch"). It is only when she appropriates Buffy's body (literally embodying herself with the qualities that make Buffy a success) that she is truthful to herself and finally begins her path to redemption.

For Buffy the events that take place during the body swap are important for demonstrating that her romantic relationships are flawed and distract her from her responsibilities. It is unimportant that no one recognizes she and Faith have switched places, with one exception: Riley, who sleeps with Faith-as-Buffy and does not notice anything unusual. Once again, Faith functions to indicate problems in Buffy's romances:

Faith: ... in the dream, this self-righteous blonde chick stabs me and you wanna know why? Buffy: You had it coming.

Faith: That's one interpretation, but in my dream she does it for a guy. [...] I wake up to find out that this blonde chick isn't even dating the guy she was so nuts about before. I mean, she's moved on to the first college beefstick she meets. And not only has she forgotten the love of her life, she's forgotten all about the chick she nearly killed for him.

The conversation is interesting because Buffy expects Faith to grow and reflect in her coma, while Faith is preoccupied that she was stabbed because of Buffy's relationship with Angel. So when Faith-as-Buffy sleeps with Riley, Buffy is confronted with the same issues she faced before, only this time Buffy knows for certain that the romance between Riley and Faith took place. The fact that Riley is unable to notice something amiss (despite Faith-as-Buffy's unusual requests for kinky sex and her abrupt departure in the middle of the night) disturbs Buffy. Her friends fail to notice the difference from a

\footnotetext{
${ }^{19}$ Throughout the episode she says this line numerous times, but only in condescending or mocking tones.
} 
distance, but Riley is physically intimate with someone test driving her body. In this way, Riley's sex act with Faith-as-Buffy is not unlike a cheating boyfriend.

The insecurities that Faith creates in Buffy once again continue into the next episode, even though Faith has already abandoned Sunnydale for Los Angeles (where she has gone to see Angel, ironically ${ }^{20}$ ). Although Adam is running around mutilating and plotting, Buffy spends the entirety of "Superstar" (4.17) wondering about her relationship with Riley and attempting to reconnect with him. This occurs once more, with Spike in "Dirty Girls" (7.18), although by this point Faith has begun her redemption and can no longer be considered a Big Bad.

It is clear that Faith plays a crucial function as a personalized villain. As Buffy's shadow double, she represents the qualities that lead to the failure of a Slayer: lack of responsibility and appreciation for human life, inaction and submission. In contrast, Buffy's methods are proven once again to be the successful combination required to fight in the supernatural world. The two serve principally to balance each other, since Faith represents elements Buffy hides within herself (the association of sex, death and Slaying) while Buffy represents Faith's ideals because she has ties to the world, thereby demonstrating Faith's "lack." A second important function Faith serves is her role as a romantic foil for Buffy's romantic relationships: her actions create friction between Buffy and her boyfriend (be it Angel or Riley) and also serves to emphasize how Buffy's emotional investment in romance is detrimental to her responsibilities to Slaying. These elements do not apply to all personalized villains, though. When examining Dark Willow it is clear that personalized Big Bads have a number of functions and consequences in

\footnotetext{
${ }^{20}$ Faith appears for two season one episodes: "Five By Five" and "Sanctuary" (A1.18-19). She reappears in season four to help recapture a soulless Angelus in "Salvage," "Release," and "Orpheus" (A4.13-15) before Willow picks her up to transport her to Sunnydale for "Dirty Girls."
} 
Buffy's life, especially when it comes to balancing her dual selves and the responsibilities that accompany them.

Willow is similar to Faith in one specific way: the resource that allows them to do evil deeds (magic and Slayer strength) is the same resource that they previously used to combat evil. Faith uses her skills to kill vampires and demons until the accidental death of Allan Finch - it is because she uses her powers irrationally and refuses to take responsibility for her actions that she becomes a villain. In this way, Faith's Big Bad is internally motivated because she actively becomes evil because she wants to.

Willow is both the same and different: her magical abilities are among the most powerful Buffy has in her armoire, although it is often hinted at that Willow is using forces that she may not be able to handle. Initially, in season six, Willow's dependency on her magical abilities is used in the 'magic-as-drug' metaphor. The end of her relationship with Tara prompts Willow's rehabilitation and it is only when Warren, lead member of the Trio of Nerds, shoots and accidentally kills Tara that Willow reverts back to her magical ways and becomes Dark Willow.

As a result the instigating forces for Willow's Big Bad are internal and external. Tara's death is the motivating disaster that initiates Willow's return to magic (external), although it is Willow's (internal) grief and rage that drive her to commit murder, hurt her friends and ultimately try to destroy the world.

Unlike Faith, who attempts to deny responsibility for her evil actions, Willow always accepts the blame for her irresponsible use of magic. Earlier, in "Something Blue" (4.09), when her spell goes awry and almost gets everyone killed, Willow feels awful and repents. After Tara leaves her and Willow injures Dawn while high, she breaks down, 
blames her own weakness and asks Buffy for help. She spends the period between "Wrecked" (6.10) and "Seeing Red" (6.19), as well as most of season seven, rehabilitating from her addiction in an effort to not only repair the damage she has done, but ensure it does not happen again.

In this way, Willow demonstrates responsibility for her own actions. As a Big Bad, her function is not to demonstrate the success of Buffy's choices. Instead Willow/Dark Willow parallels Buffy's lack of responsibility. This applies to her job as a friend and as a Slayer. It is her sexual obsession with Spike that prevents Buffy from stopping the Trio of Nerds and ultimately allows the death of Tara and the ascension of Dark Willow, the season's true Big Bad.

One of Buffy's principal failures is her use of Willow as a weapon. Characters often remark on Willow's power (Kennedy in "Get It Done," 7.15; Tara in “Tough Love," 5.19; Buffy in "Chosen," 7.22) and Buffy repeatedly calls on Willow to use magic to defend against or defeat villains. The problem is that she rarely recognizes the dangerousness of Willow's craft - instead responsibility falls on Giles and Tara, who serve as Willow's magical mentors. Instead Buffy only recognizes Willow's dangerousness when a spell directly affects her, as in "Something Blue," "Tabula Rasa" (6.08) and "Wrecked." This is primarily because Buffy is too concerned with her own problems to see Willow's (echoing Buffy's comments to Jonathan in "Earshot," that no one feels his pain because they're too busy dealing with their own).

As a result, Willow and Dark Willow are used throughout season six to expose Buffy's hypocrisy. Buffy questions Willow about her magic dependency only after Dawn is injured in a car accident, mainly because Buffy herself has been out of control having 
sex with Spike. It is only after Dawn is injured - Buffy's literal flesh and blood - that she recognizes the dire circumstances her friend is in. In this way, Willow's addiction shows how Buffy's sexual relationship with Spike denies her responsibilities as a friend. Had Buffy been paying attention to her heartbroken friend, she could have intervened, thereby preventing the accident.

The use of parallel addictions - Willow to magic and Buffy to sex with Spikedemonstrates how much more responsible Willow is: her actions, though more destructive, force her to recognize her problems and cause her to seek aid. Buffy on the other hand, recognizes Willow's addiction mirrors hers, but cannot accept responsibility for her actions and does not ask for help. The result is that she remains silent about the relationship, even though she considers it destructive. It ultimately preoccupies so much of her attention that the Trio of Nerds are not apprehended until "Seeing Red," and even then Warren escapes. It is Buffy's inaction in stopping the Trio of Nerds that allows his return, the death of Tara and Willow's turn to dark magic.

Willow's history with magic, and dark magic, foreshadows the appearance of Dark Willow early in the series. Her introduction to magic occurs mid-way through the second season, which J. Lawton Winslade attributes to Jenny Calendar's death in "Passion" (2.17). With Jenny dead, there is a vacancy in this specific information technology, and so Willow, who is already proficient in one (computer technology), takes her place in the other.

This inheritance is hinted at initially in "The Dark Age" (2.08) when Jenny asks Willow to help teach computer basics for extra credit. This ties the two women together as masters (within the group) of computer information systems, although Jenny's skills 
extend into the occult. ${ }^{21}$ When Angelus kills Jenny, Willow hesitantly takes over her computer class, explaining that she'll follow the lecture plans Jenny created before her death. In this way, Jenny schools Willow even after her death, through her lecture plans as well as the disc that contains the spell to reinstate Angel's soul.

The two technologies (computer and magic):

...depend and center on text: not necessarily books but on sites of collected knowledge that must be accessed. Both magic and technology work this way in Buffy; both are textual archives that yield information when "read" correctly. Proficiency with the language of magic allows Willow to situate a current problem within its supernatural context - the spell, the alternate reality, the demonic power - while proficiency with the language of computers allows her to locate the mundane context - the engineering diagrams, the newspaper articles, the police files. Her "readings" of both magic and computers are active; she must analyze and apply these stored knowledges, activating the texts to make them effective in the context of the series. (Overbey \& Preston-Matto, 79)

Therefore, the computer disc containing the ancient Gypsy curse that turns Angelus back into Angel is a unification of the two communication modes. And while Lawton Winslade is correct in implicating Giles as another purveyor of these two systems, as the series progresses, it is clear that Willow is the stronger and more knowledgeable of the two.

This progression from book-shy young woman to full-fledged Wicca begins in "Becoming, Part 2" (2.22) when Willow attempts to perform the curse from her hospital bed. Importantly, this is also the first real indication of the dangerous power of spells. Despite Xander's insistence that she is weak and "this is some pretty powerful stuff," Willow resolves to perform the spell.

Willow explains that although Oz doesn't know Latin, "You don't have to understand it. You just have to say it...I hope" In this early episode, the knowledge that

\footnotetext{
${ }^{21}$ This is demonstrated in "Prophecy Girl" (1.12) when she uses her contacts as well as her computer skills to track down signs of the upcoming apocalypse.
} 
words carry power has not yet been learned. Initially Willow speaks normally, although as the spell progresses (cross-cut with Angelus' Acathla awakening ceremony, suggestively linking Willow's spell to Angel's dark incantation) she begins to pause and breathe with difficulty. When Oz asks if she's okay, Willow's body is possessed by the curse: she issues of a stream of Romanian phrases, fails to react to the others, and grabs the tray on her lap with sudden force. Only after the orb glows white does Willow sit back and gasp, a stunned look on her face as Angel's soul returns. From this moment on, Willow's role changes to incorporate her dual identities: book-shy girl and witch. Overbey and Preston-Matto explain that:

Despite her insecurity about spell casting, Willow is widely recognized as a witch. Spike knows it when he demands that she cast a love spell for him in "Lovers Walk" (3.08); MOO (Mothers Opposed to the Occult) know it when they put the torch to her, stakebound, in "Gingerbread" (3.11), and Tara knows it from their first meeting, in "Hush" (4.10). (79)

It is significant that in "Gingerbread" both Buffy and Willow are raised on stakes by their parents - because in Joyce's eyes the skills that Buffy possesses are no less foreign than those Willow possesses. Lawton Winslade acknowledges the show's interest in presenting dual identities for its characters: ${ }^{22}$

Willow's study of magic is also consistent with the show's theme of the outcast developing a special talent to protect herself from both the adult world and the demon world. The show consistently highlights its social negotiations between the "real" human world and the world of demon slaying. These negotiations often demonstrate a savvy use of a particular type of postmodern occultism, in which the occult is not only a narrative construct with resonant psychological tropes, but a significant, continually contested discourse involving the characters' conflicted desire for both a stable and fragmented identity. (Slayage 1.1)

\footnotetext{
${ }^{22}$ Dualities include: Angel and Angelus; $\mathrm{Oz}$ and his werewolf side; Giles and his younger incarnation, Ripper. Even humans have multiple sides: Cordelia is secretly broke by the end of season three and Xander gets to play the hero in "The Zeppo" (3.13).
} 
In Battis' chapter on Willow, he suggests that Willow has multiple, fragmented identities. He identifies a number of distinct categories to which Willow belongs, including witch, lesbian, Big Bad, nerd and computer savvy individual.

Overbey \& Preston-Matto believe it is her combination of computer skills and witchcraft that "allow Team Buff to operate effectively on the Forces of Darkness" (79). Throughout season three, these moments are rare since Willow continues to doubt her own abilities, substituting her spell casting ability as an outlet for social success. This is presented in "Doppelgangland" (3.16), when Willow rebels against her boring and responsible persona. She and former vengeance demon Anya ("The Wish") accidentally transport Willow's doppelganger, Vamp Willow, into the regular Scooby dimension where she wreaks havoc before they finally send her back. As demonstrated in chapter one ${ }^{23}$ characters from alternate worlds are useful for shedding light on their 'real world' counterparts. At one point, Willow exclaims to Buffy about Vamp Willow:

Willow: That's me as a vampire? I'm so evil, and skanky. And I think I'm kinda gay. Buffy: Willow, just remember a vampire's personality has nothing to do with the person it was. Angel: Well, actually - (Buffy stares at him) - That's a good point.

The implication of Angel's highly ambiguous answer is that a vampire retains many aspects of their human identity after they are turned. Willow's comment about being "kind of gay" foreshadows her coming out as a lesbian in season four. Battis explains that “...Buffy 'double-codes' many of its scenes, using a combination of foreshadowing and subtextual references that the more discerning reader can access" (33). In this way "it is thus made clear that "bad" Willow is shaped and informed by "good" Willow, and vice

\footnotetext{
${ }^{23}$ The Buffy in the alternate universe of "The Wish" demonstrates the effect of 'real world' Buffy's friendship with Willow, Xander and Giles as well as the importance of her moving to Sunnydale in the first place. See chapter one, page 36.
} 
versa. Fittingly, then, Willow is not a static body, but rather a system of good and evil, capable of being dominated by either force" (Battis, 33).

In this way Dark Willow is another example of the qualities presented by Vamp Willow. Just as Buffy and Willow are unable to kill Vamp Willow because she remains, on some level, a variation of Willow, so is Dark Willow. Each of the three incarnations are informed by varying levels of responsibility: Vamp Willow is subject to feelings of love and loss, but remains true to her vampire responsibilities of feeding and massacring; Dark Willow believes she has a responsibility to end the world's suffering because she has the power to do so, while (regular) Willow attempts to balance the responsibilities that accompany her progressively increasing powers of magic.

"Something Blue" demonstrates how Willow handles these responsibilities as well as Buffy's inadequacy in performing her role as friend. The episode takes place after Oz departs in "Wild At Heart" (4.06), leaving Willow heartbroken and depressed. In the teaser, Willow talks to Buffy on patrol after visiting Oz's abandoned room. Instead of recognizing that Willow is in pain, Buffy talks about her new relationship with Riley. Throughout the episode, the only person to notice Willow's condition is Spike, who comments that "she's barely hangin' on by a thread. Even a ninny can see that." Only after Willow discovers Oz's room has cleaned out does Buffy begin to understand the impact of Oz's departure.

One of the episode's central conflicts is not Willow's loneliness about Oz's departure, but the fact that no one makes an attempt to understand her situation, especially Buffy. Just as Faith's narrative function is exposing the lengths to which Buffy's relationship with Angel is detrimental to her responsibilities as a Slayer, 
Willow's function is to expose Buffy's failure in her Buffy role. The teaser is a precursor to Buffy's actions for the rest of the episode: she remains blissfully ignorant of Willow in favour of bickering with Spike, raving about Riley or accompanying him on a picnic date.

The results of Willow's "have my will done" spell are comical as well as telling. The spell cast against Buffy, for her to marry Spike, not only foreshadows their future relationship, but also implies the degree to which Buffy's relationships take priority. Although no one else attempts to understand Willow's depression, save Giles, Buffy is Willow's best friend and spends the most screen time with her in the episode. The episode firmly establishes that Buffy's burgeoning relationship with Riley is a priority another example of friendship coming second to romance and sex. ${ }^{24}$

"Something Blue" is also important because it contrasts Buffy's irresponsibility to her Buffy role as a friend with Willow's responsibility once the effects of her spell are revealed. The fact that she didn't realize the harm she inflicted establishes two actions when investigating Willow's use of magic: (1) she rarely knows when she has abused her powers, but (2) when she does, she takes responsibility for her actions and apologizes (here she does so with a plate of cookies). In fact, her feelings of guilt over the spell are so strong that this marks the last time she attempts another that affects her friends until "Tabula Rasa.",25

From the beginning, it is established that Giles is the only member of the core foursome that watches over Willow's developing powers. Giles can therefore be seen as a Watcher to both Buffy and Willow, which endorses Wilcox's belief that the two girls can

\footnotetext{
${ }^{24}$ See chapter four for examples involving Angel and Spike.

${ }^{25}$ It is not a coincidence that she meets Tara in the following episode and they are a couple until "Tabula Rasa." This lapse in time between spells that hurt the Scoobies suggests that it is Tara's role as a magical mentor and moral compass that prevents Willow's dangerous spells.
} 
be seen as doubles. ${ }^{26}$ In "Something Blue" Giles warns Willow against doing spells when she's grieving and her energy is unfocused, marking one of several encounters between Giles and Willow on the subject of magic. One of the first references is in "Enemies" (3.17), when Willow tells Buffy that ascension is mentioned in a text Giles keeps hidden because it has "magic secrets Giles doesn't think I'm ready for."

The conflict between Giles' parental control and Willow's increasingly independent use of her magical abilities is explored early in season six. Following Buffy's death, Giles leaves Sunnydale in "Bargaining, Pt. 1" (6.01). It is clear that the other Scoobies - Willow, Tara, Xander and Anya - have been waiting for Giles to leave before attempting to resurrect Buffy. This is the first indication that Willow, who is the de-facto leader and spell caster, knows what she is doing is dangerous and irresponsible, or else she would have consulted Giles. ${ }^{27}$ These ideas are expanded on when the ritual echoes the spell from "Becoming, Part 2," only with increased violence: Willow smears doe's blood on her cheeks and forehead; unseen forces slash her arms, she expels a snake from her mouth and is engulfed in fiery red light that looks like flames. When demon bikers destroy a sacred, irreplaceable urn that is key to the spell, Willow emits a terrible scream, several octaves lower than her regular speaking voice (one that she will use again following Tara's death in "Seeing Red").

Giles returns in "Flooded" (6.04), for a showdown with Willow. ${ }^{28}$ The argument is important because it is the first time that Willow threatens Giles after he scolds her.

\footnotetext{
${ }^{26}$ Wilcox suggests that Willow and Faith are both doubles of Buffy, but on opposite ends: Faith represents a lack of control whereas Willow is associated with a dangerous desire for control. Buffy is somewhere in the middle. (Why, 49)

${ }^{27}$ It also echoes Giles' comments to Buffy when she keeps Angel's return secret until "Revelations," suggesting once again that Buffy and Willow's narratives mirror each other.

${ }^{28}$ See Appendix I for full transcript.
} 
This is a more adult refute to those she has given in the past (when she would apologize), suggesting that her self-esteem is tied to her ever-increasing powers:

Giles: You were lucky.

Willow: I wasn't lucky. I was amazing. And how would you know? You weren't even there.

Giles: If I had been, I'd have bloody well stopped you. The magics you channeled are more ferocious and primal than anything you can hope to understand and you are lucky to be alive, you rank, arrogant amateur!

(He goes to leave)

Willow: You're right.

(Giles stops)

Willow (con't): The magics I used are very powerful. I'm very powerful, and maybe it's not such a good idea for you to piss me off.

The body language between Giles and Willow is significant, as Kevin Johns notes:

Willow moves from a passive sitting position to a more active standing position, while Giles gradually moves towards the doorway and into the shadows, as though in retreat. By the end of the scene, Willow has solidified her position of dominance.

In this way Willow demonstrates that she is no longer the book-shy girl that Giles once influenced in the Sunnydale High library; instead she has become a mature woman with powers that far exceed his own.

At this point Giles is the only one who recognizes the dangerous procedure that Willow undertook to resuscitate Buffy. It is not until Willow crashes a car with Dawn inside that both Buffy and Willow realize that she needs help. The problem is that Buffy doesn't understand how magic works - she simply accepts that Willow has a talent for it and asks that it be used when she needs support. At the end of "Wrecked," Buffy tells Willow she doesn't understand, "why you'd go to see somebody like Rack"29 in an accusatory tone that suggests she doesn't understand Willow's magic addiction. When she asks if Willow lost control "because of Tara" she proves she doesn't know the reasons behind Tara's departure (Willow's excessive use of magic) or its effect on

\footnotetext{
${ }^{29}$ Rack is the magic dealer who takes an interest in Willow because she is so powerful.
} 
Willow (who has been partying on magic non-stop since the break-up). In this way, Buffy's simplistic explanation that Willow's behaviour is "because of Tara" demonstrates her inability to identify with Willow's suffering (for Tara, for injuring Dawn, for being unable to control herself) just as in "Something Blue." Her comments also suggest that she remains unable to relate to humans following her resurrection. It is hardly surprising then, that when Willow does become Dark Willow, Buffy is not the one who helps her.

Despite appearing in only three episodes, Dark Willow is one of the most memorable Big Bads because of the impact she has on the Scooby gang. Unlike the other villains, even Faith and Angelus, Willow is an integral part of the group and has been a member of the core foursome since the very first episode. Jes Battis believes that it is Willow's role within the Scooby gang - her function as an information resource - that makes her threatening:

Because she serves as an information system, and as a repository of magical power, her transition from ally to adversary is all the more threatening. It is Willow's magic that enables Buffy to fight cybernetic Adam via the enjoining spell [...] That same magic is the only weapon capable of weakening Glory, and the only power against which Buffy's own strength cannot contend. Willow has proven herself to be Buffy's surrogate sister, the twin to Xander's "big brother" identity that Buffy herself hints at in "Restless" (4.22). Yet she is also the sole force capable of defeating the Slayer - capable, as well of annihilating her family, and with them the world (31-32).

As indicated above, Willow's transformation from good to evil is physically manifested by a change in appearance. On the show, invocations of magic are accompanied by a change in eye colour (the "enjoining" spell in "Primeval," 4.21, turns Buffy's eyes gold), and dark magic spells turn Willow's eyes completely black. Interestingly, the episodes when Willow visits Rack to get 'high' ("Smashed," 6.09; "Wrecked") also turn her eyes black, suggesting that Rack peddles black magic. It is key that Willow's eyes colour changes in these episodes are inspired by the "high" of the 
magic, whereas in "Seeing Red" it is due to Willow's own will. This is only the second time she has influenced her own eye colour change in the series. The first is "Tough Love" (5.19), when Glory mind-sucks Tara, prompting Willow's ransacking of the Magic Shop's dark arts section. The episode associates Buffy and Willow as mirror characters because Willow's powers are tied to her emotions like Buffy, but, more importantly, demonstrates Buffy's inability to relate to Willow as a friend. While arguments can be made that Buffy is not sympathetic to Willow's situation in "Wrecked" because of her resurrection, the same circumstances occur and inspire the same reaction from Buffy one season earlier in "Tough Love."

Here Buffy tries to reason with Willow not to attack Glory because it is suicide. Her rational argument does not appeal to Willow, who is in a state of grief and rage. As Spike tells Buffy, "So you're saying that a powerful and mightily pissed-off witch was plannin' on goin' and spillin' herself a few pints of god blood until you, what explained?" It is interesting then, that when Spike was kidnapped in the previous episode "Intervention" (5.18) Buffy immediately mounted a cavalry and risked facing Glory to rescue him. Coincidentally Buffy kisses Spike for the first time without being prompted by a spell in the same episode. ${ }^{30}$ It is clear from the way that Buffy reacts to Spike's capture in "Intervention" and the way she addresses Willow in "Tough Love" that she does not condone emotionally-fueled reactions unless they are her own, suggesting that Buffy is allowed to act a certain way when someone she loves is in danger, but her friends are not.

\footnotetext{
${ }^{30}$ See chapter four - Spike - for an examination of this relevance of this episode in the Buffy-Spike relationship.
} 
This double-standard, as well as Willow's actions in "Tough Love," foreshadow the events of "Villains" (6.20). Just as she failed to make rational decisions following Tara's attack, Willow completely shuts herself off emotionally after Tara's death. In this way her transformation into Dark Willow mirrors Buffy's conflict throughout season six. Following Tara's death, Willow embraces dark magic in order to avoid truly grieving for Tara - her actions are an attempt to deny her responsibility as a human being who has lost a lover. Buffy's physical relationship with Spike is an excuse to avoid rejoining the living world and rebuilding her human connections - it is easier to submit to him than face her responsibilities as a friend, sister, guardian and surrogate daughter. The difference is that Willow's decision to destroy the world stems from her sense of responsibility to end the suffering of its people, while Buffy's conflict denies her responsibilities as both the Slayer and Buffy because it primarily affects her.

This is demonstrated in "Villains" when Buffy explains that she "can't understand anything. Not what happened a-and not what you must be going through. Willow, if you do this, you let Warren destroy you, too." Buffy is trying to appeal to Willow's understanding of the supernatural world, suggesting that Tara died a human death and that she wants to prevent Willow from becoming like Faith. Buffy is trying to stop her friend from exacting vengeance, but she's approaching the situation with the rationale of the Slayer - she's not thinking about how she reacted emotionally when Angelus was killing her friends. Buffy expects Willow to adhere to the rules that guide her Slaying by letting the human laws deal with Warren, despite the fact that she neglects them when she feels emotional. In this way she is unable to separate her Slayer responsibilities and objectively interact with Dark Willow in her Buffy role as a friend. 
Although Buffy's need to be objective about Warren is a reflection of her Slayer side, she isn't approaching the situation the same way she would any other villain, either. She lacks a distinctive Slayer trait in her Dark Willow interactions: her punning. If one of Buffy's powers is the ability to laugh and poke fun at villains, then her treatment of Willow is different. Unlike other Big Bads, who face the physical and verbal wrath of the Slayer, Buffy does not interact with Willow in this way. ${ }^{31}$ So while Buffy "doesn't understand" the emotional support Willow needs from a friend, she doesn't adopt the amusingly adversarial position usually reserved for Big Bads, either. As a result Buffy is unsuccessful at performing her responsibilities as both Buffy and the Slayer in regard to Dark Willow.

Even when Buffy and Xander return home, she continues to reiterate her position, refusing to accept the emotional damage that Warren has done. Although Xander agrees that Willow should not act the way she is, he understands the injustice that has been done. He 'feels' for Willow. This is why when the climatic battle with the Big Bad occurs, it is not Buffy who saves Willow and the world, but Giles and Xander.

If Giles is the one who attempts to control Willow's maturation as a witch, then Xander is the one who forces Dark Willow to confront her human side. With the aid of Giles' magic-cocktail, designed to reawaken Willow's connection to the world, Xander is able to reach the girl he's known since childhood with his "yellow crayon" speech. Together it is Xander and Giles who become heroes in the moment that Buffy is

\footnotetext{
${ }^{31}$ This situation is repeated in "Selfless" (7.05), when Buffy decides to kill Anya when she wreaks vengeance on a fraternity. In the episode, Buffy is unable to approach Anya as a friend because she has killed humans, but she doesn't use her verbal wits either. She is ultimately unsuccessful at defeating Anya and the situation is only resolved when Anya's boss, d'Hoffryn, appears to mediate.
} 
powerless, trapped in a literal grave with Dawn. ${ }^{32}$ Just as Buffy is unable to fight Willow - the only Big Bad she does not battle - it is only Giles and Xander who can save the day, as Battis explains in this lengthy passage:

It is the Coven's stolen power that taps into Willow's "spark of humanity," allowing Xander's own speech act to penetrate her. What might seem terribly hackneyed (good triumphs over the corrupted soul) is made interesting by the profound ambivalence of the situation. For Willow attempts to destroy the world not out of villainous, moustache-twirling ire - or because she feels betrayed by a world that falsely imagines her and renders her an outcast - but because she wants to annihilate human suffering. Her connection to the source of all magic allows her to experience a terrifying collectivity of earthly pain, anger and despair, the depth of which she cannot withstand. And she could not experience this without Giles' "gift" of the Coven's power. Thus, the emotional event that drives her to extinguish all human life is the same event that allows Xander to reach her, and foster her dying "spark" of individuality (40).

It is important that the season end on a note of ambiguity (Buffy and Willow do not see each other before Willow goes to England) because the problems in their relationship remain unresolved. By not addressing Buffy's failure as a friend or her inability to defeat Dark Willow, these problems are allowed to continue in season seven. This is demonstrated throughout the season, when Willow's magic is treated as a weapon that Buffy cannot use because of Willow's fear of the losing control. Willow's fears echo her initial attempt to stop her magical dependency after "Wrecked" and are justified in "Bring on the Night" (7.10) when the spirit of the First briefly possesses her. From this moment on, Willow is afraid to use her magic against the First, effectively reducing her to a powerful bystander.

This situation is unacceptable to Buffy, which she makes clear in her "everyone sucks but me" speech in "Get It Done" (7.15). In her initial monologue, Buffy tells the

\footnotetext{
${ }^{32}$ In this way Willow once again helps Buffy by transporting her into the underground grave. Buffy's sixth season journey began with her resurrection when she clawed her way out of the ground, but she pines for its return for most of the season. When, in "Grave," she is faced with dying once again, she learns the value of life and decides to embrace it, promising Dawn she doesn't want to protect her from it, but show it to her.
} 
group, "I've been carrying you - all of you - too far, too long. Ride's over." When Kennedy tries to confront her and Willow intervenes, the camera focuses on looks that pass between Buffy and Willow. Afterwards, Buffy tells Kennedy, "You're new here, and you're wrong because I use the power that I have." When she says the line, she is looking in the same place and direction - at Willow. The previous eyeline matches between the two girls suggests that Buffy is critiquing Willow for not "using [her] power."

It is significant that she identifies Willow as one of people who have contributed the least. After examining season six, when Buffy is revealed as an ineffective friend and Slayer in the events concerning Dark Willow, her speech in "Get It Done" suggests an attempt to erase the past and return the relationship to its pre-Dark Willow status. Essentially Buffy has returned to her previous position: using Willow's powers as a weapon, even though Willow's refusal to use magic reflects her increased responsibility since she is afraid of injuring people. Buffy's ignorance of this suggests that, by failing to defeat Dark Willow, she has not learned from the experience. The relationship between Buffy and Willow remains static and unchanging, insinuating that Buffy's life is only altered by the Big Bads that she vanquishes herself. ${ }^{33}$

This is made all the more clear when Buffy jumps into its portal later in "Get It Done." Her actions are rash considering the group has no idea how they will get her back. Although Buffy's answer, "Find a way," is directed to the entire group, it is intended for Willow since she alone has the magical skills required to re-open the portal. In this way Buffy has put the responsibility on Willow for her return, even though the rest of the

\footnotetext{
${ }^{33}$ Interestingly Buffy reacts similarly to Andrew, the sole remaining Trio of Nerds member. She continues to treat him as a juvenile geek and rarely includes him as a valued member of the group, despite his willingness to die for the cause in "Chosen."
} 
group recognizes that re-opening the portal could "[send] Willow over the deep end." Willow's acceptance of the situation, "I've gotta get her back" (emphasis added) relegates her to a position of passivity, in that she allows Buffy to dictate her role in the group as that of spell-caster. And while this is the situation that prompts Willow's return to full-fledged magic, there is a clear indication in the narrative that the magic can still adversely affect her recovery when she temporarily turns back into Dark Willow: her eyes go black and her scream is reminiscent of "Villains" and "Bring on the Night."

The problems in Buffy and Willow's relationship have dangerous implications when Buffy places the entire offensive on Willow in the series finale. The spell to transfer Buffy's powers returns their relationship to the times before Dark Willow: Buffy asks her friend to perform a spell that will determine the entire outcome of the battle, and Willow fails to inform her that she fears that the spell will turn her evil. As she tells Kennedy the night before the battle, "The darkest place I've ever been - this is what lies beyond that."

Although the outcome of these choices favour Buffy (as always), the fact that she neglects to consider Willow's hesitation suggests that Buffy has learned very little from her experiences with Dark Willow. The lack of resolution and climatic battle between Buffy and Dark Willow enables their previous relationship to continue unabated. That such a relationship is marked by Buffy's indifference to Willow's responsibilities (to continue becoming a powerful witch and to use restraint in order to prevent another evil transformation) indicates that her friendship with Willow comes second to her use of Willow's magical abilities as weapons. 
Additionally, Willow's magic addiction in season six parallels Buffy's relationship with Spike in order to demonstrate how Buffy's sexual relationships deny her responsibilities. Her interactions with Dark Willow reflect this lack of responsibility as Buffy is unable to negotiate a balance between her responsibilities as a friend or as the Slayer. This is made clear in her failure to talk Willow out of committing evil acts, as well as her inability to physically defeat her in a climatic battle. As such, while Dark Willow helps Buffy to recognize the value of life by forcing her to realize her responsibility to save Dawn, Buffy in turn, does nothing to help Willow when she truly needs help. It is for this reason that Dark Willow is unique among Big Bads. 


\section{Chapter 4 \\ "Every Slayer Has A Death Wish": \\ The Influence of Buffy's 'Bad Boys'}

This final chapter will continue to examine personalized villains by focusing on Buffy's romantic and sexual relationships with Angel and Spike. If the previous chapter, involving Faith and Dark Willow, was an analysis of friendships gone bad, then this chapter examines the consequences of love gone bad. If Faith affects Buffy like a dark sister, illustrating the importance of properly balancing responsibility and ties to the real world, and Willow illustrates Buffy's inability to rectify her two halves when a friend becomes a villain, then Angel and Spike affect her ability to function as the Slayer because her judgment is impaired by her love for the "bad boys."

Although Faith's relationship with Buffy has been analyzed as an example of lesbian jealousy, ${ }^{34}$ and at least one essay examines why the show denies such a relationship between Buffy and Willow, ${ }^{35}$ the female personalized Big Bads do not affect Buffy romantically. Whereas Faith acts as a catalyst for problems in Buffy's relationships, Angel and Spike are the ones responsible for Buffy's "clouded judgment." Buffy's inability to battle Angelus in the second season stems from her lingering love for Angel and suggests a denial of her responsibility as a vampire Slayer that has disastrous consequences. The fact that sex with Angel is tied to death - be it the deaths he cultivates as Angelus or hers when he feeds on her - finally forces the end of their relationship. However, her relationship with Spike is tied to the same elements and leads to the same results: she is so concerned with Spike that she fails to perform her Buffy role for

\footnotetext{
${ }^{34}$ Kaveney suggests that Faith's actions echo Angel's in "Surprise": "the attempt to leave town on a freighter, the fight against overwhelming odds on the docks" (19).

${ }^{35}$ Farah Mendelson's 'Surpassing the Love of Vampires; or, Why (and How) a Queer Reading of the Buffy/Willow Relationship is Denied' in Fighting the Forces.
} 
Willow, prompting the creation of season six's Big Bad. It is only when Buffy disavows a sexual relationship with Spike that she is able to balance her dual roles and accept her responsibility as a leader. In doing so, she creates an opportunity in which she can finally be freed from her duties as a Slayer. The fact that neither Angel nor Spike is there for her in the end suggests that it is only once the burden of romantic relationships have been lifted that Buffy is able to rectify her situation as the Slayer and begin a normal life.

Angelus and Spike's function as Big Bads, then, is to demonstrate Buffy's inability to fulfill her responsibilities as a Slayer because of her Buffy desires when she is in a relationship - be it sexual, romantic or both. From the very first episode, Buffy's comments about living a 'normal' life include boys. She desperately pleads with Giles to let her go on a date in "Never Kill a Boy on the First Date" (1.05), one that will mark her sole 'official' romantic venture in the first season. Cordelia encourages her to experience the thrill of University boys in "Reptile Boy" (2.02), and she pursues, in Willow's words, a "normal" boy (Scott Hope) in the early episodes of season three. Even when she acquires mind reading powers in "Earshot" (3.19) she pauses in the hallway when she hears a boy thinking about her body in a complimentary way. When it comes to thinking about boys and sex, Buffy's desires are presented as those of a normal teenage girl.

It is her status as the Slayer that prevents her from pursuing a regular boyfriend, as Giles notes in "Never Kill a Boy on the First Date." By allowing someone to get close to her, she risks revealing her secret, which is dangerous for her, the other Scoobies and the boy. This is demonstrated when Owen is nearly killed by religious vampire Andrew Borba at the crematorium. The narrative suggestion is that Buffy can only date individuals that can accept her calling and accommodate the situations that accompany it. 
This narrows the list down to three men: Angel, Riley and Spike. Riley can handle Buffy's secret identity because, as a member of the Initiative, he also has one. Angel and Spike can handle it because as vampires they already know who she is. Additionally, all three are physically capable of defending themselves, thereby avoiding the "boyfriend in distress' category that befalls Owen.

There are several important differences between Riley and Buffy's vampire boyfriends, however. Although Riley is an important character in Buffy's life in seasons four and five, he doesn't fulfill all of Buffy's boyfriend requirements. This is demonstrated in "Something Blue" (4.09) when she talks about how "something's missing" in their relationship, later elaborating that he is not a "bad boy." The problems continue in early season five episodes when she begins patrolling after their sexual encounters, which suggests that their sexual encounters are not enough to satisfy her. When Riley comes to the same realization, he leaves Sunnydale in "Into the Woods" (5.10).

In contrast to her bland relationship with Riley, Buffy's relationships with Angel and Spike are full of passion, mystery and distrust. As she insinuates in "Something Blue," Buffy is only truly satisfied when the men she dates are "making [her] miserable," because they are "bad boys." And despite the fact she claims she wants to get away from "someone who will cause me heartache," she continually turns to the bad boys for relationships because she is drawn to their darkness - their association with death, power and sex. ${ }^{36}$

\footnotetext{
${ }^{36}$ See footnote 76 about the relationship between Sartre's visqueux - the temptation of sex - and Buffy's duties as a Slayer. Since visqueux is a sort of death, it embodies both of Buffy's desires. Her relationships afford her an opportunity to be materialistic (putting her own desires first), indulge in her sexual urges and fulfill her Slayer death wish, all of which distract her from her responsibilities as the Slayer.
} 
This link between sex and death and its association with the Slayer is key for understanding Buffy's romantic relationships with men. While these parallels have been drawn by a number of academics, ${ }^{37}$ these examinations are not done in conjunction with an analysis of the role her relationships have on her responsibilities.

Chapter four will analyze the impact of Buffy's romantic relationships and how they disassociate the girl from the Slayer. It is the feelings of the normal girl - the Buffy - that allows these creatures to live long enough to be redeemed, but it is also her normal girl side who must contend with the consequences when innocents are injured, killed or turned into vampires. The result of Buffy's sexual attraction to death (Angel and Spike) ties her to a long line of Slayers with death wishes, and produces a Slayer whose emotions may give her power. At the same time, her Buffy desires ultimately blind her to the responsibilities her roles demand, be they Slayer or Buffy. In this way, Buffy's prioritization of her sexual/romantic relationships is the best example of the unhealthy mix of girl (Buffy) sexual desires and Slayer death wish. This combination ultimately puts not only the world and her friends' lives in jeopardy, but her own life as well.

Angel's association with death, darkness and prophecy are made clear early in the show. Krimmer \& Raval note that his season one appearances coincide with the Master's attacks, starting with "Welcome to the Hellmouth" (1.01). Angel is first glimpsed as a pair of feet, shot at ground level, following Buffy as she makes her way to The Bronze. When she leads him into an alleyway and attacks him, one of her first questions to him is, "Why are you following me?" Her question, as well as his introduction as an unknown figure stalking a young woman, connotes threatening behaviour. Later, Buffy describes

\footnotetext{
${ }^{37}$ DeKelb-Rittenhouse's 'Sex and the Single Vampire'; Krimmer \& Raval's 'Digging the Undead.' Both in Fighting the Forces.
} 
Angel as "dark, gorgeous in an annoying sort of way." Her comments make it clear that Buffy finds him attractive, despite his hostile actions and antagonistic mannerisms ("Is there a problem, ma'am?"; "I thought you'd be taller").

When Angel reappears in "The Harvest" (1.02) the two continue their flirtatious banter. The fact that their second conversation takes place in a crypt foreshadows the principal locations that are associated with their romance: graveyards, crypts, and abandoned mansions, all settings of death and decay. Krimmer \& Raval explain that "Given the omnipresence of death, it is not surprising that the cemetery is the locus not only of Buffy and Angel's formal introduction ("The Harvest"), but also of many of their most passionate kissing sessions" (154).

By the time they become physically romantic in "Angel" (1.07), the precedent is set. Their first kiss occurs "after barely escaping the attack of the Three, warrior vampires sent by the Master" while their "second kiss follows the confrontation with Darla in which Angel saves Buffy's life by staking his sire and former lover" (Krimmer \& Raval, 154). The first kiss is significant because Angel's nature as a vampire is revealed when his passion unleashes his true visage. Initially Buffy shrugs off her attraction to him in order to do her job as Slayer. She packs weapons and goes to meet him at the Bronze, but at the end of their confrontation finds that she cannot shoot him with the crossbow.

Her inability to kill him stems from her dual attraction to him. Her Buffy side desires a boyfriend, while her Slayer death wish attracts her because he is a vampire. In this way, her Buffy feelings are mixed-up with her Slayer desire to die, the result of which is that she spares Angel's life. This enables him to demonstrate the effects of his love by killing Darla, his old girlfriend, thereby linking romance with death. The 
romantic gestures that comprise the Buffy-Angel relationship seem inevitably tied to death, as when they go ice skating, kill an assassin and promptly make out in "What's My Line, Part 1" (2.10).

In these first season episodes, Buffy synonymously equates her Slaying not only to the demons and vampires she kills, but with her attraction to Angel. He shows up to physically aid the group, or provides Giles with warnings such as the one about Buffy's death in "Prophecy Girl" (1.12). It is significant that after hearing she will die facing the Master, Buffy rejects her calling by ripping off the cross necklace Angel gave her in "Angel" and throws it away. When she decides to fight the Master, she returns to the library to put the cross back on. Its significance is highlighted by her low-cut dress which amply displays the cross against her skin, suggesting that the reaffirmation of her role as Slayer is a return to Angel's love and protection. It is ironic, then, that the very symbol of their love is also the one that repels his kind and physically burns his skin (as it does when they kiss at the end of "Angel"). In this way the cross represents the unspoken difference between them and suggests the main obstacle in their relationship: she is a Slayer and he is a vampire, enemies who are meant to kill each other.

In this way their very existence is in opposition to one another. As the Slayer, Buffy is isolated and alone - she is the only one of her kind. Angel, and all vampires for that matter, has endless reproductive abilities by siring his victims (turning them into vampires). In this way, a vampire is never alone or isolated. Additionally, her responsibility is to save the living from death by protecting them from vampires, whose reproductive capabilities create living beings from the dead. In this way, the Slayer has a 
more masculine identity while the vampire is feminine, which contradicts the fact that she is a girl in love with a boy. As a result, vampires and Slayer stand opposed.

The only reason Angel is treated any differently is because of his soul, which transforms him into a vampire with a conscience. Buffy knows that Angel will not drink human blood, and, by extension, he will never sire a vampire because of the guilt he feels for his previous crimes. It is the "human" elements that enable Buffy to overlook their opposing statuses, but despite the differences from others of his kind, Angel remains a vampire. As a result, their very nature makes their relationship impossible. This is made apparent after Buffy's death in "Prophecy Girl," when Angel has no breath to perform CPR. His status as undead, while not detrimental to their feelings of love, cannot ultimately save her when her life depends on him.

Buffy uses this as a weapon against him as she tries to come to grips with the circumstances surrounding her death. "I've moved on...to the living," she tells him in "When She Was Bad" (2.01). Despite her statement, at the end of the episode, when Buffy needs consoling after smashing the Master's bones, it is Angel who holds her as she cries. Just as a teenager looks for support from a boyfriend, so too does Buffy turn to her lover when circumstances get tough. As a result, she remains fiercely protective of their relationship, especially when it is threatened. Herein lies the problem, since the narrative clearly demonstrates that Buffy's love causes her to deny her responsibilities as a Slayer and put Angel first when he is threatened, while at the same time it is her Slayerness that makes her attracted to him.

In "What's My Line, Part 1 \& 2" (2.10-2.11), Spike hires a group of assassins called the Order of Taraka to keep Buffy busy while he prepares a ritual to restore the 
health of his vampire girlfriend, Drusilla. After Giles makes it clear how deadly the assassins are, Buffy immediately leaves school and hides at Angel's house for protection. When, in Part 2, Giles uncovers Spike's plans to use Angel in the ritual, Buffy angrily tells the group, "Spike is going down. You can attack me, you can send assassins after me - that's fine. But nobody messes with my boyfriend." The line is comical considering how seriously Buffy treated the Order's assassins in the previous episode, but her remarks are also incredibly truthful. After it becomes clear that Spike has already captured Angel, Buffy immediately wants to spring into action. Since Kendra has been taught with the Slayer Handbook (something Giles realized would not be useful for Buffy after he met her), the second Slayer doesn't understand Buffy's willingness to save a vampire. The following exchange at Willie's bar reinforces Buffy's selective treatment of her vampire boyfriend and the conflicting attitudes that Kendra carries, which are endorsed by the Watcher's Council:

Kendra: First we must return to the Watcher.

Buffy: Excuse me? While we run to Giles, this whole thing could go down.

Kendra: But it is procedure.

Buffy: It's brainless, you mean! If we don't go now, Angel could die.

Kendra: Is that all you're worried about? Your boyfriend?

Buffy: No, it's not all, but it's enough.

Kendra: It's as I feared. He clouds your judgment. We can't stop this ritual alone.

Buffy: Are you listening to me? He could die!

Kendra: He's a vampire. He should die. Why am I the only person who sees it?

(Buffy shakes her head in disbelief and walks away)

Kendra (con't): Are you that big a fool? Good riddance, then.

The interaction between the two girls is telling. Even though Kendra makes a strong argument for returning to Giles, formulating a plan and getting back-up, Buffy cannot entertain an option where Angel could die. Just as Kendra suggests, he clouds her judgment. For Buffy, though, this is a good thing. An earlier conversation between the two Slayers in Giles' office suggests that Buffy uses her emotions to give her power, 
which is the reason she does so well in battle. Kendra does not understand this principal because she does not have personal connections. ${ }^{38}$ In contrast, Buffy has ties because of her family and friends, although it is her romantic connection to Angel that truly empowers her.

Earlier in Part 1, she tells Angel, 'You're the one freaky thing in my freaky world that still makes sense to me" and later, in "Bad Eggs" (2.12) she tells him that, "When I look into the future, all I see is you." These lines are important because they suggest that, despite her other ties, it is Angel that she values the most. No matter what the Slayer Handbook says about vampires, Buffy feels differently about Angel because she loves him ("Lie to Me," 2.07) and will do anything she can to protect him.

The other motivating factor Buffy speaks of in her conversation with Kendra (what worries her) is also potentially tied to Angel. Although it may refer to her Career Week choices, Buffy's worries may also include the restoration of Drusilla's health. Ever since she spied the Victorian girl talking to Angel in "Lie to Me," Buffy has been threatened by her presence. Although Giles explains in "What's My Line" that her insanity would make her a dangerous foe, it is clear that Buffy is less concerned about the rise of a dangerous foe than about having one of Angel's old girlfriends living nearby. This is especially true after she learns the details about what Angel did to Drusilla before turning her. ${ }^{39}$

The events of "What's My Line, Part 2" demonstrate the power of Buffy's love for Angel and the strength those emotions provide her in battle. They can also be

\footnotetext{
${ }^{38}$ She explains in the episode that her parents sent her to her Watchers when she was young and she barely remembers them.

${ }^{39}$ Both facts - her jealousy of Drusilla and the way Angel treated her - foreshadow Angelus' actions later in the season: he tortures Buffy with the same methods he used on Drusilla and it is insinuated that he begins sleeping with Drusilla again.
} 
associated with a Slayer's attraction to death. While Buffy is sexually attracted to Angel, and, by extension, death (because of his vampirism), her attempts to prevent the ritual demonstrate that her feelings cause her to react irrationally. Her decision to immediately rescue Angel fails when the Order of Taraka assassins capture her and it is only when Kendra and the other Scoobies appear that Buffy is able to hold her own. This suggests that Kendra's plan to get help (strength in numbers) was the correct choice.

Additionally, Buffy's actions foreshadow Faith's in "Bad Girls" - by running head on into danger Buffy overlooks her responsibility to protect herself from harm. As the Slayer, Buffy has a larger responsibility to remain alive in order to protect the community, one which she denies in her desperation to save her lover. Her love-clouded judgment nearly results in her own untimely demise, tying together her attraction to death with her love for Angel.

Krimmer \& Raval's beliefs regarding Buffy and Angel's relationship - that "their desire for each other originates in, and is intensified by, the imminence of death" (154) is demonstrated again in "Surprise" (2.13). Buffy's streak of horrible birthdays enters its second year when Drusilla and Spike unveil The Judge, a demon who feeds on the humanity in others. In attempting to prevent the Judge's assembly, Buffy and Angel are forced to take shelter in his apartment and finally consummate their romance (Buffy loses her virginity). When "Innocence" begins immediately thereafter, it is clear that Angel has lost his soul. His transformation is made clear not only by his change in vocal performance (which is more condescending and cocky), but also in his release of a cloud of smoke (from the prostitute he bites in the teaser). Jes Battis explains:

It is valid to observe that a character's shift from good to evil (usually rounded out by a return to good) on the show is sometimes clearly marked. As Krywinska notes, "'bad' 
Willow's black lipstick and leather or Angel's smoking and cruel laughter, indicate their changed personas" (28).

Since only Angelus smokes, the visual cue is an effective means of indicating that Angel is no longer good. The truth about his transformation is revealed to the audience in a later scene when he visits Spike and Drusilla. The fully assembled Judge informs them that he cannot be burned because "there's no humanity in him" to which Angelus tells Drusilla "Yeah, baby, I'm back." The dialogue is implicitly similar to Spike's, who uses words such as 'love,' and 'pet' when he speaks to Drusilla. Angelus' speech patterns therefore code him as evil, while simultaneously insinuating his amorous relationship with Drusilla.

His transformation is kept from Buffy until later in the episode so that it appears as though he has simply vanished after they made love. When she tracks him down at his apartment, he mocks her: ${ }^{40}$

Angel: You got a lot to learn about men, kiddo. Although I guess you proved that last night. Buffy: What are you saying? Angel: Let's not make an issue out of it, OK? In fact, let's not talk about it at all. It happened. Buffy: I don't understand. (pause) Was it...me? Was I not good? Angel (laughs): You were great. Really. I thought you were a pro.

It is clear in this scene that her love for Angel "clouds her judgment" because she is unaware of the danger she is in. Giles tells Buffy in the pilot episode that she should be able to use her Slayer skills to detect threats (as she does in "No Place Like Home," 5.05, when Glory attempts to sneak up on her). Her Slayer abilities have often been confused around Angel because of her romantic feelings ("Angel"), and "Innocence" proves this when Buffy fails to notice Angel has lost his soul and transformed into the evil Angelus.

This is because she is not interpreting his actions in terms of his evil transformation, but as an 'evil male' who is breaking her seventeen year old heart. Buffy

\footnotetext{
${ }^{40}$ See Appendix $\mathrm{J}$ for full transcript.
} 
later associates Parker's post-coital behaviour similarly ("Does this always happen? Sleep with a guy and he goes all evil?"). Although it is clear that she realizes there are limitations to her relationship with Angel, such as a lack of "little vampires" in their future ("Bad Eggs"), by associating Parker with Angel there is a suggestion that Buffy does not truly think of Angel as a vampire. Instead, she thinks of them as a couple, and treats him not as a threat, but as a boyfriend.

Their conversation proves that Buffy is not the Slayer when she is with Angel because she is too busy being Buffy, indulging in her romantic ideals. ${ }^{41}$ At the same time, her Slayerness is central to the death-wish attraction. When Spike speaks to Buffy like Angelus $^{42}$ in "Harsh Light of Day" (4.03), she beats him up. The suggestion is that Buffy will not suffer comments from people she is not in love with. In "Innocence," Buffy allows Angelus to treat her poorly because she is in love with him, and her tears are an indication of her level of emotional attachment. This human reaction simultaneously demonstrates that when it comes to Angel, Buffy's romantic idealism puts her in danger and, by extension, all those she is responsible to protect.

The end of "Innocence" is interesting because Buffy attempts to reconcile her Slayer duties when she faces Angelus for the first time since their conversation in his apartment:

When Buffy faces Angelus in the shopping Mall...she tells him that she is prepared to kill him because he isn't really Angel. He undermines her confidence by questioning "You'd like to think that wouldn't you?"' In fact, he continually asserts that he is Angel, but Angel released from the shackles of humanity, i.e. conscience and love. Like the other vampires, Angelus' personality as a vampire is defined by who he was as a human. He continues to dislike Spike and mock Xander and his obsession with Buffy is equal to his love for her (Abott, Slayage 3)

\footnotetext{
${ }^{41}$ Once again indicative of Sartre's visqueux - the hero forgets her duties when tempted with sex.

${ }^{42} \mathrm{He}$ asks her, "What exactly did it take to pry apart the Slayer's dimpled knees?"
} 
In fact, several academics, such as Kaveney and Krimmer \& Raval, associate Angelus' torment of Buffy as an expression of retaliation for the love she made him feel as Angel.

Kaveney explains that

Angelus hates her because she is what his ensouled self loved, and determines to destroy her a little at a time, just as he did Drusilla in the days when she was still human, eventually deciding to destroy the world primarily as a piece of spite against her (17).

These sentiments are echoed by Krimmer \& Raval, who believe

For Angelus, the desire to love merges with the desire to kill. He himself gives expression to this twisted conflation when he tells Spike that "to kill this girl [Buffy], you have to love her" ("Innocence"). The intensity of Angel's passion for Buffy survives in Angelus' obsession with tormenting her. Sending Buffy red roses in a black box with a death threat for Valentine's Day ("Bewitched, Bothered and Bewildered," 2.16), Angelus reverts to his former habits of "wooing" women by threatening and killing their families and friends (155-156).

In this way, Buffy's sexual attraction to death is echoed by Angelus' tactics, which focus on bridging love and death with his "wooing” habits. Just as Buffy's emotions prevent her killing of Angelus because of her feelings for Angel, Angelus acts the way he does because of his 'feelings' for her.

It is only after the events of the following episodes when he 'turns' a classmate ("Phases," 2.15), and kills Jenny Calendar ("Passion," 2.17) that Buffy finally resolves to kill him. Jenny's death is the "brutal act [that] forces Buffy to acknowledge the destructive implications of her passion and strengthens her resolve to kill Angelus" (Krimmer \& Raval, 156). Her death and the pain it causes Giles allows Buffy to recognize that her inability to overcome her Buffy feelings compromise her Slayer responsibilities to protect people like Jenny. But because of her Slayer death-wish, it remains impossible for Buffy to date a normal guy, so it is both Buffy sides that are to blame for Jenny's death. 
Although "I Only Have Eyes For You" (2.19) initially appears unrelated to the seasonal arc between Buffy and Angel/Angelus, it is important because the denouement of the episode provides a cathartic resolution for Buffy. In acting out the ghosts' reconciliation, Buffy and Angelus share a moment of romance that allows Buffy to satisfy her continued romantic feelings for Angel and recognize that Angelus is not the man she loved. Buffy finally admits to herself that her boyfriend is gone and that she has a responsibility to kill Angelus, even if he is simply a darker variation of Angel. The kiss satisfies her Buffy desires for reconciliation with her lost love, and allows her Slayer self to move forward with what must be done for the good of the people...before Angelus destroys the world.

The attempted apocalypse of "Becoming, Parts $1 \& 2$ " (2.21-2.22) demonstrates that the second season structure follows a similar pattern to the one established in the first season. Just as Buffy's battles with the Master grow in severity as the season progresses, the stakes in the Buffy-Angelus battle rise with each successive episode. The discovery of Jenny's disc coincides with the discovery of the demon Acathla, thereby collapsing the season's storylines into a single timeline: the Scoobies must activate the curse and restore Angel's soul before he can awaken Acathla.

At the start of the finale, power is divided between Buffy and Willow: Buffy acts as the distraction in an attempt to buy Willow enough time to perform the ritual. Following the events of the part one, Buffy realizes that she can no longer depend on anyone, but herself to stop Angelus. It is implied that in Part 1, Buffy still hoped that her romantic relationship with Angel could be salvaged by returning his soul. The attack on the library finally forces her to recognize that Angelus must be killed. It is at this point 
that Buffy assumes full responsibility and embraces her powers as the Slayer (considering she is associated with action, her role as diversion in the first half does not suit her Slayer skills). It is only when she accepts her responsibility to dispatch Angelus that the climatic battle between Slayer and Big Bad takes place.

Abbott believes that this climax is precipitated by Buffy's forced leadership throughout the episode. She explains that Buffy is forced to "detraditionalize herself" and assume the role of the leader because Giles has been captured. As a result she must make the decisions, "rescue Giles and face Angel on her own." Her solitary role as leader works in conjunction with her distinction as Slayer (which connotes aloneness), ${ }^{44}$ both of which play vitals role in the final battle. There is a point when it appears that Angelus will defeat Buffy, as he maneuvers her into a seated position in a corner of the terrace without a weapon. Abbott explains that Angelus' strategy is ineffective:

As Angel prepares to deliver what he thinks will be the fatal blow, he attempts to use her isolation against her by pointing out how everything she holds dear has been stripped away from her, "That's everything huh? No weapons, no friends, no hope. Take all that away and what's left?" to which she responds "Me" as she catches the blade between her two hands and turns the fight back on Angel. The process of seemingly stripping everything away from her has taken her to a new level in her power, given her the strength to "stand alone in the world" and brought her one step closer to independence and her true power (Slayage 3).

Angelus' comments are interesting in that he identifies her friends within the same parameters as weapons and hope. He recognizes the importance of having friends in her role as Slayer, which is ironic considering the battle scenes are cross-cut with scenes of Willow, Cordelia and Oz performing the curse. This suggests that Buffy is not alone and

\footnotetext{
${ }^{43}$ By this Abbott means abandoning traditional female roles such as passivity and group follower. By "detraditionalizing herself" Buffy becomes an active agent who makes her own plans and does not follow orders.

${ }_{44}$ Especially at this point, since she is symbolically the only remaining Slayer following Kendra's death in "Becoming, Part 1."
} 
is aptly demonstrated when, just as Buffy is about the deliver the killing blow, Angel's soul is returned.

This narrative development is extremely difficult for Buffy because of her duality: for the Buffy side, the love of her life has returned, while for the Slayer side, Angel's death is the only thing that can close the wormhole. Her decision to kill Angel is informed not only by the recognition of her responsibility as the Slayer to stop the impending apocalypse, but also in recognition of the suffering her Buffy side created by allowing innocent deaths. Ultimately she reconciles her two selves: she kisses her lover, then stabs him through the chest, killing him and closing the portal.

This reconciliation of dualities is not altogether productive, as the events of "Becoming" prove so damaging to her Buffy self that she once again disavows her Slayer responsibilities and runs away. There is a suggestion that the end of her relationship with Angel - his death at her hands - is as traumatic as her death at the Master's hands. Both events cause her to revoke her Slayer status and cause recurring flashbacks, as seen in "When She was Bad" and "Faith, Hope and Trick." It is only after Buffy confronts the fact that Angel returned to his normal self before she killed him that her suffering ends. At the end of "Faith, Hope and Trick," she is prepared to put their relationship behind her, which is visually suggested when she symbolically leaves his ring in the mansion, but this is the same moment that he reappears.

Angel's return from Hell causes significant problems for Buffy. She decides to keep it a secret because she is afraid that her friends will try to kill him, and also because she idealistically hopes for the return of her boyfriend. Despite knowing that they can never again consummate their relationship for fear of breaking the curse and, in spite of 
his activities as Angelus, Buffy holds out on the basis that she might once again have "the one thing that makes sense" in her freaky world. Not unlike her future interactions with Willow as a Big Bad, Buffy has not learned from her experiences with a personalized villain. As soon as Angel reappears, her Buffy side takes over and her responsibilities are compromised. This is insinuated in the Scoobies' comments about her distance, and when she plays Giles and Joyce off each other in order to spend time with Angel in "Band Candy" (3.06).

It is clear that Buffy understands that her actions are wrong because she lies. Her attempts to maintain her distance from Angel all meet with failure: she is driven to see him. Their tai-chi session in "Revelations" is filled with sensual undertones (especially prevalent in the pervasive Buffy-Angel theme music and the close-ups on his hands on her body as he guides her movements). Deep down, however, Buffy knows that the rules that govern their relationship have not changed, so when Angel explains in "Revelations" (3.07) that the Glove of Myneghon can never be taken off once it is put on, she replies, "So no touching. Just like us." Despite this statement, it is not long before the two begin kissing again. When they are seen by Xander, the Scoobies stage an intervention: ${ }^{45}$

Buffy: It was wrong, OK? I know that, and I know that it can't happen again. But you guys have to believe me. I would never put you in any danger. If I thought for a second that Angel was going to hurt anyone -

Xander: - you would stop him. Like you did last time with Ms. Calendar.

(Buffy looks at him, shocked)

Willow: Buffy. I feel that when it comes to Angel, you can't see straight. And that's why we're - we're all going to help you face this.

The Scoobies' concerns highlight their distrust of Buffy's ability to remain clearheaded around Angel. In addition to Willow's line "that when it comes to Angel, you can't see

\footnotetext{
${ }^{45}$ See Appendix K for full transcript.
} 
straight" (shades of Kendra's line about clouded judgment), Xander and Cordelia are both fearful that Buffy will give Angel "a happy" and the curse will be revoked.

Buffy's frustration at their intervention illustrates her competing desires: as the Slayer, she knows that Angel is harmless because he has a soul, but she secretly shares their concerns because she knows she has been unable to resist Angel's advances. The problem is that she fails to empathize with the reasons behind the intervention. She never stops to think about why her friends are scared of Angelus. Cordelia mentions his fondness for killing Buffy's friends, Xander mentions Jenny Calendar's death and Giles reminds her in his office immediately afterwards that he was brutally tortured by Angelus in "Becoming, Part 2." ${ }^{46}$ In this way it is clear that Buffy's feelings for Angel are more important than those for her friends because she refuses to acknowledge their concerns, no matter how warranted they are. It is only when Angel rescues Willow at episode's end that the concerns regarding another evil transformation are silenced, but this is in no way attributable to Buffy.

Instead she goes out of her way to protect her relationship by battling Faith, who has an obvious interest in him. She previously inquired about him while she and Buffy were on patrol, and Buffy's refusal to speak about him is partially attributable to Faith's attempt on his life. When the two Slayers battle, as previously discussed, there is little effort to communicate. It is because of Buffy's protection of Angel that the other Slayer lets Gwendolyn Post in and, as a result, Faith's ability to trust is destroyed. In this way, Buffy's actions have severe consequences: her desperation to preserve her relationship with Angel creates a personalized Big Bad in Faith.

\footnotetext{
${ }^{46}$ See Appendix L for full transcript.
} 
Concerns about the return of Angelus reemerge in "Enemies" when Faith believes she has stolen his soul. As mentioned earlier, one of Faith's functions as a personalized Big Bad is to play the romantic foil for Buffy's relationships. In "Enemies," Buffy's already conflicted reaction to Angel's act as Angelus is further complicated by the belief that she saw Faith and Angel kissing earlier. Although by episode's end, her Slayer side is satisfied with the information they have acquired about the Mayor, her Buffy side is unable to separate the role-playing from the torture tactics Angelus' employed the previous season. Her decision to call a break is simultaneously informed by her jealousy about the kiss and what may or may not have happened between him and Faith. Despite the fact that Buffy now has the information necessary to research the Mayor, thereby carrying out her responsibilities as a Slayer, Buffy is unable to overlook her feelings. This continues into the next episode, "Earshot," when she attempts to read Angel's mind.

This inability to focus on her responsibilities as a Slayer is once again clearly demonstrated in the season finale when Angel is poisoned just before the Mayor's ascension. Buffy spends all her time attempting to find a cure, which lends weight to Tjardes' belief that Faith, Buffy and Angel form the principal conflict of the season (75). As mentioned in chapter three's section on Faith, Buffy's actions are determined by her emotional desires, so her decisions to kill Faith and offer herself to Angel as a cure are not made in the interests of the community. ${ }^{47}$ It is the desires of the girl whose boyfriend is dying, not the Slayer, that drive "Graduation Day, Part 1" and the initial scenes of part two.

\footnotetext{
${ }^{47}$ This is a variation of the visqueux. If Buffy embraces her death wish (visqueux can be a sort of death) to preserve her romantic relationship - that is preserving Angel's safety - she submits to temptation by forgetting her responsibilities to protect the community from the Mayor's ascension.
} 
When Buffy allows Angel to bite her, it is the ultimate denial of her responsibilities as a Slayer. She knows that such an act can conceivably kill her, thereby leaving the graduating class to the mercy of the Mayor, but she goes forward with her decision anyways. The resulting scene carries connotations of Buffy's vampire bite from "Prophecy Girl" in the way that the camera focuses on the pain on her face and the trail of blood seeping from the wound. The suggestion is that saving Angel has the same consequences as facing the Master; namely that such an act is deadly. At the same time, however, Buffy's facial expressions eventually give way to pleasure and, in what Whedon describes in the audio-commentary as "not one of our deepest metaphors," the two fall horizontally onto the concrete in slow-motion, with Angel pressing down on Buffy in a deeply sexualized manner. In this way, the couple is allowed a second act of copulation, although this time it is so directly influenced by death and violence that Buffy is almost killed. The implications are clear: the Buffy-Angel relationship is doomed because each time they connect sexually, either Angel will turn evil or Buffy will die.

Their sexual deficiency is problematic because a significant portion of their attraction is fuelled by the connection between passion and death. Their sexual interest in each other is derived from that which is forbidden: initially it is Buffy's virginity and later it is the curse. Their romance is situated in areas marked by death; and copulation brings out a demon that tortures and kills her friends. Even when Angelus torments her, though, Buffy still cannot distinguish between her boyfriend and the monster who wears his face. Her Buffy self remains attracted to the "tall, dark in an annoying sort of way" man, while her Slayer side is attracted to its opposite because of her death-wish. 
For these reasons, the lovers accept a lie when they decide to separate at the end of the third season. It is not because Angel cannot give Buffy a 'normal life' that they must go their own ways, but because of the lack of sex. Considering that the show continually references Buffy's inability to live a 'normal' life, it would be impossible for Angel to provide the solution. Instead the true reason that Buffy and Angel do not remain a couple is sex: the demonstration of which is one of both Angel and Angelus' primary narrative functions. Buffy's desires are mixed up with her Slayer death wish, which serves to privilege her boyfriend and their relationship above her Slayer duties. This would not be a problem (Buffy always manages to save the day), but the realization that sex unleashes a killer cannot be condoned by either of Buffy's selves. Although she hesitates to kill Angelus in season two and defends Angel's right to live upon his return, it is the knowledge that in consummating their relationship they are putting both elements of Buffy's life in danger that neither of them can condone. And since they cannot overcome their passion for one another, both realize it is only a matter of time before they submit to their sexual chemistry. Therefore, Angel must leave.

Despite this fact, the connection between sex and death is not easily broken for Buffy. Angel sets a dangerous precedent, ultimately serving as a formula for Buffy's romantic relationships. Just as the Master creates a mold to which all other Big Bads can be compared, Angel forms the romantic mold: his are the parameters that mark successful or unsuccessful romantic relationships with Buffy Summers.

The problems that Buffy has with Angel are the problems that she cannot overcome in her next relationship. Her dissatisfaction with Riley stems from his lack of association with darkness, from his good-guy status and the sexual connection, while 
viable ("Where the Wild Things Are," 4.18), is ultimately insufficient. Her Buffy side cannot be entirely blamed, as a result, for it is equally the fault of the Slayer's death wish that she is attracted to these types of men. Instead, the Buffy-Angel relationship, built on the intersection of sex and death, foreshadows the failure of Buffy's future relationship with Riley, just as it prepares for one with Spike.

Spike is coded similarly to Angel, in that his relationship with Buffy is associated with sex and death. The principal difference is that Spike and Buffy's relationship is not founded on romantic idealism. Instead it originates in mutual hostility when Spike is the Big Bad for the first part of season two. He first appears in "School Hard" (2.03) in a static high angle shot, peacefully looking down on the 'Welcome To Sunnydale' sign. After a moment of silence, a black car breaks into the frame and drives over the sign. There is a cut to a ground level shot as the driver's door opens and a black boot steps out onto the pavement. This sequence introduces Spike in a near identical shot to Angel (from "Welcome to the Hellmouth"), thereby linking the two vampires together: they are threats.

Buffy and Spike meet when he crashes Parent Teacher Night at the high school. The relationship between the two is immediately classified under sexual terms, as Jennifer Crusie explains:

Adding to the attraction is the fact that, from the beginning, their conflict is sexual. In their first real physical confrontation...he knocks her to the ground and straddles her, saying, "I'll make it quick. It won't hurt a bit," and she says, "Wrong. It's gonna hurt a lot," foreshadowing the next five years of violence. (89)

Spike's language is loaded with sexual connotations. He calls Drusilla "pet" and "love," and associates a similar sexual relationship with Buffy by using the same language. This is because Spike sees Buffy as another Slayer to kill - he keeps track of 
his numbers the same way men keep track of their sexual conquests. Buffy reciprocates his advances, as in "What's My Line, Part 2" when she switches spots with Kendra so that she can fight Spike. He tells her that he'd rather be fighting her, to which she replies, "Mutual".

She responds to Spike the same way she responds to Angel: she is attracted to his dark nature, except that Spike is truly deadly. In this way Spike is the flip side of Angel: one is acceptable to fall in love with because he has a soul, while the other is unacceptable because he lacks one. Although falling in love with either vampire is an undesirable trait for a Slayer, Buffy doesn't see a problem with her relationship with Angel because he doesn't threaten society. ${ }^{48}$ Spike, on the other hand, is evil and because he does not have a soul, he cannot be trusted not to cause trouble ("Lovers Walk," 3.08; "Harsh Light of Day," 4.03). Even after he is implanted with a chip by the Initiative in season four, Spike remains a menace ("The Yoko Factor," 4.20).

As his character redeems himself over the seasons, especially in seasons five through seven, Spike's animosity towards Buffy turns into attraction. By this time Spike's implanted chip effectively neuters him, reducing his role to comedic relief. Buffy recognizes this and fails to reciprocate his desires, reinforcing her inability to date a man who is not a "bad boy."

There are several episodes that chronicle the changes in Buffy's attitudes towards Spike: "Something Blue" foreshadows their romantic relationship, although it ends as soon as Willow's spell is broken, while "Intervention" (5.18) marks the first time Buffy

\footnotetext{
${ }^{48}$ This changes after Angel's transformation into Angelus - in which case her love for Angel is a threat to society because it interferes with her ability to battle Angelus. When he returns in season three with his soul intact, though, loving him is not a threat to society so long as they remain physically chaste. Their separation at the end of the season stems, in part, from their inability to do so, which risks unleashing Angelus once again.
} 
and Spike kiss. It is this episode that marks a turning point in Buffy's interactions with Spike. When he is kidnapped and tortured by Glory, Buffy immediately goes to rescue him. It is interesting that this occurs immediately after she discovers that Spike is in love with her and using a Buffy-bot for sexual purposes, considering that in the following episode she tells Willow that attacking Glory is dangerous. The suggestion is that if it one of her lovers (or love interests) that is in trouble, she is more likely to enter into dangerous situations. "Intervention" opens the possibility that Buffy does have feelings for Spike, which is demonstrated at the end of the episode, when Buffy visits Spike to determine if he told Glory about the key. To do so, she impersonates the Buffy-bot and eventually kisses him. It is significant that Buffy chooses to kiss him (she does not have to), and admits that "what you did for me and Dawn - that was real." In this way, she recognizes the potential for good in Spike, which fuels his drive to better himself, but also increases his desire.

"Intervention" foreshadows a number of important narrative developments. Buffy's fear that she is losing her ability to love prompts her to go on a spirit walk in the desert. There she discovers a guide in the appearance of the first Slayer that tells her "death is your gift." These words not only foreshadow Buffy's decision to martyr herself in the season finale, but also address her relationships with men, specifically Spike. The guide explains that she "is full of love" and that "Love is pain, and the Slayer forges strength from pain." This suggestively ties in with Buffy's admission in "What's My Line, Part 2" that her emotions give her strength, insinuating that her capacity for love is a weapon in her Slaying. 
As demonstrated by her interactions with Angel, however, these emotions are also a weakness. Her love for the "bad boys," for men who "make [her] miserable," connects to her attraction to death. If "love will bring you [Buffy] to your gift" and "death is your gift," then the insinuation is that Buffy's ability to love ties her to death. This applies to her actions in "The Gift" (5.22) when she sacrifices herself, as well as her attraction to Spike.

This attraction to sex and death is fully explored following her resurrection in season six. Her return is marked by an emotional distance from her friends. This does not extend to Spike, who is the only one Buffy confides in about her stay in heaven in "Afterlife" (6.03). The confession takes place in an alley behind the Magic Shop where Spike sits in the shadow. Significantly Buffy moves out of the light and into the shadow to be with him, suggestive of her embrace of the darkness in him. She tells Spike because she feels he is the only one who can appreciate her circumstances (because he has also died and returned to life). When Buffy confesses the truth to the rest of the Scoobies in “Once More, With Feeling” (6.07), she admits that she doesn't feel anything emotionally. This changes in the final scene when she sings to Spike, “This isn't real / but I just want to feel" before kissing him. In her current state, their physical contact is the only way that she feels alive.

In this way, her sexual relationship with Spike, which begins in this episode, is based on Buffy's ability to feel, to connect emotionally with another being. The fact that it is a vampire without a soul, who despite his redemptive path remains dangerous, is highlighted when Spike discovers he can hit her in "Smashed" (6.09). Although Spike's 
comment that Buffy has "come back wrong" refers to her genetics, it also applies to her attraction to him.

The suggestion throughout the season is that Spike's attraction to Buffy is wrong because of their conflicting status as Slayer and Vampire. Her relationship with Angel indicates that Buffy's attraction to sex and death has disastrous consequences and Spike's lack of soul codes him as even more dangerous. By continuing a sexual relationship with Spike after she knows that he can injure her, Buffy's actions are in contrast to her responsibilities: both her selves know that Spike is dangerous (he's killed two Slayers) and that a relationship with him is wrong (she lies to her friends about their affair). The fact that Spike can (and does) hurt her recalls Buffy's responsibility to protect herself by staying alive so that she can look after the innocent. By deliberately entering into a sexual relationship with Spike, she denies this responsibility in order to "feel."

The dangerous implications are paralleled by Willow's addiction. The car accident that injures Dawn in "Wrecked" (6.10) proves to Willow that she needs help, and forces her to recognize that she is not using her power responsibly. Buffy recognizes the same problems in her relationship with Spike, which physically manifest as bruises on her body. These marks are a reminder that Spike is a villain that hurts her and that their affair is physically damaging. Buffy exposes her own hypocrisy by remaining silent about her own addiction even as she criticizes Willow's lack of control.

As a result, Buffy's desire to "feel" - her sexual addiction to Spike - interferes with her Buffy responsibilities. Her affair prevents her from recognizing the pain Willow is suffering, which is a significant failure for a friend and continues throughout the 
season. "Wrecked" establishes a pattern that is adhered to until "Entropy" (6.18), when the Scoobies finally uncover Buffy's relationship with Spike.

By this time Buffy has broken off her relationship with Spike, but its destructive impact remains. By focusing principally on Spike, Buffy has also neglected to address the threat posed by the Trio of Nerds. In fact Buffy uses their attacks as an excuse not to perform her responsibilities. When the Trio of Nerds render her invisible in "Gone" (6.11) she uses her situation as an excuse to have sex with Spike and their attempt to frame her for murder in "Dead Things" (6.13) goes unpunished. Buffy's relationship with Spike affects her ability to function as the Slayer: her reactions to "Gone" and "Dead Things" are passive in that she does not track down the Trio and stop them. Instead she allows others to do her work for her (Willow uncovers the destructive properties of invisibility and helps return Buffy to normal, while Spike tracks down the demons involved in the murder after Buffy tries to offer herself to the police).

By reverting to inaction, Buffy associates herself with Faith as an unsuitable Slayer. The result of her inaction is revealed in "Seeing Red," which marks the culmination of several storylines in season six. The first is the end of Buffy's relationship with Spike when he tries to rape her in her bathroom. Spike appears as Buffy tries to take a bath in the aftermath of her battle with Warren. Initially she makes only feeble attempts to push him off, but when he rips open her housecoat she finally reacts and kicks him in the chest. It is clear that Spike's obsessive love for Buffy is dangerous. Throughout the season this fact has been represented metaphorically by everything from bruises to destroyed houses, but it is his attempted rape that shows the lengths of his ability to hurt Buffy. Her screams and cries are the final example of his ability to make her feel - Buffy 
knows now that her sexual addiction to Spike is both physically and emotionally damaging. The kick is a return to action and breaks the physical connection they share in season six. Following this event they never have sex again.

The second instance of narrative storylines wrapping up in "Seeing Red" is the return of Warren and Willow's embrace of dark magic. Since Buffy's addiction continues despite her attempts to stop, it is suggested that Willow's addiction - as a parallel to Buffy's - will return. When Buffy allows Warren to get away earlier in the episode, the disastrous consequences of her inability to follow through and complete her responsibilities are demonstrated: Warren shoots Buffy and kills Tara. The result of her unhealthy sexual relationship with Spike - the reason Buffy is too distracted to take the Trio of Nerds seriously as opponents - is made clear by Buffy's role in Tara's death and the creation of Dark Willow.

The fallout from season six influences Buffy and Spike's relationship in the final season. Spike returns to Sunnydale with a soul as penance for the attempted rape, which prompts Buffy's acceptance of him in "Beneath You" (7.02). Their relationship now closely echoes the one she had with Angel: Buffy's sense of irresponsibility for being attracted to a vampire is overcome because he has a soul. This is important because it informs her decision not to kill Spike when he is triggered by the First to kill. By locking him up and remaining close to him, Buffy reacts the same way she did with Faith after Finch's murder. She feels a sense of responsibility for both Spike and Faith because she is involved in their suffering: she was with Faith during the murder and her inability to love Spike drove him to get a soul. 
It is important that although Buffy and Spike share an emotionally supportive relationship in season seven, they discontinue having sex. Looking back at season two and six, each time Buffy has sex, her responsibilities are neglected as a result. By maintaining an emotionally supportive relationship without the sexual yearnings present in season three, Buffy is capable of making rational decisions, although certain episodes still suggest a diminished capacity to lead because she is concerned for Spike's wellbeing, such as "Sleeper"-"Showtime" (7.08-7.11), when he is being triggered.

Her decision to keep a killer in a house with a group of teenage potentials is a sign of clouded judgment to her friends. Part of her decision to keep Spike nearby is strategic - he is one of her few weapons, especially with Willow sidelined - but it is also because she has feelings for him. The fact that she is unable to control him (indicated by his attack in "Never Leave Me," 7.09) suggests that there is good reason for the others' fears, and echoes Buffy's decision to keep Angel alive after his return in season three. In both situations Buffy's choice is correct, but these situations continue to demonstrate her determination to protect her relationships even though they may be detrimental to the safety of others and her responsibilities as a Slayer.

The First's activation of Spike's trigger is meant to be used as a weapon against Buffy, but proves ineffective because of their feelings for one another: he begins to remember his activities, and when he takes her to the house where he has buried the bodies, she doesn't kill him (as the First suggested she would). Buffy's dialogue in "Sleeper" suggests her conflict between her duties as the Slayer and her feelings for Spike:

Buffy: Find me some proof that he did this. Anya: Really, are you sure that's what you want? Buffy: Find me the proof that he didn't. 
Whether or not she wants to find out if Spike is evil or innocent is irrelevant - her inability to stake him reveals that there is more to their relationship than simple heroics. While she rationalizes keeping Spike in the house so that she can question him about the First, his importance to her as a romantic possibility is clearly represented in their conversation in "Never Leave Me."49

The scene is clearly reminiscent of their conversation outside the Magic Box in "Afterlife," when Buffy moved into the shadows to be with Spike. Here Buffy and Spike are several feet apart, and she is illuminated under a light hanging above the sink. As the conversation continues, she moves closer to him, leaving behind the light and entering the gloom. By the time Buffy tells him that she believes in him, there is a re-establishing two shot with the two now standing face to face in the gloom, suggesting that she has symbolically left behind the light to rescue him from the dark.

Buffy spends the following two episodes addressing her need to rescue Spike, although once again her comments speak of her need for his heroic capabilities, as well as her need for his safe return. When she approaches him at the end of "Showtime," there is a repetition of both of the aforementioned scenes from "Afterlife" and "Never Leave Me" when Buffy and Spike stand together in silence before she carries him away into the darkness.

"Sleeper" through "Showtime" as well as "Lies My Parents Told Me" (7.17) show the troubling effects Buffy's feelings for Spike have on her responsibilities. Aside from these episodes, however, Buffy uses his love as an emotional crutch - an aid to get

49 See Appendix M for the full transcript. 
through difficult times - especially when the others mutiny against her in "Empty Places" (7.19).

It is only with Spike's support in "Touched" (7.20) that Buffy is able to rediscover her role in the final conflict. For the last time, she attempts to disavow her duties, sitting listlessly in a house because she is "tired." It is Spike's admission that he loves "what you are. What you do" and her ability to trust him to hold her while she sleeps that prompts Buffy's return to her responsibilities as a Slayer. The next morning she engages Caleb in battle in the vineyard, steals the scythe and returns to lead the defeated potentials.

The Buffy-Spike relationship is crucial to the final episode. With the scythe and the amulet (delivered by Angel), both Buffy and Spike have powerful new weapons at their disposal. The events of the previous seasons have prepared them to accept the responsibilities that accompany these powers, so that Spike understands his self-sacrifice and associates it with his chance to receive Buffy's love and complete his redemption. Buffy, meanwhile, uses the scythe to pass along her powers to all the potential Slayers, thereby freeing herself from the isolation and responsibilities of being the Slayer. In this way, the series' closure is marked by an explosion of multiplicity: Spike's acceptance of his role disintegrates him into millions of pieces and, along with him, the ubervamps, while Buffy explodes the idea of what it means to be the Slayer by distributing her powers to all of the potentials.

The fact that the series ends with an independent Buffy, free of men and responsibilities, is no accident. Her reign as the Slayer is marked by an attraction to sex and death, embodied in her two vampire lovers. When Buffy passes along her powers and 
ceases to be, as Faith comments, "the one and only Chosen one," she also ends her attraction to death. At the end of the series, Buffy stares at the wreckage of Sunnydale and her open-ended future. This future is marked by choice: she can continue to use her superpowers just as she can continue to date bad boys. The availability of choice, however, is only possible since Buffy is alone. Spike is an element of her life as the Slayer - a life that no longer exists. This is clear because the words from his moralboosting speech in "Touched" ("You're the one, Buffy" - emphasis added) no longer apply.

With the Big Bad dispatched and the dissemination of her powers, Buffy is no longer the one. The series ends on a note of hopeful optimism. With the end of her responsibilities as the Slayer and the ruin of Sunnydale, Buffy is free to finish baking and find a suitor to eat her. ${ }^{50}$

\footnotetext{
${ }^{50}$ This is the awkwardly sexual metaphor she uses to describe her continually evolving identity to Angel in the opening scene of "Chosen."
} 


\section{Conclusion: \\ "NewsFlash, Hairdo. It's Not Always About You": Glory as Representative Big Bad}

In the world of Buffy the Vampire Slayer, there are a number of elements worthy of academic analysis: genre (and its hybridity), gender/sex roles, the role of sexuality, and the implications of race and 'Otherness.' If examinations of these elements in reference to specific characters is included, then Buffy swiftly becomes more complicated and worthy of analysis than initially anticipated.

At the same time, there seems to be an unintentional stigma against certain characters and episodes. The Joss Whedon episodes (writing, directing or both) are the most analyzed, ${ }^{51}$ which is understandable considering he is the series creator and often writes key episodes (season finales, 'twist' episodes such as "Innocence" and others with important information such as "The Body," when Buffy's mother dies). However, as Kevin Johns argues, this negates the importance of other episodes, especially blueprint episodes wherein the conflicts and plot points of entire seasons are set up in a single episode, such as "Flooded" (6.03), "Revelations" (3.07) or "Something Blue" (4.09). Additionally, it places the focus on a single individual, as opposed to the talented writing and directing team that creates Buffy, including writers Jane Espenson, Drew Goddard and Doug Petrie and show producer Marti Noxon.

For characters, the academic interest circles around Buffy and her Scoobies (Buffy as feminist icon; Willow as lesbian; Xander and Spike as emasculated men; Spike

\footnotetext{
${ }^{51}$ His most analyzed episodes include, among others, the pilot episodes "Welcome to the Hellmouth/The Harvest" (1.01-1.02), as well as "Prophecy Girl" (1.12), "Innocence" (2.14), "Hush" (4.10), "Restless" (4.22), "The Body" (5.16), "Once More, With Feeling" (6.07) and "Chosen" (7.22). Wilcox's Why Buffy Matters analyses 7 individual episodes, including "Innocence," "Restless," "The Body," "Once More, With Feeling" and "Hush" and at least half of the essays in Slayage analyze these same episodes.

${ }^{52}$ Rhonda V. Wilcox argues episodes such as "Restless", "Tabula Rasa" (6.08) and "Fear, Itself" (4.04) are blueprint episodes in Why Buffy Matters (60).
} 
and Angel as updates on the vampire lothario; Giles as representative of Britishness and book-learning, etc). Even here, though, there is a lack of analysis on periphery characters such as Dawn, Anya and Tara (who ironically receives ample focus in $\underline{\text { Seven Seasons of }}$

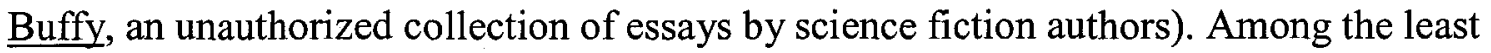
studied characters, however, are the villains of the show. Whether they are the one-off characters such as the praying mantis lady in "Teacher's Pet" (1.04), Der Kindestod in "Killed By Death" (2.18) or the Big Bads, these characters are rarely examined beyond their relevance to the 'high-school-as-hell' metaphor that drives the show.

Pigeon-holing these characters avoids other avenues of analysis that proves to be both fruitful and interesting. Indeed, if part of the appeal of the show is the level to which Buffy balances both her worlds - the Slayer and the normal girl - then it is the villains who create the conflict. On other shows driven by teen characters, such as Dawson's Creek (Williamson, 1998) or One Tree Hill (Schwahn, 2003), conflicts originate from personal relationships between families, lovers and friends. Although Buffy contains these elements, there is another angle from which conflict emerges: the supernatural world. By introducing an alternate avenue for tension, the supernatural compliments or complicates already existing problems, allowing the show greater storytelling diversity.

In this way, villains add greatly to the narrative of the show. And while one-off villains appear in one or two episodes and can therefore affect the narrative in limited ways, it is Big Bad villains who control and shape a season's storylines. These characters appear repeatedly, often throughout a single season, as foils to complicate Buffy's life with nefarious schemes of death, power and apocalypse. These plans often coincide with Buffy's important dates, such as dates, proms and exams, so that she must balance the 
responsibilities that accompany her personal life (family, friends, lovers) and her powers as the Slayer. In this way, Big Bads exist on Buffy the Vampire Slayer to demonstrate the conflict that exists in the responsibilities of Buffy's two roles as Slayer and Buffy.

Chapter one examines the Master and the First as Buffy's first and final Big Bad. While the Master emphasizes Buffy's reluctance to incorporate her Slaying in her new life in Sunnydale, by the time she encounters the First in season seven, not only has she embraced both her selves, she has accepted her responsibility to share her powers with the potentials.

The Master creates a template for successive Big Bads in his use of ritual and prophecy (equated with the written word and pre-ordained destiny) to battle Buffy. She, in turn, uses this power against him with the aid of the Scoobies' researching skills, as well as her own linguistic power: a mixture of puns and verbal dexterity. In this way, Buffy balances modern (her fashion sense, feminism and quick wit) and ancient practices (the Slayer lineage and its adherence to prophecy), enabling her to defeat the rigidly of the past (often associated with adults, including both Giles and her mother, Joyce).

In contrast, the agelessness of the First presents problems for Buffy. The Scoobies' inability to research or battle it physically creates fissures within the group dynamic as Giles, Faith and Buffy struggle for the right to lead the group. The First's seemingly indestructible nature is indicative of the shift in Big Bad characteristics established in season four, when they become significantly harder to destroy to match Buffy's transition into adulthood. The problems presented by the First prompt Buffy's interest in discovering the origins of her powers, as well as the rejection of the patriarchal order that rigidly controls the lineage and limitations of Slayers. By assuming leadership 
of the group and using the scythe (created by a female order), Buffy circumvents history, and the men behind it, to grant Slayer powers to all potentials. In this way, she is finally able to choose the option of living a 'normal' life since she no longer bears the isolation and burden of being 'the chosen one.'

Chapter two focuses on institutional Big Bads such as the Mayor, the Initiative and Adam. Each occupies a hierarchical rank within a socially constructed system at either the municipal or federal level. The Initiative presents Buffy with an opportunity to join a team of equally adept fighters, which includes her boyfriend at the time, Riley. Given Buffy's nature as a Slayer, this is her only opportunity to join a workplace that endorses conformity (mentally as well as fashion and diet). Her time with the Initiative suggests that her methods in dealing with the supernatural are superior even to those of a government sponsored agency. In light of the Initiative's black-and-white distinction, which is exposed as an ill-equipped in "Primeval" (4.21) when the soldiers are unprepared for Adam's battle, Buffy's 'grey zone' moral position (in regards to demons and vampires) is identified as the correct one. As a result, Buffy and the Scoobies singlehandedly defeat Adam and rescue the remaining soldiers, which demonstrates their superior efficiency.

In comparison, Adam is an unsuccessful Big Bad. Unlike the Initiative, which directly affects Buffy emotionally and physically, Adam subcontracts his plans to vampires ("Who Are You?," 4.16; "The Yoko Factor," 4.20) instead of getting involved. He is continuously upstaged by Spike ("The Yoko Factor," 4.20), Faith ("This Year's Girl" \& "Who Are You?," 4.15-4.16) and even minor, recurring characters like Jonathan ("Superstar," 4.17) because his appearances on the show are limited to brief 
conversations with other monsters or references by the Scoobies, The fact that his final battle with Buffy takes place during the penultimate episode of the season betrays the Big Bad formula that all the others adhere to, suggesting he is less important than the rest.

While the Mayor also subcontracts his plans out (with Mr. Trick and Faith), his plans affect Buffy in an extremely emotional manner. Although he remains hidden for the first portion of the third season, when he finally meets her in "Choices" (3.19), he immediately attacks her relationship with Angel - one of the most important aspects of her life. His comments underscore the problems both Buffy and Angel have been avoiding, and his comments foreshadow their subsequent break-up in the following episode. Additionally, the lack of knowledge about his plans forces Buffy to go on the offensive, first for information ("Enemies," 3.17) and then as a pre-emptive strike to derail his ascension ("Choices"). Later, his entry into the school library in "Graduation Day, Part 2" is a direct violation of the Scoobies' personal space. Ultimately, though, the Mayor's most significant function is allowing Buffy's transition from High School to the adult world in the destruction of the high school, and hints at her developing leadership skills when she organizes the graduating class into an army to battle him at the ceremony. In the third and fourth chapters, personalized villains take centre stage. These villains affect Buffy the most because they know her intimately and are therefore more familiar with her flaws and weaknesses. As a result, she endures both physical and emotional scarring from her battles with these characters.

Chapter three focuses on friendships gone wrong and analyzes Buffy's relationships with Faith and Dark Willow. Faith plays shadow/double to Buffy's Slayer with her insinuations that Buffy is incomplete because she does not embrace all the 
qualities that Slaying offers. In her role as the second Slayer, Faith highlights the need for responsibility and tactics, as well as ties to the real world in the form of friends and family. Her ability to convince Buffy to give up her responsibilities as a Slayer in "Bad Girls" (3.14) suggests the presence of similar, repressed undesirable characteristics in Buffy. Faith's other important function is as a foil in Buffy's romantic relationships - she acts as a buffer between personal happiness with Angel, Riley and Spike.

In contrast, Buffy's relationship with Dark Willow highlights her inadequacies when interacting with a troubled friend. Whereas Faith suggests what Buffy might have been under different circumstances, Willow showcases what Buffy is. In a less than flattering portrait, Buffy is presented as a user: she utilizes Willow's magical abilities when they are convenient for her in battle, but when her friend has problems, Buffy is rarely there for her. This is highlighted in "Something Blue" when Buffy prioritizes her relationship with Riley over Willow's pain, and is explored at length when their respective addictions (sex and magic) are paralleled in season six. It is not surprising then that Buffy is unable to defeat Dark Willow because she is unable to relate to her as either a friend or a Slayer. Instead, Buffy comes off as an uneven combination of the two, trying to impose her Slayer rhetoric (not killing humans), while failing to recognize the importance of Tara's death. As a result Dark Willow is the only Big Bad that Buffy cannot defeat, and the relationship between the girls remains static and unchanged in the seventh season.

The final chapter continues to examine personalized villains, but shifts to accommodate Buffy's romantic and sexual relationships with Angel and Spike. These relationships are different from the other villains because they illustrate the effect of her 
Buffy desires to have a boyfriend while simultaneously illuminating her Slayer deathwish.

Just as the Master creates the formula for the successive Big Bads, so too does Angel create the formula for Buffy's boyfriends. He is the one who establishes her connection between sex and death, especially present when she and Angel sleep together and he turns into Angelus. Her inability to stake him, as well as the lengths to which she goes to protect him in season three, establishes a pattern in which Buffy prioritizes her romantic relationships above all others, often at a price (her "emotions give [her] power" as often as "they cloud her judgment"). The impossibility of a sexual relationship between Buffy and Angel demonstrates the importance of sex when they break up at the end of season three. He leaves not because he "can't give her a normal life," but because sex comes at a dangerous price (his return to evil or her death) and neither of them can resist their physical attraction to the other.

Buffy's relationship with Spike continues to explore these issues. His interactions with Buffy are also coded in sexual terms, and as the seasons progress he further highlights the link between sex, death and its implications for a Slayer ("Fool For Love," 5.07). Her attachment to sex with him in season six, which enables her to "feel," negates her responsibilities as both as friend (to Willow) and as a Slayer (in preventing the activities of the Trio of Nerds). It is only after the events of "Seeing Red" - "Grave" (6.19-6.22) that Buffy definitively ends her sadomasochistic relationship with Spike and reconnects with the world when Dawn is threatened. 
Their relationship changes in season seven when Spike returns with a soul, enabling Buffy's affections without feeling irresponsible because he is no longer a threat to society. Despite her friends' concerns about his trigger, Buffy and Spike's mutual belief in one another and the chastity of their relationship allows both to become champions in the series finale: Buffy with the scythe and Spike with the amulet. His death is necessary for Buffy's ultimate freedom at the end of the series: without him, she has no further ties to Sunnydale or her stint as the Slayer.

This thesis has only touched on nine of the twelve Big Bads. A full analysis of the Trio of Nerds (season six) and Drusilla (season two) would require separate chapters. It can be briefly elaborated upon that both serve to educate Buffy on balancing her dualities. Drusilla functions more or less in conjunction with Spike and Angelus. She is the driving force behind Spike's hiring of the Order of Taraka in "What's My Line, Part 1 \& 2" (2.10-11), although once she assumes a position of power, she is immediately replaced by Angelus. For Buffy, Drusilla poses a sexual threat to her relationship with Angel (hinted at in "Lie to Me," 2.07), especially after Angelus moves into the factory and it is insinuated that their (sexual) relationships begins anew.

The Trio of Nerds strike Buffy following her resurrection in season six when she is at her weakest. Kevin Johns explains that these Big Bad are in keeping with the theme of season six (Life is the Big Bad) in that they skewer the progression of ever increasingly powerful villains (starting with vampires in seasons one and two, then demons in seasons three and four and a god in season five). Instead the Trio is merely a group of nerdy teenagers who decide to become supervillains:

This is....in keeping with the season's focus on the humanization of Buffy's challenges. The ostentatious plans of villain's like the Master and Glory have been 
replaced with the trio's plan which consists merely of the "super-cool" mission statement "So, you guys wanna team up and take over Sunnydale?" (Johns, 4)

The "humanization" of Big Bads parallels Buffy's less glamourous challenges in season six: getting a minimum wage job to pay the bills, encountering an ex-boyfriend, and overcoming an entirely physical relationship with no future. This culminates in the least climatic battle in Buffy history when Warren uses a gun (the most human of weapons) to shoot Buffy in her backyard. It is only when he shoots and kills Tara that the true Big Bad emerges as in the form of Dark Willow.

Naturally, both Drusilla and the Trio of Nerds require more detailed sections to fully appreciate their contributions to the show, but this is not the venue for such an examination..$^{53}$ Instead, the rest of this conclusion will tie together the narrative functions of the Big Bad in an analysis of the season five villain. Glory is an important Big Bad in that she embodies a number of qualities taken from the other Big Bads in addition to her own distinctive elements. In effect, the fifth season itself is indicative of the series as a whole in its conflicts, character types and actions.

Glory, as a character, is defined by her physicality. Her introduction is an inversion of expectations when a monk exclaims, "The Beast, as a solid steel door is broken in. When it is revealed that "the beast" is, in actuality, a miniscule girl with blonde curls who is capable of great feats of strength, an association between Buffy and Glory is established. As a result, just as Faith is a shadow double capable of

\footnotetext{
${ }^{53}$ The Trio is particularly interesting given their status as human villains who reflect Willow's magical and technological expertise, thereby foreshadowing her descent into evil. Additionally, they embody a half-way position between personalized villains (those villains with personal relationships to Buffy) and the others (who are not known by Buffy until they appear in Sunnydale and announce their plans). Both Warren and Jonathan appear in earlier episodes, but are periphery (Jonathan) or one-off characters (Warren, in "I Was Made to Love You," 5.15)
} 
demonstrating the darkness in Slaying (Buffy without friends or morals), Glory is another double, representing Buffy with godlike powers.

Glory also has a dual identity, although hers is far more literal. She shares a body with Ben, an intern at the hospital, and their conflicting possession of a single body clearly echoes Buffy's alternation between the girl and the Slayer. Ben even comments to himself that all he wants to have is a normal life after he is fired from his job in "Tough Love" (5.19) and both sides remark on the other's unfair possession of the body and the damage it causes to their separate plans. In this way, both Ben and Buffy desire a normal life: his decision not to help Glory find the key is reminiscent of Buffy's shirking of her Slayer responsibilities. ${ }^{54}$ Whenever Ben is overtaken by Glory, it recalls the times that Buffy must give up her girl role and become the Slayer, although with Glory these changes are represented literally in morphing sequences.

This conflict suggests a schizophrenic personality disorder that is literally represented onscreen in Glory's need to mind-suck humans in order to remain sane. In "No Place Like Home," 55 the editing reflects this instability in a series of jump cuts after she begins to talk incoherently. This ends only after she mind-sucks a security guard whom she is holding prisoner.

Another way Glory and Buffy are tied together is in their self-centeredness. The hell-god is one of the most egocentric characters to appear on the show because she constantly talks about herself: her wants, needs, and feels. Her group of minions act on

\footnotetext{
${ }^{54}$ As a part of Glory, Ben's fate is tied to hers so his resistance is detrimental to their success. Even if he does not cooperate and she misses her window to perform the ritual, he will still have to battle her for possession of their body and it is implied that she is becoming stronger because she takes possession with increasing regularity and for longer periods of time.

${ }^{55}$ This is another quality that links her to Faith and characterizes her as a shadow double. See chapter three - Faith.
} 
her orders and suggestions (they are servants in every possible manner considering they spy for her, bring her food, fight for her and even die to serve her wishes). This bears resemblance to Buffy's own function in the narrative: she is the center of the universe and the being that unites the group (Wall \& Zyrd, 60). The Scoobies follow her instructions and back up her actions, and, as the titular heroine, it is clear that the show revolves around her.

Glory's associations with Buffy recall the other Big Bads who are employed by the narrative to comment on Buffy's situation. The Master is associated with Buffy in that his prophecies coincide with important days in Buffy's life; Faith's actions suggest the secret desires Buffy keeps hidden, and Angelus' monologue reflects Buffy's emotions as he voyeuristically watches her in "Passion" (2.17).

The hell god's speech patterns closely parallel other Big Bads. Her selfcenteredness is tied to her tireless conversation, which puts her in line with Spike, Angelus and the Mayor as villains who like to speak. She is sarcastic like the two vampires ("Buffy, if I came here to fight you would know by being dead already"), while her conversation skills are nearly identical to the Mayor, in that casual comments preface deadly threats. In "Checkpoint” (5.12), Glory says of Dawn, "She's sassy. I like her. And I'll kill her," which sounds disturbing similar to the Mayor's comments to Giles about Buffy in “Graduation, Part 2" (3.22), “That's one spunky girl you've raised. I'm going to eat her."

In terms of formidable physical opponents, Glory bears a resemblance to Adam. Like the Frankenstein-cyborg, Glory is incredibly strong, and far more powerful than Buffy. As a result, the injuries Buffy and Spike sustain serve as physical reminders of 
Glory, not unlike the battles with the First's minions (ubervamp and Caleb) in season seven, which regularly leave Buffy with bruises. The source of Glory's strength is related to her status as a hell-god. Unlike Adam, she does not run on a power source and, unlike vampires or demons, she does not get bitten or ascend. This is because, unlike other Big Bads like the Master, Spike, Angelus, Drusilla or Adam, Glory's status as an ancient god suggests that she simply possesses great strength, a quality which is more in tune with the First (and Buffy). In this way, Glory adheres to the pattern of progressively more difficult villains, established in the first four seasons. As Buffy grows and matures through the seasons, the villains become physically and mentally more difficult in order to challenge her. The severity of their status, from vampire to demon to god reflects Buffy's own progression from insecure new girl to High School senior to University freshman to adult.

Glory continues the narrative direction that began in season four when Buffy realizes that she is more powerful as an individual, and chooses to leave the confines of an identity effacing organization such as the Initiative or the Watchers Council. Season five increases Buffy's level of responsibility to match her newfound powers of selfconfidence. Initially these responsibilities mean protecting Dawn (something Buffy already does for her friends), but after Joyce's death, she must take on more responsibilities to become a parent/guardian to Dawn. Whereas season four drove the Scoobies apart, the inclusion of Dawn draws them back together and returns the group to the Summers household, or more specifically the living room, which Jes Battis believes is the emotional centerpiece of the group. The University is seen less and less until Buffy finally drops out in "Tough Love." In this way, the storylines that occupied much of seasons three and four - Buffy's responsibility to herself and her future - are converted 
into her responsibility to Dawn. As a result, Buffy reorients her priorities to appease both her selves since Dawn is at once important to her Buffy self (as a blood sibling) and to her Slayer side (Dawn's protection from Glory ensures the world's safety).

In season five, the extended family regroups around Buffy's blood relative conflicts: Joyce's mysterious illness occupies the first half of the season and protecting Dawn occupies the entire season. Glory's presence threatens Buffy's family, which becomes the central conflict for the season, rebuilding the damage acquired during season four and building towards the ultimate extended family, complete with potentials, in season seven.

This is Glory's main function as season five's Big Bad: rallying the various combinations of family in Buffy against the death of one of their own and increasing Buffy's adult responsibilities. Her character is a combination of the Master and the First because, like Buffy's first and seventh season adversaries, Glory is ancient. She explains in "Blood Ties" (5.13) that she has been around "just this side of forever," suggesting that she is much older than the Master, and more in line with the First. This is problematic for the group because as an ancient being, she "pre-dates the written word," meaning that researching her is nearly impossible.

Similarly, in "No Place Like Home," Giles explains that the Dagon Sphere Buffy's discovers while escaping from her initial encounter with Glory is "a protective device used to ward off ancient primordial evil, created to repel 'That which cannot be named."' As a result, until episode eight, Glory's name is unknown by the Scooby gang, who refer to her as 'the blonde girl' until Buffy overhears a minion refer to her by name. The lack of name for a seasonal Big Bad with a generic title (the blonde girl) 
foreshadows the same narrative device in season seven, when the group is unsure they are fighting the First until Buffy names it in "Never Leave Me" (7.09). Until then, the First is described only with the statement 'From beneath you, it devours' and proves impossible to understand or battle. In the Buffyverse, monsters without names are impossible to conquer. This is clearly demonstrated in season five, when Giles and the others make little progress researching Glory until they know her name and ask for help from the Watchers Council. Only then do they discover she is a god.

At the same time, Glory straddles the information divide that separates early Big Bads from later ones. For the first three seasons, Buffy and the gang are capable of researching their villains for weaknesses or clues about their plans. Following the introduction of the Initiative and Adam in season four, however, the Big Bads are more elusive and research becomes more difficult or impossible (such as season six's villains, the Trio of Nerds and Dark Willow - neither of whom has a written history). In this way, Glory is more difficult to combat because her plans are not accessible in written (and therefore searchable) texts. Understanding Glory's plans requires a variety of information sources (Watchers Council, Knights of Byzantine and Tara's mental disorder after "Tough Love"), just as the means to defeat her draws on a number of previously unrelated storylines (the troll hammer from "Triangle," 5.11; Xander's access to a wrecking ball from his developing contractor skills; Spike's Buffy-Bot from "Intervention," 5.17; and the Dagon Sphere from "Real Me").

Glory is associated with the Master because of their religious connections. In "No Place Like Home," Giles explains that "anything that goes unnamed is an object of deep worship or great fear - maybe both," which echoes the Master's lack of proper name in 
season one. Like Glory, he too is associated with religion (the ruined church and scripture passages) and fear (rituals and prophecies). Glory functions on a similar set of guidelines: her ritual to open the dimensional portals to return home must be performed on a specific night at a specific time.

A key difference between the two is the performative function of their rituals. Glory's does not fall at an important moment in Buffy's life. This runs counter to the Master, whose prophecies function by pitting Buffy's two selves in conflict by forcing her to be the Slayer on nights when she wants to be Buffy (the prom, date night, etc). By season five, Buffy has accepted her calling, and prophecies therefore function differently. Glory threatens Buffy's role as sister and parental guardian by attempting to kill Dawn, thereby combining Buffy's need to save her sister (the Buffy self) as well as the universe (the Slayer responsibility) by preventing the ritual. In this way, just as the Master's rituals expose the conflicting desires of Buffy's selves, Glory's ritual mimics Buffy's acceptance of both selves by forcing her into a situation that affects both Slayer and Buffy.

Another tie between Glory and the Master is their ability to kill Buffy. In the history of the show, these are the two Big Bads who are capable of forcing Buffy to sacrifice herself. In this way, Buffy's decision to effectively martyr herself in "The Gift" (5.22) mirrors her death in "Prophecy Girl." The key difference is that Buffy fights against her role in the Codex prophecy and dies anyways. Buffy struggles because she doesn't want to die at sixteen, whereas four years later, at twenty, she has matured and accepted her roles to the point that martyring herself is the only responsible choice. When she leaps into the void in "The Gift," she is actively choosing this path - giving her life 
willingly to protect her sister (Buffy self) and the rest of the world (Slayer self) from destruction.

Glory, therefore, adheres to the Big Bads' central function on the show: creating situations that force Buffy to consider the responsibilities that accompany her powers, thereby revealing the conflict between Buffy's girl self and the Slayer. In this way Glory, while echoing defining characteristics of all the other Big Bads, most closely mirrors the Master and the First.

The Master forces Buffy to reconcile her two selves by accepting that she is the only person capable of stopping his ascension. The First, on the other hand, forces her to recognize that the only way to win an impossible battle is to share her power - thereby making all the potentials responsible for the safety of the world and removing her distinguishing characteristic as the Slayer. Glory seamlessly melds the two concepts together with her endgame. By threatening both Buffy's family as well as the world, she unites Buffy's selves in one act of responsibility: as a sister, Buffy cannot let Dawn die, but, as the Slayer, she cannot let the portal open. The only choice for either self is to sacrifice herself, to pay the ultimate price with her life, to protect her Buffy world (her sister and friends) as well as the world (her Slayer self).

As a result, the fifth season is crucial to the series. The introduction of Dawn forces Buffy to become more responsible as an adult and draws the Scoobies back together after a season of drifting apart. Buffy's death and subsequent resurrection establish the central conflicts that drive the rest of the series as the characters transition into full adulthood and the show transitions from the WB to UPN. These developments do not negate the show's past, though: just as a number of elements from season five are 
required in the fight against Glory, so too does the fifth season rely (and reminisce) on the events of the four previous seasons.

This is especially apparent in the fifth season opener, "Buffy vs Dracula" (5.01), which pays homage to and parodies the great vampire at the same time. The episode serves to reintroduce key ideas for Buffy: namely, the duality between traditional horror conventions and the show's modern update of those conventions, its tongue-in-cheek humour, its intertexual and intratextual references and, finally, exploring the definition of "Slayer."

This concept of Slayer is fluid in that it is continuously redefined in terms of sexuality, death and history (the death-wish that accompanies Slaying; the creation of the Slayer line by men through symbolic rape; a Slayer's gift is death, etc). However, these elements do not define Buffy's role in the series. Instead, it is her responsibilities - as the Slayer, as well as a normal girl - that dictate who Buffy is. Her actions define her, no matter which of her dual selves she is serving, and her actions are determined by the responsibility that comes with power (thereby embodying Sartre's existential hero). Her actions are in reaction to the plans of twelve Big Bads, each of whom challenge Buffy to confront her dual selves and accept responsibility or face the consequences. In this way, it is the Big Bads who prompt Buffy's development as both Slayer and normal girl.

After examining the show so intensely, it does not surprise me that there is a plethora of academic attention devoted to Buffy the Vampire Slayer. The only surprise is the limitations of critical analysis to this point, and that whole areas of the show that have gone unexamined. The purpose of this thesis was to examine one such overlooked area of Buffy: the Big Bads and their narrative function on the show. The results prove that these 
characters play an integral part on the show in determining conflict, structure and character development. Ideally, the result of this analysis will prompt further examination of these characters, as well as other characters and elements of the show that are passed over in favour of conventional subjects and topics. And just as the open-ended final line of the series suggests an endless variety of options for Buffy, so too does the show offer limitless subjects worthy of examination. Therefore, it is the responsibility of Buffy academics to answer the question: What are we going to do now? 


\section{$\underline{\text { Works Cited }}$}

Abbott, Stacey. 'A Little Less Ritual, A Little More Fun' in Slayage 3.

http://www.slayage.tv/essays/slayage3/sabbott.htm

Albright, Richard. “'[B]reakaway pop hit or book number?": "Once More, With Feeling" and Genre' in Slayage 17.

http://www.slayage.tv/essays/slayage17/Albright.htm

Battis, Jes. Blood Relations: Chosen Families in Buffy, the Vampire Slayer and Angel. Jefferson, N.C.: McFarland, 2005.

Campbell, Richard \& Caitlin Campbell. 'Demons, Aliens, Teens and Television' in Slayage2.

http://www.slayage.tv/essays/slayage2/campbell.htm

Crusie, Jennifer. 'Dating Death' in Seven Seasons of Buffy. Dallas, TX: BenBella. P. 8595.

DeKelb-Rittennhouse, Diane. 'Sex and the Single Vampire' in Fighting the Forces: What's At Stake in Buffy, the Vampire Slayer. Lanham, Md.: Rowman \& Littlefield. 2002 P. 143-152.

Edwards, Lynne. 'Slaying in Black and White: Kendra as Tragic Mulatta in Buffy' in Fighting the Forces: What's At Stake in Buffy, the Vampire Slayer. Lanham, Md.: Rowman \& Littlefield. 2002 P.85-97.

Johns, Kevin. “"It's unbelievably important”: "Flooded” as Blueprint Episode.' Unpublished Essay. March 20, 2006.

Kaveney, Roz. "'She Saved the World. A lot": An Introduction to the Themes and structures of Buffy and Angel' in Reading the Vampire Slayer: An Unofficial Critical Companion to Buffy and Angel. London; New York: Tauris Parke. 2001. P.1-36.

Keller, Donald. 'Spirit Guides and Shadow Selves: From the Dream life of Buffy (and Faith)' in Fighting the Forces: What's At Stake in Buffy, the Vampire Slayer. Lanham, Md.: Rowman \& Littlefield. 2002. P.165-177.

Krimmer, Elizabeth \& Shilpa Raval. "“Digging the Undead:" Death and Desire in Buffy' in Fighting the Forces: What's At Stake in Buffy, the Vampire Slayer. Lanham, Md.: Rowman \& Littlefield. 2002. P.153-164.

Krzywinska, Tanya. 'Hubble-Bubble, Herbs, and Grimoires' in Fighting the Forces: What's At Stake in Buffy, the Vampire Slayer. Lanham, Md.: Rowman \& Littlefield. 2002 P. 178-194. 
Lavery, David. 'Apocalyptic Apocalypses: The Narrative Eschatology of Buffy, the Vampire Slayer' in Slayage 9.

http://www.slayage.tv/essays/slayage $9 /$ Lavery.htm

Lawton Winslade, J. 'Teen Witches, Wiccans, and "Wanna-Blessed-Be's": Pop-Culture Magic in Buffy the Vampire Slayer" in Slayage 1.1.

$\mathrm{http} / / / \mathrm{www}$. slayage.tv/essays/slayage1/winslade.htm

Mendelson, Farah. 'Surpassing the Love of Vampires; or, Why (and How) a Queer Reading of the Buffy/Willow Relationship is Denied' in Fighting the Forces: What's At Stake in Buffy, the Vampire Slayer. Lanham, Md.: Rowman \& Littlefield. 2002 P. 45-60.

Middents, Jeffrey. 'A Sweet Vamp Thing: Critiquing the Treatment of Race in Buffy and the American Musical Once More (With Feeling)' in Slayage 17.

$\mathrm{http}: / / \mathrm{www}$. slayage.tv/essays/slayage17/Middents.htm

Money, Mary-Alice. 'The Undemonization of Supporting Characters in Buffy' in Fighting the Forces: What's At Stake in Buffy, the Vampire Slayer. Lanham, Md.: Rowman \& Littlefield. 2002 P. 98-107.

Overbey, Karen E. \& Lahney Preston-Matto. 'Staking in Tongues: Speech Act as Weapon in Buffy" in Fighting the Forces: What's At Stake in Buffy, the Vampire Slayer. Lanham, Md.: Rowman \& Littlefield. 2002 P. 73-84.

Petrie, Doug. DVD Featurette. "Season 3 Overview." Season 3, Disc 3.

Rambo, Elizabeth. "'Lessons” for Season Seven of Buffy the Vampire Slayer' in Slayage $11 \& 12$.

http://www.slayage.tv/essays/slayage11_12/Rambo.htm

Ramlow, Todd R. '“I Killed Tara": Desire and Death on Buffy.' PopMatters 4 June 2002: http://www.popmatters.com/tv/reviews/b/buffy-the-vampire-slayer2.shtml.

Rose, Anita. 'Of Creatures and Creators' in in Fighting the Forces: What's At Stake in Buffy, the Vampire Slayer. Lanham, Md.: Rowman \& Littlefield. 2002. P.133-142.

Saxey, Esther. 'Staking a Claim: The Series and its Slash Fan-Fiction' in Reading the Vampire Slayer: An Unofficial Critical Companion to Buffy and Angel. London; New York: Tauris Parke. 2001. P.187-210.

Sartre, Jean-Paul. Being and Nothingness: An Essay on Phenomenological Ontology. New York, Philosophical Library: Methuen \& Co Ltd. 1956. 
Sartre, Jean-Paul. 'Existentialism is a Humanism' in Existentialism from Dostoevsky to

Sartre. London: Meridien. 1956.P. 288-311.

http://jya.com/sartre-eih.htm

Sayer, Karen. 'It Wasn't Our World Anymore - They Made it Theirs' in Reading the Vampire Slayer: An Unofficial Critical Companion to Buffy and Angel. London;

New York: Tauris Parke. 2001. P.98-119.

Schneider, Steven J. 'Manifestations of the literary double in Modern Horror Cinema' in Horror Film and Psychoanalysis. Cambridge: Cambridge University Press. 2004. P. 106-121.

Tjardes, Sue. "'If You're Not Enjoying it, You're Doing Something Wrong": Textual and Viewer Constructions of Faith, the Vampire Slayer' in Athena's Daughters:

Television's New Women Warriors. Syracuse, N.Y.: Syracuse University Press. P. 66-77.

Wall, Brian \& Michael Zryd. 'Vampire Dialectics: Knowledge, Institutions and Labour' in Reading the Vampire Slayer: An Unofficial Critical Companion to Buffy and Angel. London; New York: Tauris Parke. 2001. P.53-77.

Whedon, Joss. DVD Audio-commentary: "Welcome to the Hellmouth." Season 1, Disc 1.

Wilcox, Rhonda \& David Lavery. 'Introduction' in Fighting the Forces: What's At Stake in Buffy, the Vampire Slayer. Lanham, Md.: Rowman \& Littlefield. 2002. P. xviixxix

Wilcox, Rhonda V. "There Will Never Be a "Very Special' Buffy": Buffy and the Monsters of Teen life' in Slayage 2.

http://www.slayage.tv/essays/slayage $2 /$ wilcox.htm

Wilcox, Rhonda V. "'Who Died and Made Her the Boss?" Patterns of Mortality in Buffy" in Fighting the Forces: What's At Stake in Buffy, the Vampire Slayer. Lanham, Md.: Rowman \& Littlefield. 2002 P. 3-17.

Wilcox, Rhonda V. Why Buffy Matters: The Art of Buffy the Vampire Slayer. New York, N.Y.: I.B. Tauris \& Co. 2005.

Wilson, Steve. 'Laugh, Spawn of Hell, Laugh' in Reading the Vampire Slayer: An Unofficial Critical Companion to Buffy and Angel. London; New York: Tauris Parke. 2001. P.78-97.

Yeffeth, Glenn. Ed. Seven Seasons of Buffy: Science Fiction and Fantasy Authors Discuss Their Favorite Television Show. Dallas, TX: BenBella Books. 2003. 


\section{$\underline{\text { Appendix A }}$}

The First's Speech at the end of "Lessons" (7.01):

Warren/First: Of course she won't understand, Sparky. I'm beyond her understanding. She's a girl - with sugar and spice and everything useless, unless you're baking. I'm more than that. More than flesh-

Glory/First: -More than blood. I'm-You know, I honestly don't think there's a human word fabulous enough for me. Oh, my name will be on everyone's lips, assuming their lips haven't been torn off. But not just yet. That's all right though.

Adam/First: I can be patient. Everything is well within parameters. She's exactly where I want her to be and so are you, Number 17. You're right where you belong.

The Mayor/First: So what'd you think? You get your soul back, and everything would be jim-dandy? A soul's slipperier than a greased weasel. Why do you think I sold mine? [Chuckles] Well, you probably thought that you'd be your own man, and I respect that. But you never will - (overlap)

Drusilla/First: (overlap) - will. You'll always be mine. You'll always be in the dark with me singing our little songs. You like our little songs, don't you? You've always liked them. Right from the beginning. And that's where we're going.

The Master/First: Right back to the beginning. Not the bang. Not the word. The true beginning. The next few months are going to be quite a ride and I think we're all going to learn something about ourselves in the process. You'll learn you're a pathetic schmuck if it hasn't sunk in already. Look at you, trying to do what's right just like her. You still don't get it. It's not about right. It's not about wrong.

Buffy/First: It's about power. 


\section{Appendix B}

The mutiny argument at the end of "Empty Places," (7.19):

Buffy: Look, I know what you're thinking, but I had a visit today at the school from Caleb.

Dawn: Buffy, wh-why didn't you-

Buffy: I'm fine. I mean, it wasn't fun, but I'm fine. I'm better than fine. I figured something out. He kept making all this noise about the school.

Robin: Is it that seal again?

Willow: Do we need to try shutting it again?

Buffy: No, that's just it. We've spent all this time worrying about the Seal and the Hellmouth. Wh-why isn't Caleb guarding them? Why doesn't he have someone there protecting it? Why is he camped out at the vineyard? The bad guys always go to where the power is. So if the Seal is so important to Caleb and the First, they would be there right now. They're protecting the vineyard, or something at the vineyard. I say it's their power and I say it's time we go in and take it away from them.

Faith: Or, in the alternative, how 'bout we don't? I mean, it's a neat theory, B., but I'm not going back in that place, not without proof - and neither should you and neither should they.

Buffy: I'm not saying it's gonna be easy.

Robin: I think Faith had the floor.

Faith: Maybe it ends up the way you wanna play it, but maybe it doesn't. And right now, I don't think I want you playing the odds.

Buffy: Did you come here to fight?

Faith: Listen, we're fighters, all of us, but you gotta give me something to fight.

Something real, not-

Giles: Windmills.

Buffy: There is something there.

Giles: Maybe, but w-we can't be sure of that. Y-You- This is a hell of a lot to ask.

Robin: Too much.

Buffy: I-I don't understand this. For seven years, I've kept us safe by doing this - exactly this. Making the hard decisions. A-A-And, now, what, suddenly you're all acting like you can't trust me?

Giles: Didn't you say to me today that you can't trust us? Maybe there's something there that should be addressed.

Buffy: Is that why you sent Spike away, to ambush me? 
Giles: Come on.

Rona: You know what? I am sick of your deal with this Spike guy. This isn't about him, this is about you. You're being reckless.

Buffy: What?

Rona: You are! Man, I don't even know you and I can tell. You are so obsessed with beating $\mathrm{Caleb}$ you are willing to jump into any plan without thinking.

Buffy: This is not what I'm doing.

Kennedy: Well, that's how it feels to us. People are dying.

Willow: Kennedy.

Kennedy (to Willow): Why are you always standing up for her?

Willow: I'm not.

Buffy: What do you mean you're not?

Willow: With everything that's happened, I-I'm worried about your judgment.

(silent pause as Buffy looks around)

Buffy: Look, I wish this could be a democracy. I really do, but democracies don't win battles. It's a hard truth, but there has to be a single voice. You need someone to issue orders and be reckless sometimes and not take your feelings into account. You need someone to lead you.

Anya: And it's automatically you. You really do think you're better than we are.

Buffy: No, I-

Anya (con't): But we don't know. We don't know if you're actually better. I mean, you came into the world with certain advantages, sure. I mean, it's the legacy.

Buffy: I-

Anya: But you didn't earn it. You didn't work for it. You've never had anybody come up to you and say that you deserve these things more than anyone else. They were just handed to you. So, that doesn't make you better than us. That makes you luckier than us.

Buffy: I've gotten us this far.

Xander: But not without a price.

Buffy: Xander.

Xander: I'm trying to see your point here, Buff, but I guess it must be a little bit to my left...cause I just don't.

Buffy: Look, I'm willing to talk strategy. Okay, I'll hear suggestions on how to break this down, but this is the plan. We have to be together on this, or we will fail again.

Giles: We are clearly demonstrating that we are not together on this.

Buffy: Which is why you have to fall in line. I'm still in charge here.

Rona: And why is that exactly? 
Buffy: Because I'm the Slayer.

Rona: And isn't Faith a Slayer too?

Faith: What? Whoa, whoa, whoa. So not what I meant. I'm not "in charge chick." I think B. here just needs to chill out for a little bit, take a siesta or something but I'm not the one you want.

Kennedy: Maybe we need a vote...to see who wants Faith to have a turn in charge.

Buffy: No.

Kennedy: No what?

Buffy: No, you don't get to vote until I've had my chance to pal around, you know, get everybody drunk. See, I didn't get that this was a popularity contest. I should have equal time to bake them cookies, braid their hair.

Faith: Learn their names.

Buffy (scoffs): You're just lovin' this, aren't you?

Faith: You have no idea what I'm feeling.

Buffy: Come in here. Take everything I have. I mean, you did it before. Did you tell them that? Did you tell them how you used to kill people for fun? Hey, you guys think that's nifty?

Giles: Buffy, that's enough!

Faith: I didn't come here to take anything away from you, but I'm not gonna be your little lap dog, either. I came here to beat the other guy. To do right, however it works. I don't know if I can lead, but the real question is, can you follow?

Robin: So, we vote.

Buffy: Wait, guys. (she looks around) I can't watch you just throw away everything- I know I'm right about this. I just need a little- I can't stay here and watch her lead you into some disaster.

Dawn: Then you can't stay here. Buffy, I love you...but you were right. We have to be together on this. You can't be a part of it. So, I need you to leave. I'm sorry... but this is my house, too.

(Buffy leaves) 
Buffy's “everybody sucks but me" speech in "Get It Done," (7.15):

Buffy: Anybody want to say a few words about Chloe? (silence) Let me. Chloe was an idiot. Chloe was stupid. She was weak. Anyone in a rush to be the next dead body I bury? It's easy. Just think of Chloe and do what she did and I'll find room for you next to her and Annabelle. I'm a Slayer, the one with the power and the First has me using that power to dig our graves. I've been carrying you - all of you too far, too long. Ride's over.

Kennedy: You're out of line.

Willow: No, she's not.

Kennedy (to Willow): You're gonna let her talk to you like that? Willow, she's not even the most powerful one in this room. With you here, she's not close.

Buffy: You're new here, and you're wrong because I use the power that I have. The rest of you are just waiting for me.

Xander: Well, yeah, but only because you kind of told us to. You're our leader, Buffy, as in "follow the."

Buffy: Well, from now on, I'm your leader, as in "do what I say."

Xander: Jawoh! But let's not try to forget, we're also your friends.

Anya: I'm not!

Buffy: Then why are you here? Aside from getting rescued, what is it that you do?

Anya: I provide much needed...sarcasm.

Xander: Um, that'd...kind of be my job, actually.

Buffy (to Anya): You're here because you're scared.

Xander: Same goes for everyone in this room.

Buffy: Fine. Anya, all of you, be as scared as you'd like. Just be useful while you're at it. Willow: Come on, Buffy. You know everyone here is doing everything they can.

Buffy: And the First isn't impressed. It already knows us. It knows what we can do and it's laughing. You wanna surprise the enemy, surprise yourselves. Force yourself to do what can't be done or we are not an army. We're just a bunch of girls waiting to be picked off and buried.

(Spike goes to leave)

Buffy (con't): Where are you going?

Spike: Out. Since I'm neither a girl nor waiting all this speechifying doesn't really apply to me, does it?

Buffy: Fine. Take a cell phone. That way, if I need someone to get weepy or wailed on, I can call you.

Spike (stops): If you've got something to say-

Buffy: I just said it. You keep holding back, you might as well walk out that door. 
Spike: Holding back? You're blind. I've been here, right in it - fightin', scrappin'. Buffy: Since you got your soul back?

Spike: Well, as a matter of fact, I haven't been quite relishing the kill the way I used to. Buffy: You were a better fighter then.

Spike: I did this for you! The soul, the changes - It's what you wanted.

Buffy: What I want is the Spike that's dangerous, the Spike who tried to kill me when we met.

Spike: Oh, you don't know how close you are to bringing him out.

Buffy: I'm nowhere near him. (still looking at Spike) Dawn, get the potentials upstairs and break out that emergency kit.

Dawn: What are you gonna do?

Buffy (exiting room): I'm declaring an emergency. 


\section{Appendix D}

The Colonel's conversation in the Initiative with the Scoobies from "Primeval" (4.21)

Buffy: Colonel-

Colonel: Shut up. You've got some nerve lady

Buffy: You have to listen to us

Colonel (opening bag): You think you and your friends can just keep waltzing into a government installation Brandishing weapons like- (holds gourd) Like...

Willow: It's a gourd.

Giles: Magic gourd.

(Silence)

Colonel: What kind of freaks are you people?

Buffy: Adam is here, Colonel. In the Initiative.

Colonel: Nice try.

Buffy: Those overcrowded containment cells of yours - courtesy of Adam. He's pulling a Trojan Horse on you. He's just waiting-

Colonel: Every inch of this installation is under constant 24-hour surveillance.

Willow: Including the secret lab?

Colonel: Including everything! (Silent pause) What secret lab?

Buffy: The one Adam's been using. The one built for the final phase of the 314 project. (he gives her a blank look) And you have no idea what I'm talking about.

Colonel: I know everything that goes on around here. A tick on a mouse couldn't get in without my knowing it and if Adam wants to try, we're ready for him.

Giles: Jolly good. How exactly do you plan to get close enough to Adam to remove his power source?

(Silence)

Colonel: Hit him simultaneously with multiple taser blasters. Incapacitate him with as much voltage as we can muster.

Xander: Great plan. That's right up there with "duck and cover."

Buffy: I've seen Adam hit with taser blasts. He feeds on it. And now you're going to provide him with an all-you-can-eat buffet?

Colonel: You telling me my business?

Buffy (advancing): This is not your business. It's mine. You, the Initiative, the boys at the Pentagon - you're all in way over your heads, messing with primeval forces you have absolutely no comprehension of.

Colonel: And you do?

Buffy: I'm the Slayer. You're playing on my turf.

Colonel: Up there, maybe. But down here I'm the one who's in control

(Lights go out) 


\begin{abstract}
Appendix E
The Mayor discusses the Buffy/Angel relationship in "Choices" (3.19)

Mayor: I wish you kids the best, I really do, but, uh, if you don't mind a bit of fatherly advice...I, uh...I just don't see much of a future for you two. I don't sense a lasting relationship. And not just because I plan to kill the both of you, but you got a bumpy road ahead.
\end{abstract}

Buffy: I don't think we need to talk about this.

Mayor (chuckles): Y-You kids, you know... you don't like to think about the future, you don't like to make plans but unless you want Faith to gut your friend like a sea bass you will show a little respect for your elders

Angel: You're not my elder. I got a lot of years on you.

Mayor: Yeah and that's just one of the things you're gonna have to deal with. You're immortal. She's not. It's not easy. I married my Edna Mae in '03 and I was with her right until the end. Not a pretty picture. Wrinkled and senile and cursing me for my youth. Wasn't our happiest time. And let's forget the fact that any moment of true happiness will turn you evil (snickers). I mean, come on, what kind of life can you offer her? I don't see a lot of Sunday picnics in the offing. I see skulking in the shadows, hiding from the sun. She's a blossoming young girl and you want to keep her from the life she should have til its passed her by. And by God, I think that's a little selfish. Is that what you came back from hell for? Is that your greater purpose?

(Buffy closes her eyes; silence)

Mayor: Make the trade. 


\section{Appendix F}

Buffy and Faith's conversation at the end of "Revelations" (3.07)

Buffy: Place looks nice.

Faith: Yeah, it's real Spartan.

Buffy: How are you?

Faith: Five by five.

Buffy (nodding slightly): I'll interpret that as good. (pause) Look, Gwendolyn Post or whoever she may be, had us all fooled. Even Giles.

Faith: Yeah, well, you can't trust people. I shoulda learned that by now.

Buffy: I realize this is going to sound funny coming from someone that just spent a lot of time kicking your face...but you can trust me.

Faith: Is that right?

Buffy: I know I kept secrets, but I didn't have a choice. I'm on your side.

Faith: I am on my side. And that's enough.

Buffy: Not always.

Faith: Is that it?

(pause)

Buffy: Yeah, I guess.

Faith: All right. Well, then, I'll see you. (turns back to tv)

(Buffy turns to leave)

Faith: Buffy?

Buffy (turns): Yeah?

(Pause)

Faith: Nothing.

(Buffy leaves) 


\section{Appendix G}

Faith's conversations with Buffy in "Bad Girls" (3.14)

1 - Faith goes to follow the E1 Illuminati:

Buffy: Wait! Stop! Think.

Faith: No, no, no!

Buffy: It's a manhole, tight space, no escape, 6 against 2 - not unlike 3 against one.

Faith (grabbing her by the hand): And there might be more, so come on.

Buffy: You're just going to go down there. That's your plan?

Faith: Who said I had a plan? I don't know how many's down there, but I want to find out. And I'll know when I land, and if you don't come in after me, I might die.

(She jumps down. Buffy hesitates, then follows)

$-$

2 - In Faith's motel, following Allan Fitch's death:

(Faith cleans her blood stained shirt in the sink)

Buffy (v.o): Faith, it's me.

(Faith opens door)

Buffy: Hey.

Faith: Hey.

(Faith returns to sink to clean t-shirt)

Buffy: So, I, uh- (sees the shirt) How are ya doin'?

Faith: I'm all right. You know me.

Buffy: Faith, we need to talk about what we're gonna do.

Faith: There's nothing to talk about. I was doing my job.

Buffy: Being a Slayer's not the same thing as being a killer. (silence) Faith, please don't shut me out here. Look, sooner or later, we're both gonna have to deal.

Faith: Wrong.

Buffy: We can help each other.

Faith: I don't need it. (pulls plug on sink and walks into main room)

Buffy: Yeah? Who's wrong now? Faith, you can just shut off all the emotions that you want. But eventually, they're gonna find a body.

Faith: Ok, this is the last time we're gonna have this conversation and we're not even having it now, understand me? There is no body. I took it, weighted it, and dumped it. The body doesn't exist.

Buffy: Getting rid of the evidence doesn't make the problem go away.

Faith: It does for me.

Buffy: Faith, you don't get it. You killed a man.

Faith: No, you don't get it. I don't care.

(Close-up of Buffy's disbelieving face; Credits) 


\section{Appendix H}

Faith and Buffy's conversation at UC Sunnydale in "This Year's Girl" (4.15):

Faith: So...check you out, B. Nice, the big girl on campus thing's really working for you. Buffy: I've been looking for you.

Faith: I've been standing still for eight months, B. How hard you look?

Buffy: Are you alright?

Faith: 5 by 5 . That's the thing about a coma. You wake up feeling all rested and rejuvenated and ready for some payback.

Buffy: So much for pleasantries, huh?

Faith: What'd you think, I'd wake up and we'd go for tea? You tried to gut me, blondie.

Buffy: You'd have done the same to me if you had the chance.

Faith: So let's have another go at it, see who lands on top.

Buffy: It doesn't have to be like this, you know?

Faith. Actually, I think it has to be exactly like this.

Buffy: Faith, these are innocent people.

Faith: No such animal.

Buffy: I guess it was too much to hope that you'd use your down time to reflect and grow.

Faith: Could say the same about you. I mean, you're still the same old "better than thou" Buffy. I mean, I knew it somehow. I kept having this dream. I'm not sure what it means, but in the dream, this self-righteous blonde chick stabs me and you wanna know why?

Buffy: You had it coming.

Faith: That's one interpretation, but in my dream she does it for a guy.

(Willow tries to sneak behind her)

Faith - con't: Try it Red, and you lose an arm.

(Buffy motions to Willow to stop)

Faith - con't: I wake up to find out that this blonde chick isn't even dating the guy she was so nuts about before. I mean, she's moved on to the first college beefstick she meets. And not only has she forgotten the love of her life, she's forgotten all about the chick she nearly killed for him. So that's my dream. That and some stuff about cigars and a tunnel. But, uh, tell me, college girl what does it mean?

Buffy: To me? Mostly...that you still mouth off about things you don't understand. (sirens)

Buffy - con't: Uh-oh. I guess somebody knows you're here.

(Faith punches her) 


\section{Appendix I}

Giles and Willow's Argument in "Flooded" (6.04):

Giles: Tell me about the spell you performed.

Willow: Oh. Okay, first of all, so scary. Like, the Blair Witch would have had to watch like this. (covers eyes with hand and peeks through) A-And this giant snake came out of my mouth and there was all this energy crackling and this pack of demons interrupted, but I totally kept it together. And then, the next thing you know...Buffy.

(she eats a cookie)

Giles: You're a very stupid girl.

Willow (stops eating): What? Giles.

Giles: Do you have any idea what you've done? The forces you've harnessed, the lines you've crossed?

Willow: I thought you'd be impressed or something.

Giles: Oh, don't worry. You've...made a very deep impression. Of everyone here...you were the one I trusted most to respect the forces of nature.

Willow: Are you saying you don't trust me?

Giles: Think what you've done to Buffy.

Willow: I brought her back.

Giles: At incredible risk!

Willow: Risk? Of what? Making her deader?

Giles: Of killing us all. Unleashing hell on earth. I mean, shall I go on?

Willow (standing): No. Giles, I did what I had to do. I did what nobody else could do.

Giles: There are others in this world who can do what you did. You just don't want to meet them.

Willow: No, probably not, but-Well, they're the bad guys. I'm not a bad guy. I brought Buffy back into this world and maybe the word you should be looking for is "congratulations."

Giles: Having Buffy back in this world makes me feel indescribably wonderful but I wouldn't congratulate you if you jumped off a cliff and happened to survive.

Willow: That's not what I did, Giles.

Giles: You were lucky.

Willow: I wasn't lucky. I was amazing. And how would you know? You weren't even there.

Giles: If I had been, I'd have bloody well stopped you. The magics you channeled are more ferocious and primal than anything you can hope to understand and you are lucky to be alive, you rank, arrogant amateur!

(He goes to leave)

Willow: You're right.

(Giles stops)

Willow (con't): The magics I used are very powerful. I'm very powerful, and maybe it's not such a good idea for you to piss me off. 


\section{Appendix J}

Angel and Buffy's post-coital conversation in "Innocence" (2.16):

Buffy: I was freaking out. You just disappeared.

Angel: What? I took off.

Buffy: But you didn't say anything. You just left.

Angel: Yeah. Like I really wanted to stick around after that.

Buffy: What?

Angel: You got a lot to learn about men, kiddo. Although I guess you proved that last night.

Buffy: What are you saying?

Angel: Let's not make an issue out of it, OK? In fact, let's not talk about it at all. It happened.

Buffy: I don't understand. (pause) Was it...me? Was I not good?

Angel (laughs): You were great. Really. I thought you were a pro.

Buffy: How can you say this to me?

Angel: Lighten up. It was a good time. It doesn't mean we have to make a big deal.

Buffy: It is a big deal.

Angel: It's what? Bells ringing? Fireworks? A dulcet choir of pretty little birdies? Come on, Buffy. It's not like I've never been there before.

(He goes to stroke her cheek and she jerks back)

Buffy: Don't touch me.

Angel: I should have known you wouldn't be able to handle it.

(He laughs and goes to leave)

Buffy: Angel! (he turns) I love you

Angel: I love you, too. (walks to door) I'll call you

(He exits) 


\section{Appendix K}

The Angel Intervention argument in "Revelations" (3.07):

Buffy: What's going on?

Giles: We know Angel is alive. Xander saw you with him. It would appear that you've been hiding him and that you lied to us.

Willow: Nobody's here to blame you, Buffy. But this is serious. You need help.

Buffy: It's not what you think.

Xander: Hope not. Because I think you're harboring a vicious killer.

Willow: This isn't about attacking Buffy. Remember, 'I' statements only - "I feel angry." "I feel worried."

Cordelia: Fine. Here's one - I feel worried...about me! Last time around, Angel barely laid a hand on Buffy. He was way more interested in killing her friends.

Buffy: But he's better now.

Xander: Better for how long, Buffy? I mean, did you even think about that?

Buffy (standing): What is this, Demons Anonymous? (turns) I don't need an intervention, here.

Giles: Oh, don't you? You must have known it was wrong seeing Angel or you wouldn't have hidden it from all of us.

Buffy (struggling): I was going to tell you, I was. It was just that I - I didn't know why he came back. I just wanted to wait.

Xander: For what? For Angel to psycho again the next time you give him a happy?

Buffy: I'm not going to - We're not together like that.

Oz: But you were kissing him.

(silence)

Buffy (to Xander): You were spying on me? What gives you the right?

Cordelia: What gives you the right to suck face with your demon lover again?

Buffy: It was an accident.

Xander: What, you just tripped and fell on his lips?

Buffy: It was wrong, OK? I know that, and I know that it can't happen again. But you guys have to believe me. I would never put you in any danger. If I thought for a second that Angel was going to hurt anyone -

Xander: - you would stop him. Like you did last time with Ms. Calendar.

(Buffy looks at him, shocked)

Willow: Buffy. I feel that when it comes to Angel, you can't see straight. And that's why we're - we're all going to help you face this. 
Buffy: But he's better now. I swear. Look, you guys, he's the one who found the Glove of Myhnegon. He's keeping it safe for us in the mansion.

Xander: Right! Great plan. Leave tons of firepower with a scary guy and leave us to clean up the mess (he walks away)

Buffy: You would just love an excuse to hurt him, wouldn't you?

Xander: I don't need an excuse. I think lots of dead people actually constitutes a reason.

Buffy: Right. This is all nobility. This has nothing to do with jealousy.

Cordelia: Hello? Miss Not-Over-Yourself-Yet?

Buffy: Don't you start with me.

Willow: Giles, no one's doing the 'I' statements.

Giles: That's enough! Everybody. Now Buffy knows our concerns, and her actions, however ill-advised, can be understood. Our...priority right now is to retrieve the Glove of Myhnegon and try to destroy it. Now, all of you, back to classes.

\section{Appendix L}

Giles' reminds Buffy of Angelus' torturous activities in "Revelations":

Buffy: Thanks for the bail in there. I know this is a lot to absorb, but Angel did find the glove, and that was a good -

Giles: - Be quiet. I won't remind that the fate of the world often lies with the Slayer. What would be the point? Nor shall I remind you that you've jeopardized the lives of all that you hold dear by harboring a known murderer. But, sadly, I must remind you that Angel tortured me...for hours...for pleasure. You should have told me he was alive. You didn't. You have no respect for me or the job I perform.

(He sits down, looking away from her. She turns and exits silently) 


\section{Appendix M}

Buffy and Spike's Basement Conversation in "Never Leave Me" (7.09)

(Buffy starts off at the sink in long shot)

Spike: Have you ever really asked yourself why you can't do it - off me? After everything I've done to you, to people around you? It's not love. We both know that.

Buffy: You fought by my side. You've saved lives. You've helped-

Spike: Don't do that. Don't rationalize this into some noble act. We both know the truth of it. (pause) You like men who hurt you.

Buffy: No.

Spike: You need the pain we cause you. You need the hate. You need it to do your job to be the Slayer.

Buffy (forcefully): No. I don't hate like that. Not you... or myself. Not anymore.

(She approaches) ...

Buffy: You may not believe in you Spike. But I do. I do. I believe in you Spike.

(By this point they are in a medium two-shot a short distance apart) 


\section{Appendix: Characters}

\section{The White Hats (aka the Good Guys)}

Buffy: The Slayer, chosen to fight monsters, who moves to Sunnydale with her divorced mother after she is expelled from her high school in Los Angeles. Her calling as the Slayer is accompanied by super strength and the ability to heal quickly. Additionally she is often clumsy and has a tendency to date the bad guy.

Willow: Buffy's best friend. Initially shy and book smart, Willow develops into a powerful witch in the second season and comes out as a lesbian in season four. In season six she tries to destroy the world as Dark Willow after her girlfriend Tara's death and spends most of season seven trying to comes to grips with her powers.

Xander: Buffy and Willow's best friend. Xander has no powers, which often forces him to play the comic sidekick who gets hurt. His eye is gouged out in season seven and his former fiancée, Anya, is killed in the series finale.

Giles: Initially the Sunnydale High librarian and Buffy's Watcher - part of a Council of adults who train Slayers. He loses both his jobs in season three: he is fired from the Watchers Council for being too fond of Buffy and then the school is blown up. When he was younger he was part of a black magic group and went by the name of Ripper.

Angel: Buffy's vampire boyfriend from season one through three. Angel was once a violent beast until he turned a young gypsy girl named Drusilla whose clan cursed him with a soul. In season two he loses his soul when he experiences a moment of happiness with Buffy and becomes Angelus - his soulless vampire alter-ego - and kills several of her friends, including Giles' girlfriend. Buffy kills him in the season two finale, although he returns with his soul intact in season three. He leaves at the end of the season to go to Los Angeles.

Dawn: Buffy's sister, created out of energy by monks in season five to protect her from Glory. Her blood is used to open a portal that collapses universes together, forcing Buffy to sacrifice herself in Dawn's place. Her role is less significant in seasons six and seven, although she helps Buffy reconnect to her responsibilities and the world during Dark Willow's reign.

Oz: Willow's boyfriend in seasons two through four. He is a bassist for the band Dingoes Ate My Baby and a werewolf. His inability to control his mutation causes him to leave Sunnydale in season four.

Tara: Willow's first girlfriend from season four to six. She also serves as Willow's magical mentor, helping her to develop her magical skills. She is killed by Warren in "Seeing Red" (6.19) and her death fuels Willow's transformation into Dark Willow. 
Anya: The former vengeance demon who creates the alternate universe in "The Wish" (3.09) later becomes Xander's fiancée. Her speech is distinctive in that she often tells the literal truth without sugarcoating. She dies in the series finale.

Riley: Buffy's boyfriend in season four and part of season 5. He initially works for the Initiative as a high ranking commando, but his relationship with Buffy convinces him that the Initiative's methods, morals and practices are corrupt. After he stops taking the Initiative's supplements, he becomes a regular guy and feels as though Buffy no longer needs him. Shortly after she discovers he has been allowing vampires to bite him, Riley takes a job with former commando Graham in Paraguay and leaves Sunnydale.

Wesley: Giles' replacement after he is fired from the Watchers' Council. His strict adherence to the rules goes awry when he tries to abduct Faith after she accidentally kills Alan Finch. His plan is in part responsible for turning Faith against the Scoobies and he leaves Sunnydale at the end of the third season.

Cordelia: Originally a rich bitch cheerleader, Cordelia becomes entangled in various adventures with the group, including fighting the beast that emerges from the hellmouth in "Prophecy Girl" (1.12) and later dates Xander until mid-season three. In terms of speech, she is Anya's predecessor because she always speaks her mind, often about herself.

Jenny Calendar: Giles' love interest in seasons one and two, she is a descendant of the gypsy clan that cursed Angel. Her ties to computer technology and magic are a useful tool for the Scoobies, but her silence about Angel's curse ostracizes her from the group when he becomes Angelus. On the eve of her reunion with Giles, Jenny is killed by Angelus.

Joyce Summers: Buffy's divorced, single mother. Initially she is unaware of Buffy's status as the Slayer until Buffy tells her the truth in "Becoming, Part 2" (2.22). After this she becomes interested in Buffy's job, but is always eager and hopeful for a chance for Buffy to live a normal life. She dies of a brain tumour in season five.

Kennedy: Willow's second girlfriend, a potential Slayer who stays at the Summers house in season seven. She is highly antagonistic when she deals with authority figures, especially Buffy's treatment of Willow.

Robin Wood: The new principal of Sunnydale High in season seven and the son of the second Slayer killed by Spike. He is initially presented as a possible villain before he becomes a powerful ally to Buffy, presenting her with the Slayer's "emergency kit" in "Get It Done" (7.15) that allows her to discover how the First Slayer was created.

Kendra: The second Slayer, called after Buffy dies in "Prophecy Girl" (1.12). She appears in only three episodes ("What's My Line, Parts 1 \& 2," 2.10-2.11, and "Becoming, Part 1") before she is killed by Drusilla. 


\section{The Black Hats (aka the Big Bads and other villains)}

The Master (season 1): The Master is a 600 years old vampire with no true name. He was trapped in a church underground following an earthquake that forces him to adhere to prophecies detailing the specifics of how and when he can escape. In the first season's final episode, he drowns Buffy and ascends to the school roof. Buffy is revived and stakes him on a broken library table beneath the skylight.

Darla (season 1): The Master's favourite minion and Angel's sire (the vampire who turned him). She is staked by Angel in 1.07 as a demonstration of his goodness.

Spike (season 2): A youthful vampire who comprises one half of season two's Big Bad couple, Spike eventually begins working with Buffy to save the world (starting with "Becoming, Part 2," 2.22). He becomes a main character in season four when the Initiative implants him with a chip to prevent his injuring people, and falls in love with Buffy in season five. The two begin a sexual relationship in season six, which ends when he tries to rape Buffy. The guilt drives him to get a soul before returning to Sunnydale. He ultimately becomes a champion in the series finale when he uses an amulet to kill all the ubervamps, but dies in the process.

Drusilla (season 2): Spike's vampire girlfriend. She is Spike's sire, and Angel sired her. It is because of Drusilla that the gypsies inflicted Angelus with a soul. Her primary function is making Buffy jealous about Angel, although she also kills Kendra in "Becoming, Part $1 . "$

Angelus (season 2): The main villain of the second half of season two. Angel loses his soul after experiencing a moment of true happiness with Buffy in "Surprise" (2.13) and becomes Angelus. He initiates an apocalypse after torturing Buffy by killing her friends.. Buffy stops him, but not before he tortures Giles and starts the ritual, forcing her to kill him even though his soul is reinstated.

The Mayor (season 3): Richard Wilkins III is the founder of Sunnydale and its perennial Mayor. His plan is to ascend and become a pure demon. This coincides with Buffy's graduation day, forcing her to kill him by blowing up the school. His other important role is as a father figure to Faith, for whom he provides the means to switch places with Buffy in the body-swap episodes in season four.

Faith (season 3/4/7): The second Slayer called after Kendra's death, Faith arrives in Sunnydale after a vampire named Kakistos kills her Watcher. The relationship between the two Slayers is never open and takes a turn for the worse in "Revelations" (3.07) when her trust is abused by fake Watcher Gwendolyn Post. When she kills the deputy Mayor, Allan Finch, in "Bad Girls" (3.14), Faith tries to blame Buffy and escape from Sunnydale rather than face the consequences. She joins the Mayor as a rogue Slayer and ultimately tries to poison Angel. To save his life, Buffy stabs Faith and she spends the next eight months in a coma, returning to swap bodies with Buffy in "This Year's Girl/Who Are You?"'(4.15-4.16). After escaping to Los Angeles and giving herself up to the police, 
Faith returns to Sunnydale to battle the First in season seven. The animosity between Buffy and Faith continues when the potentials elect Faith to lead her, although Buffy ultimately regains her position of authority. Faith survives the final battle and the finale suggests she and Robin begin a mature relationship.

The Initiative (season 4): A government military organization located under Sunnydale U whose members include Riley and Maggie Walsh, Buffy's psych professor.. They capture and implant Spike with a chip and recruit Buffy through her boyfriend (Riley) and Walsh. Eventually Buffy discovers that Walsh is building a Frankenstein-like creation named Adam and that the Initiative drugs all their commandos with performance enhancing supplements. She and Riley quit and lead their own rebellion against Adam, whose endgame destroys the Initiative.

Adam (season 4): Walsh's creation is a human-demon cyborg. After killing Walsh, Adam kills humans and demons to study their anatomy. His endgame involves starting a war between Buffy and the demons held captive inside the Initiative in order to create an army of demonoid-hybrids like himself. Buffy ultimately destroys him by merging with the essence of her three friends and ripping out his uranium core power source.

Glory (season 5): One of three gods ruling a hell world adjacent to earth. Following a battle with the other two gods, she was imprisoned in the body of a human male named Ben. Over the years she grows powerful enough to take over Ben's body and begin searching for her key - a mystical ball of energy that will open the portal to her home world. She spends the entire season stalking and torturing Buffy's friends when she's not mind-sucking humans to retain her own sanity. When she discovers Dawn is the key, she attempts to initiate the ritual, but is stopped by Buffy. Giles suffocates Ben to prevent Glory's return.

Trio of Nerds (season 6): A group of three human boys - Warren, the leader, and Jonathan and Andrew - who try to take over Sunnydale. Each has a unique skill (robots, demon calling and spellcasting) that they use to test and ultimately try to kill Buffy with. She ignores them until "Seeing Red" when she puts Jonathan and Andrew in jail, but allows Warren to escape. He shoots her and kills Tara at the end of the episode. Dark Willow tracks him down and flays him, forcing Jonathan and Andrew to flee Sunnydale for Mexico. Both return in season seven, although Andrew kills Jonathan at the First's bidding before becoming a de-facto Scooby to atone for his sins. He survives the final battle.

Dark Willow (season 6): Willow's transformed state following Tara's death. She soaks up the contents of all the Magic Box's dark arts books, kills Warren and removes the bullet from Buffy's chest. When the Scoobies attempt to stop her, she insults and belittles them. She is unknowingly put in touch with the feelings of the world after she steals Giles' magical powers, which enables Xander to talk her down after she initiates an apocalypse to end the world's suffering. Dark Willow is the only Big Bad in the series that Buffy does not defeat. 
The First (season 7): The being that created evil and previously appeared in "Amends" (3.10). The First is incorporeal and must therefore rely on minions to do its bidding (the Bringers, ubervamps, Caleb) or use its speech to frighten and intimidate. Its endgame involves entering every man, woman and child on earth. Buffy uses the power of the scythe buried in the vineyard to transfer her powers to the potentials, and Spike uses the champion's amulet to burn the ubervamps and collapse the entire town, effectively burying the First.

Caleb (season 7): A crazed preacher who is the only human capable of merging with the First, Caleb arrives in Sunnydale for the final five episodes. He is the one responsible for blowing up the Watcher's Councill, and sending the Bringers after the Slayer lineage as well as blinding Xander and killing several Potentials ("Dirty Girls," 7.18). Buffy ultimately cuts him in half with the scythe in "End of Days" (7.21).

\section{Appendix: Plot}

\section{Season 1}

Season one introduces Buffy as the vampire Slayer: the one girl chosen to defend the world against vampires, demons and other evils. However, after Slaying in Los Angeles got Buffy expelled from school and caused her parents divorce, she only wants to be a normal girl. Together with her new friends, Xander and Willow, and Wacther Giles, she reluctantly battles the Master as he attempts to ascend - an act that will open the mouth of hell and unleash pure demons on earth.

\section{$\underline{\text { Key episodes }}$}

Welcome to the Hellmouth / The Harvest (1.01-1.02): The two part pilot that introduces the characters and initiates the Master's first prophecy: the Harvest. In order to break free of the church he has been imprisoned in for one hundred years, the Master uses his minion, Luke, as a vessel. Buffy and the others go to the Bronze, a local youth club, to stop the massacre, which is conveniently covered up as a rival gang war the next day. It is also made clear that Buffy's mother, Joyce, has no idea what her daughter is and establishes that Buffy is considered a "bad seed" by the school authorities for burning down her previous High School gym.

Never Kill a Boy on the First Date (1.05): Buffy's attempt at having a normal life takes a turn for the better when broody high school student Owen asks her out. Naturally the date takes place on the same night as a prophecy involving the Anointed One, a powerful vampire that will ally with the Master. When Giles mixes up the night, Buffy must take Owen along with her to the mortuary to stop Andrew Borba, a crazed religious man killed in a vampire attack on a bus and the one they believe to be the Anointed One. Owen is nearly killed by Borba and later reveals that he is attracted to the adventure he gets with Buffy, who must let him down easy. Giles reminds her that she shouldn't date people who don't know her secret identity as Slayer because it puts everyone at risk. The episode ends by revealing it was the little boy on the bus that is the Anointed One, and he has joined the Master underground. 
Angel (1.07): Buffy's growing attraction to the mysterious stranger, Angel, proves problematic when she learns he is actually a vampire. She learns about his curse - that he has a soul - but this doesn't stop her from trying to kill him at the Bronze. When the moment comes, neither finds themselves able to strike a killing blow, save Darla, the Master's favourite minion and Angel's sire. In order to prove his love for Buffy, Angel stakes Darla and gives Buffy a silver cross on a necklace for her protection.

Prophecy Girl (1.12): In the season one finale, Buffy learns that she is fated to die. The Codex Prophecy proclaims that the Master will kill her and ascend to the surface. The news, as well as signs of the upcoming apocalypse, prompt Buffy to reject her calling as Slayer and leave town with her mom. It is only when her mother believes she is unhappy because the right boy didn't ask her to prom and Willow relates a vampire attack on the school that Buffy realizes she must use her powers to stop the Master, even if it means her death. Dressed in her white prom dress, she follows the Anointed One underground where the Master bites her and drowns her in a shallow pool. His ascension opens the hellmouth in the library, allowing a tentacled demon to emerge and attack Giles, Jenny Calendar, Willow and Cordelia. Xander resuscitates Buffy, who emerges stronger from her brush with death and fights the Master on the roof of the school, staking him on the broken library desk located beneath the skylight.

\section{Season 2}

Buffy returns after a summer in Los Angeles suffering nightmares from her encounter with the Master. Her attention is quickly diverted to the new Big Bads in town: Spike and Drusilla. Spike spends the first half of the season trying to cure Drusilla, who is sick, and ultimately uses a ritual involving Angel's blood to restore her health. Their roles are reversed when Spike is injured, forcing Drusilla to look after him. The power balance changes when Angel loses his soul after sleeping with Buffy and becomes Angelus. The rest of the season is occupied with Buffy's attempt to overcome her romantic feelings for her former lover, who torments and kills her friends before attempting to invoke an apocalypse. Willow performs the curse moments to return Angel's soul, but he has already opened the portal, forcing Buffy to kill him and run away.

\section{Key Episodes}

School Hard (2.03): The episode that marks the transition from season one to season two. Spike and Drusilla arrive in Sunnydale and Spike decides to kill Buffy on a prophecized night. Instead of waiting, though, he attacks a day early during Parent Teacher Night while Principal Snyder tries to tell her mom what a bad student she is. Joyce quickly learns to respect her daughter's ability to defend herself, while the early interaction between Buffy and Spike serves to demonstrate that he is nothing like the Master: he is young, sexual and does not adhere to rituals. This is further demonstrated when he returns to the factory and hoists the Anointed One into the sunrise.

What's My Line, Pt 2 (2.11): The conclusion of the two part finds Buffy and Kendra in a stand-off in Angel's apartment, each claiming to be the Slayer. After it is discovered that they are both telling the truth, Kendra takes Buffy to rescue Angel, who has already been kidnapped by Spike for the ritual to restore Dru's health. When Giles discovers that 
the ritual will kill Angel, Buffy and Kendra return to Willie's where they bicker about what to do next. Buffy wants to go directly after Angel, whereas Kendra believes Angel "clouds her judgment" and lets her go with Willie by herself. Buffy is led into a trap, and rescued just in time by Kendra and the other Scoobies, who defeat the assassins from the Order of Taraka that Spike hired to kill Buffy. After Spike and Buffy face off, she saves Angel and collapses a church organ on top of Spike and Dru. The episode ends with Angel's safe return, but reveals that Dru's health has been restored as she carries off an unconscious Spike with ease.

Innocence (2.14): The unofficial second half of a two-part cliffhanger begins immediately after "Surprise" (2.13) ends: with Angel gasping for breath in the rain outside his apartment. When he kills a hooker, it is clear that something is wrong - a fact explained when he turns up at the factory and the fully assembled Judge informs Spike (now in a wheelchair) and Dru that there's no humanity in him. Buffy is unaware that Angel has lost his soul when they meet later and he mocks her sexual skills. When he tries to attack Willow at the school, Buffy and Jenny realize that he is no longer Angel, but Angelus. The episode's climax occurs when Dru and Angelus take the Judge to the mall to feed and Buffy destroys him with a rocket launcher - Xander's birthday present to her. Buffy faces Angelus, but finds herself unable to kill him, promising that she will soon overcome her hesitation.

Becoming Pt 1 \& 2 (2.21-2.22): Willow discovers the cure to reinstate Angel's soul as Angelus sets to work on initiating an apocalypse by awakening Acathla - a stone demon who will suck the world into hell with a single breath. The two sides race against each other until it becomes clear that Angelus is missing something from his ritual. He and Buffy meet to spar, but neither puts in their full effort. It becomes clear to Buffy that Angelus is performing the same time-stalling function for Drusilla as she is for Willow and races back to the library. She encounters Principal Snyder and is expelled before discovering Kendra has been killed (by Dru), Xander's arm is broken, Willow is in a coma and Giles has been abducted. The first part ends when the police arrive.

The second part begins as Buffy escapes. She visits Willow at the hospital in disguise and encounters an unlikely ally in Spike, who wants to make a bargain: if she allows him and Dru to escape, he will help her stop Angelus. She agrees, but when she attempts to leave her mother forbids her to go, even after being told the truth about Buffy's status as the Slayer. Joyce tells Buffy if she leaves never to return, which Buffy accepts. At the hospital Willow attempts the curse a second time, sending Xander to tell Buffy to stall. Because he dislikes Angel, Xander says nothing to Buffy when he meets her on the way to Angel's mansion. Inside, Xander rescues Giles, who has been tortured by Angelus, and Spike knocks Dru unconscious and slips away with her, leaving Buffy and Angelus to battle it out with swords. Willow invokes the curse at the last moment, restoring Angel's soul moments after Acathla opens its mouth. Buffy kisses Angel and then stabs him, closing the portal. Completely distraught, she leaves Sunnydale by bus without a word to anyone. 


\section{Season 3}

After Buffy returns following her summer in Los Angeles where she has been working as a waitress under another name, she finds she must earn back the trust of her friends, mother and Principal Snyder. Another Slayer appears named Faith, whom everyone is initially excited about, but is ultimately excluded by the group. Just as Buffy's life begins to resemble her life beforehand, Angel returns. Buffy keeps his presence secret, but the truth comes out, much to the group's concern and dismay.

Meanwhile, the season's new Big Bad has been secretly operating behind the scenes: Sunnydale's Mayor, who uses Mr. Trick, one of the vampires trailing Faith, as his henchman. After Faith accidentally kills the deputy Mayor, she tries to blame Buffy and run away, but Buffy encourages her to stay. Unfortunately, Faith joins the Mayor after staking Mr. Trick, and operates as his mole amongst the group. She is discovered when Angel goes undercover as Angelus to discover that the Mayor is planning to ascend to pure demon-hood at the Sunnydale High Graduation. To stop Buffy, Faith shoots Angel with a poison whose only cure is Slayer's blood. This initiates a deadly battle between the Slayers that ends when Buffy stabs Faith, who manages to escape but ends up in a coma. This prompts Buffy to offer herself to Angel, but he nearly kills her. In a dream Faith tells Buffy how to defeat the Mayor, and Buffy organizes the entire student body into an army to oppose him come graduation day. Using the knife she stabbed Faith with, Buffy leads the transformed Mayor - now in the form of a giant snake - into the library where she and Giles have laid an explosive trap. Together they destroy the school and the Mayor, paving the way for University and adulthood. With the battle done and their relationship over, Angel leaves to go to Los Angeles.

\section{Key Episodes}

Revelations (3.07): A new Watcher arrives for Faith, Gwendolyn Post, who exposes the lengths to which Faith is an outsider among the Scoobies. Together the two women bond over their shared exclusion - a meeting that the Scoobies organized as an intervention when Xander sees Buffy and Angel kissing at his mansion. They confront her about Angel's return and the reasons behind her secrecy, which she defends because Angel has his soul. What Buffy fails to understand is the reasons behind their concerns, especially Giles, who reminds her that he was brutally tortured. Xander's distrust of Angel prompts his to misrepresent Angel's role as guardian of a powerful glove called the Glove of Myneghon. Spurred by Xander, Faith goes to mansion and discovers Angel has attacked Post - who is actually a traitor who wants the glove for herself. Buffy arrives in time to prevent Faith from staking Angel, and the girls have their first full out fight. They must resolve their issues when Post puts on the glove, but the damage done to Faith's trust is irrevocable, made clear in her refusal of Buffy's help in the final scene.

Bad Girls/Consequences (3.14-3.15): Faith prompts Buffy to taste the wild side when they patrol together in an attempt to stop a vampire sect that worships the demon Balthazar. Faith establishes her lack of foresight and appreciation for life when she leads Buffy into a close quartered fight in the sewers that almost gets Buffy killed. Afterwards Buffy skips school to infiltrate a vampire nest with Faith, go dancing at the Bronze, break and enter a weapons store and escape from police custody. Meanwhile, the audience finds 
out that the Mayor has become invincible as part of the 100 days leading up to his ascension.

The fun ends when Faith accidentally stakes Deputy Allan Finch in an alley and he dies. Both Slayers run away, but Faith returns, unbeknownst to Buffy, to dump the body. In a factory, Angel, Giles, Wesley and Buffy defeat Balthazar, who warns that there is a greater villain who will kill them all. The final scene takes place at Faith's apartment when she admits that she feels no remorse for the murder and refuses to accept responsibility for it or let Buffy talk to Giles.

When Buffy wakes up the next day, the news of Allan Finch's murder has become public news and Wesley asks them to investigate. Faith reiterates her position and insinuates they will both go to jail if Buffy tells anyone the truth. Meanwhile, the Scoobies discover it is the Mayor who is the Big Bad when they invade his office looking for clues about Finch. When Buffy decides she can no longer stand it, she finds Faith has already told Giles Buffy killed Finch, although he does not believe her. Angel tries to reason with Faith, but their session is interrupted by men from the Watcher's Council who abduct Faith to take her to Britain for trial. Faith escapes and tries to leave Sunnydale by freighter, but Buffy stops her, suggesting they can get through it together just as they are attacked by Mr. Trick. Buffy is almost killed until Faith rescues her by staking Trick. Although it appears order has been restored, the final image is of Faith entering the Mayor's office after offering her services in the wake of Trick's death.

Enemies (3.17): In an effort to determine what the Mayor's endgame is, Buffy, Giles and Angel concoct a scenario in which Angel's soul is stolen and Angelus returns. He hooks up with Faith and infiltrates the Mayor's office, discovering he is invincible and then his ascension takes place on graduation day. To pull off the ruse, Angel must pretend to be Angelus, including beating and verbally abusing Buffy and kissing Faith, both of which affect her ability to be with him after they have the information they want. The episode ends when Buffy tells Angel that although she knows it was an act, she needs a break.

Choices (3.19): When Buffy discovers she has been accepted at a number of prestigious Universities, she decides she wants to leave Sunnydale following graduation. Recognizing the need to stop Faith and the Mayor, she puts into action a plan to prevent his ascension by stealing the box of Gavrok he has had flown in from South America. Although she manages to steal the box from City Hall, Willow is captured in the process. Buffy decides that Willow is more important to her than her vendetta against the Mayor and they trade in the school cafeteria. Wesley claims that the entire plan was in vain because the Mayor still got his box, but by episode's end Buffy is in possession of Faith's knife and Willow stole several pages from the Books of Ascension the Mayor didn't want them to see. Buffy resigns herself to the fact that she will attend UC Sunnydale in the fall, but is pleasantly surprised to discover that Willow will join her in order to continue fighting the good fight and become a bad ass Wicca.

Graduation, Part 1 \& 2 (3.21-3.22): As everyone prepares for the final days of High School, Buffy is irritated because they still do not know what the Mayor will turn into... and because she is still brokenhearted following the end of her relationship with Angel. When Angel is struck by a poison arrow by Faith, Buffy is desperate to find a cure 
for him, despite Wesley's comments that she ought to be focusing on the Mayor and not Faith's diversion. Buffy's response is to quit the Watcher's Council and make her own decisions, which involve feeding Faith to Angel after the Scoobies discover the cure is a Slayer's blood. The long-awaited battle between the Slayers occurs at Faith's swanky new apartment and ends when Buffy stabs Faith in the gut with her own knife. Faith gets the last line, though, when she falls off the balcony and onto a passing truck. The move leaves her in a coma, and prompts Buffy to offer herself to Angel. The move almost kills her and when she is admitted to the hospital, she shares a dream with Faith in which the dark haired Slayer reveals the Mayor's weakness: his human side. When he visits Faith in the hospital, he attempts to kill Buffy and is only stopped by Angel.

Buffy manages to recover quickly and thanks for Anya's crush on Xander, they uncover the only person to survive an ascension. Anya explains that during an ascension a human transforms into a pure demon, which is larger and much more difficult to kill. The Mayor himself stops by the library to verbally threaten the group and flaunt his continued invincibility. Buffy decides to send her mother away to focus on the fight, and decides to rally the graduating students into an army to fight the Mayor and his group of vampires. Most of the students survive, and Buffy exploits the Mayor's fondness for Faith in order to lead him through the explosive laden school, which she then blows up with him in it. Angel leaves for Los Angeles as Oz remarks that they managed to survive, not the battle, but High School.

\section{Season 4}

The season opens with Buffy, Willow and $\mathrm{Oz}$ at UC Sunnydale, where Buffy immediately feels overwhelmed by the transition from high school to University. As she attempts to adjust, she overcomes hurdles such as one night stands, sharing a dorm room with a roommate and surviving Thanksgiving without Joyce. Slowly the season's Big Bad is introduced as a military commando organization is briefly glimpsed in early episodes, then fully explored in "The Initiative" (4.07). When Buffy begins dating Riley, her psychology Teaching Assistant, she is unknowingly dating a member of the military group, a fact that is revealed in the silent episode "Hush" (4.10) when each discovers the secret identity of the other.

As the season progresses, whispers of 314 begin to appear, which is later revealed to be the room where Dr. Angleman and Professor Walsh (Buffy's psychology professor and one of the heads of the Initiative) have secretly been constructed a Frankenstein-like human-demon cyborg named Adam. After Buffy joins the team, and Walsh tries to kill her, a battle between the two women seems inevitable until Adam kills Walsh in the final moments of "The 'I' in Team" (4.13). Afterwards Adam takes over as Big Bad as he initiates his endgame: a huge battle between Buffy and the captive demons in the Initiative to create body parts for his human-demon army. When Adam uses Spike to distance the Scoobies from one another, they become wary of a ruse and reunite to perform an enjoining spell that gives Buffy their best characteristics. The spell is successful and Buffy destroys Adam by removing his power source.

Additionally, Spike and Anya join the cast full time and Willow comes out as a lesbian, entering into a lesbian relationship with new character, Tara.

\section{$\underline{\text { Key Episodes }}$}


The Initiative (4.07): As Buffy and Giles research the mysterious group of commandos on campus, Riley, his friends, Forrest and Graham, and Professor Walsh are all revealed to be high ranking members. The episode makes it clear that the Initiative captures and neuters demons via implants that prevent them from hurting living beings, including Spike, who manages to escape. There is also a sinister angle to the group when it is revealed that they perform tests on their subjects. Riley decides that he likes Buffy and asks her out on a date.

Something Blue (4.09): After Oz's room is cleaned out, Willow spirals into depression, which is made worse by the fact that none of the others want to help her. To regain control, she performs a spell to have her will done, which backfires and immediately starts harming her friends. It is only when Anya's old vengeance demon boss, d'Hoffryn appears to offer her a job that Willow realizes what she has done and reverses the spell.

The "I" in Team (4.13): Buffy joins the Initiative as a commando which further distances her from the other Scoobies. When Walsh and Dr. Angleman send the team after a Polgara demon, and Buffy questions the specifics of the mission, it becomes clear that Buffy's individuality clashes with the operation style of the Initiative. Later, after Walsh spies on Buffy and Riley having sex, she sends Buffy on a suicide mission that she has no trouble surviving. When Buffy exposes Walsh's duplicity, Riley leaves the Initiative. The episode ends with Buffy rejoining the Scoobies to inform them about Walsh, who is skewered moments later by her Frankenstein creation, Adam.

The Yoko Factor (4.20): Adam promises Spike he will remove his chip if Spike can separate Buffy from her friends. Drawing upon their insecurities, Spike poisons the Scoobies against one another. Buffy goes off in search of Spike, but discovers both Forrest and Adam. In a swift battle, Adam kills Forrest and Buffy runs away.

Primeval (4.21): The Scoobies infiltrate the Initative once more to head Adam off as he initiates his endgame. As the cell doors are opened and all the captive demons attack the commandos, the Scoobies perform an enjoining spell that merges their individual characteristics with Buffy. The spell - which taps into the power of the First Slayer enables Buffy to remove Adam's uranium power core and as a group they escape the Initiative.

\section{Season 5}

The season begins with a run-in from the legendary Dracula, whose powers of persuasion over Buffy prompt her investigation of the true nature of her calling as a Slayer. The end of the first episode introduces a new character, Buffy's younger sister, Dawn, whom everyone treats like she's always been around. It is revealed that Dawn is actually a mystical key that opens dimensional portals, made out of Buffy's blood and disguised in human form for protection against the season's Big Bad, Glory.

Glory is a deposed hell-god forced to share a body with hospital intern, Ben, who is introduced when Buffy's mother falls ill with what is later revealed as a brain tumour. As her mother's health worsens, Buffy tries to blame the supernatural, but eventually resigns herself to the fact that she must protect Dawn after Joyce dies in "The Body" 
(5.16). In between shopping and mind-sucking people in order to remain sane, Glory tries to discover the whereabouts of the key, which she requires for a ritual to return to her home world. After torturing Spike and mind-sucking Tara, Glory finally discovers the truth about Dawn and steals her away, setting up the climatic battle in which numerous elements from the season (the troll hammer from "Triangle," the Buffy-bot and Xander's burgeoning carpentry skills) all play a part. Ultimately Glory is beaten into submission and Giles kills Ben to prevent her return, but the portal is already opened. In order to save both Dawn and the world, Buffy sacrifices herself. Her tombstone is the final image of the season.

\section{Key Episodes}

Fool For Love (5.07): After Buffy is injured on a routine patrol by a non-name vampire, she pays Spike to tell her how he killed his two Slayers. He explains to her that all it takes is one bad day, but that ultimately their failure depends on the death wish they possess as Slayers. He tells her that the only thing that has saved her this long is her "ties to the world" (her friends, mother and sister) and that when she finally wants to dance, he'll be there. When she tells him it will never be him because he is "beneath her," he decides to kill her, but after discovering her crying in the aftermath of the news that her mom is staying overnight in the hospital, he comforts her instead. Meanwhile, Riley goes commando on the other Scoobies by blowing up a nest of vampires in the middle of the night, foreshadowing the feelings of insignificance that will cause him to leave Sunnydale in "Into the Woods" (5.10).

Intervention (5.18): Fearing that she is losing her ability to love, Buffy goes on a spirit walk in the desert with Giles. There she discovers from a guide in the form of the First Slayer that her ability to love is one of her greatest gifts, as is death. Back in Sunnydale, the Scoobies become concerned when they see Spike having sex with the Buffy-bot he commissioned from Warren and stage an intervention when Buffy returns. By this point, Spike has been kidnapped after Glory's minions, who have been spying on the group, mistakenly identify him as the key. The realization that Spike may give up Dawn under torture prompts Buffy and the group to successful mount a rescue attempt, although the Buffy-bot is damaged during the fight. Buffy takes its place to determine if Spike told Glory anything. The episode ends when Spike realizes he is dealing with the real Buffy when she kisses him and tell him that what he did for her and Dawn was "real" and she won't forget it.

Tough Love (5.19): Buffy receives word that Dawn is skipping classes and increases her resolve to be a true guardian by cracking down or else social services will take Dawn away. Meanwhile, Tara and Willow have an argument about Willow's growing magical abilities, which ends in tragedy when Glory mistakenly believes Tara is the key. When she discovers she's wrong, Glory sucks Tara's mind, leaving her in an incapacitated mental state. In a rage, Willow ransacks the Dark Arts section of the Magic Box and attacks Glory in her tower, despite Buffy's assertions that it would be suicide. Buffy is ultimately forced to rescue her and the episode ends when Glory breaks down the wall where the girls are hiding in time to hear Tara expose Dawn as the key. 
The Gift (5.22): After Buffy comes to her senses following Dawn's kidnapping, she forcefully tells the Scoobies that she will kill anyone who tries to touch Dawn when the ritual begins. Using Tara's guidance to the proper location, Buffy uses all of her available weapons, including the troll hammer, the Buffy-bot, the Dagon Sphere and even Xander's wrecking ball to delay the start of the ritual. Although Buffy prevents Glory long enough and Giles kills her human form (Ben) so that she can never return, the portal is still opened. As the dimensional walls break down, Buffy realizes her blood can close the portal because Dawn was made out of her. She sacrifices herself by plunging to her death and the season ends with her tombstone.

\section{$\underline{\text { Season } 6}$}

Once Giles leaves to return to England, Tara, Anya, Xander and Willow resurrect Buffy, although she reappears looking and acting dazed. She later reveals to Spike that she was in heaven, and not hell as the others believed. Confiding in him proves to be the first step towards a sadomasochistic sexual relationship that is paralleled by Willow's increasing reliance on magic. When Tara leaves her, Willow goes on a binge courtesy of magic dealer, Rack, until she crashes a car while high and injures Dawn. The event prompts her rehabilitation, even as the Trio of Nerds (Warren, Andrew and Jonathan) decide to take over Sunnydale. Buffy's preoccupation with Spike causes her to neglect taking out the boys until "Seeing Red" (6.19), although Warren returns to shoot her, and accidentally kills Tara in the process.

In a grief fuelled rage, Willow absorbs all the dark arts she can find in her crusade to punish the Trio: she flays Warren, but is unable to kill Jonathan or Andrew because of the Scoobies. After stealing all of Giles' magic, bestowed to him by a powerful coven, Willow in put back in touch with the feelings of the world and decides to annihilate it to end its suffering. She deposits Buffy and Dawn in a grave, but is rescued by Xander who, as her best friend, is able to connect to her with a story from their childhood. The season ends with Buffy's promise to show the world to Dawn, now that she has rediscovered her will to live and be a part of it.

\section{Key Episodes}

Wrecked (6.10): Both Buffy and Willow must deal with the consequences of the previous night when they awaken: Buffy to the realization that she has slept with Spike and Willow, who is confronted by Tara for the first time since their break-up, after she spent the night performing magic and getting high at Rack's. Ultimately neither can prevent a relapse, although Willow's addiction spirals out of control when she takes Dawn with her to get high and ends up crashing their car in an effort to escape a demon. When Buffy confronts her after Dawn is injured in the crash, Willow admits that she needs help - a declaration that echoes Buffy's own sentiments about her new relationship with Spike, despite the fact that she remains silent.

Villains (6.20): In the aftermath of Warren's shooting spree, and Tara's death, Willow becomes Dark Willow, even after Buffy lies dying in the hospital. After ransacking the Magic Box, absorbing all of the dark arts books and removing the bullet from Buffy's chest, Dark Willow sets off to kill Warren, who is attempting to flee town. Despite her 
friends' attempts, she discovers and flays him in the woods at the end of the episode, declaring that there are still "two to go" since she has decided to kill both Jonathan and Andrew. Meanwhile, Spike arrives in Africa to begin his trials to earn back his soul in an attempt to pay penance for his attempted rape on Buffy.

\section{Season 7}

Both Spike and Willow return to Sunnydale as the revamped High School opens. This brings with it a new principal, Robin Wood - the son of a Slayer - and a job offer for Buffy as a guidance counselor for troubled teens. Spike is suffering from the conscience that accompanies his new soul and is part mad, living in the school basement, although it later becomes clear that he is also being influenced by the nearby seal of Danzalthar. This is revealed when he is triggered to begin killing again, prompting Buffy to chain him up in the Summers basement. She realizes that the being everyone describes as "From Beneath You It Devours" is actually the First, an entity that she battled in the third season episode "Amends" (3.10). When Giles arrives with a handful of potential Slayers - girls that will be killed in the event of Buffy's death - it is revealed that the First has declared war on the Slayer lineage by killing Watchers and potentials, as well as blowing up the Watchers Council.

When its first minion, an ubervamp, appears, Buffy and the Scoobies are overwhelmed and Buffy suffers serious injuries. It is only when she realizes that she must instill the will to live in the potentials that she can overcome the ubervamp, although she suffers from doubts as the number of potentials living in her house rapidly climbs. When Buffy continues to criticize her friends and leads the potentials into a deadly trap at the vineyard, they elect the newly relocated Faith to lead them. Using Spike's love and confidence in her abilities as motivation, Buffy discovers a powerful scythe forged by a group of women who have watched over the Slayer line and uses it to cut the First's vessel, Caleb, in half. The series finale ends in a giant battle with the Scoobies fighting thousands of ubervamps after Willow uses the scythe to transfer Buffy's Slayer powers to every potential. They are saved when the amulet Spike wears, which is designed for a champion, spreads sunlight throughout the caves, killing the ubervamps and collapsing the town. Buffy and the others escape by bus to a future full of possibilities.

Bring on The Night (7.10): Buffy is haunted by visions of her mother, who tells her that she cannot win a battle against something (evil) that has always existed. Using Andrew's knowledge, the group locates the seal of Danzalthar and covers it in an effort to deaden its influence, although Willow's locator spell to track the First goes awry when it possesses her. Giles appears with three potential Slayers in tow as Buffy goes head to head with the ubervamp, whom she barely escapes from. When they meet again after it kills one of the potentials, it almost kills her. At the end of the episode, the group is worried about Buffy, but when she appears, she announces that they are going to form an army.

Get It Done (7.15): The First Slayer appears to Buffy in a dream to tell her that "it's not enough" on the same night that the First convinces a potential, Chloe, to commit suicide. Digging the young girl's grave prompts Buffy to give her "everyone sucks but me" speech, which insinuates that both Willow and Spike are not using their powers. The 
result: Buffy opens the Slayer emergency kit Robin inherited from his mother and opens a portal to discover the origins of the Slayers powers. The move forces Willow and Spike to use their powers - magic and vampire strength - to reopen the portal and bring Buffy home. She discovers that it was a group of Shadow Men that created the Slayer by essentially raping a woman with the essence of a demon. When she refuses the same treatment in exchange for more power, they give her a vision that makes her realize the First Slayer's words were correct: an image of thousands of ubervamps waiting to attack under the seal.

Dirty Girls (7.18): Willow returns from Los Angeles with Faith moments behind the First's vessel, Caleb - a misogynistic priest responsible for organizing the attacks on the Slayer lineage across the globe. After Buffy hears a message from a potential Caleb attacked, she mounts an offensive to attack him at the vineyard. It soon becomes clear that it is a trap when several potentials are injured and Xander is blinded in one eye.

Empty Places (7.19): In an effort to deal with the disastrous effects of "Dirty Girls," Buffy distances herself from the group and suffers another attack by Caleb at the school. Giles sends Spike and Andrew on a reconnaissance mission to a parish they believe Caleb may have visited and Faith takes the girls to the Bronze to blow off steam. When the police attack her because she is a fugitive, the girls rally around her, even when Buffy shows up. Later, Buffy tries to rouse the group for another attack when she believes Caleb is protecting something, but the group puts their support behind Faith. The episode ends in mutiny when Buffy is ordered out of the house.

Touched (7.20): The night before Faith's attack on the vineyard, couples reach out to each other for comfort, including Spike and Buffy. When Spike tracks down Buffy in an abandoned house, he professes his love and admiration for her in an attempt to restore her confidence in her abilities. The episode ends as Faith's team walks into an explosive trap while Buffy discovers the weapon Caleb is protecting: a scythe buried in a stone that only she can remove.

Chosen (7.22): In the final episode, the Scoobies go on the offensive by opening the seal at the high school as Willow uses the scythe's power to transfer Buffy's powers to all the potential Slayers in the world. Spike's amulet taps into the sun's power to obliterate both the ubervamps and Sunnyale itself as the others escape by bus. The series ends with Buffy standing on the outskirts of the precipice of her former life, as she realizes that her responsibilities as the Slayer have come to an end. 